\title{
Electronic Information Sharing to Improve Post-Acute Care Transitions
}

\author{
By
}

Dori Amelie Cross

A dissertation submitted in partial fulfillment

of the requirements for the degree of

Doctor of Philosophy

(Health Services Organization and Policy)

in the University of Michigan

2018

Doctoral Committee:

Associate Professor Julia Adler-Milstein, Co-Chair

Associate Professor Jane Banaszak-Holl, Co-Chair

Assistant Professor Lena Chen

Professor Milisa Manojlovich

Associate Professor Jeffrey McCullough 


\section{Dori Amelie Cross}

dacross@umich.edu

ORCID iD: 0000-0003-3489-3954 


\section{Acknowledgements}

I'd like to thank my full dissertation committee for their incredible guidance, support, and mentorship through this process. Every meeting, and every draft reviewed, represents an investment in my personal and professional growth for which I am truly grateful.

I'd like to thank the members of the Lab for Health IT Impact: Genna, Jordan, Sunny, Paige, A Jay, and Eric. Thank you for being amazing colleagues, and for sharing in the joyous ups and painful downs of the research cycle. You are all stars. Julia, I can never thank you enough for the research opportunities you made available to me, and the unparalleled role you've played in my development as a scholar. I am deeply indebted.

To my dear friends in the Health Services Organization and Policy Program: Genna, Jordan, Mike, Anup, Sasha, Betsy, Zach, Phil, Michael, and Charley. This would have been impossible without your love, encouragement, commiseration, and support. I am a smarter, better person for knowing each of you. I wish we could all do Wednesday trivia together forever.

My mentors that I've carried with me since before my $\mathrm{PhD}$ days continue to be role models and sources of inspiration. Thank you, Joy Grossman, for so patiently developing my knowledge of healthcare markets and delivery systems. My ability to identify good research questions, and good coffee, is largely due to your influence. Morris Weinberger, I am so glad I walked in to your office in August of 2008. You never understand how special you are, but I know just how fortunate I am to have a lifelong mentor and friend so invested and compassionate. Your impact on my trajectory cannot be overstated.

My heart feels full when I think of the incredible network of friends around the country who have been cheering me on, and allowing me to come visit them when I needed escape. Jill, Britt, Hannah, JoAnne, Brittany, Kevin, Erin, Katie, Mandy, Divya - I love and appreciate you.

To Jeff - you never let the coffee, beer, or cookie supply run dry! Thank you for your humor, your endless patience, your love, and your true partnership. I am lucky to be living my life with you. I love you, a lot a lot.

Finally, and most importantly, I want to express my deepest love and appreciation for my family. Mom, Dana, Evan, and Lainie - there are no expressions of gratitude big enough for a lifetime of unconditional support. You keep me humble, you keep me laughing, and you give me warm places to visit as I insist on moving to ever-colder climates. Mom- thank you for every broomstick ride you took to make sure I had the best possible education and opportunities. I hope I've made you proud. 


\section{Table of Contents}

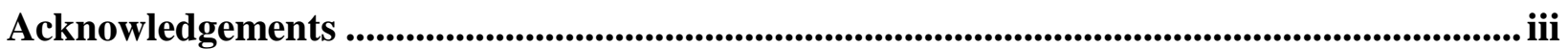

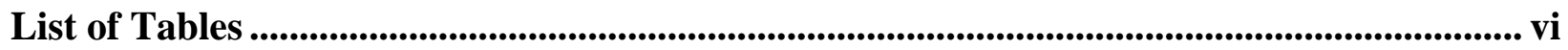

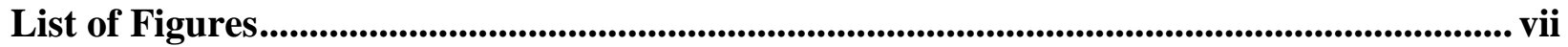

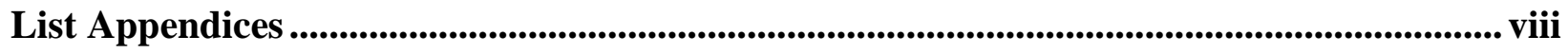

List of Abbreviations, List of Acronyms, List of Symbols ............................................. ix

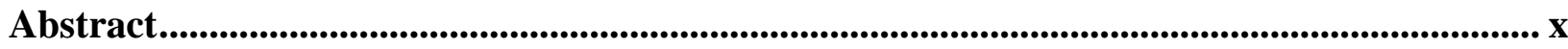

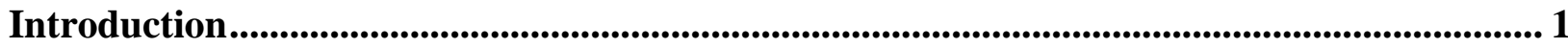

Chapter 1 : Investing in Post-Acute Care Transitions: Factors Associated with Hospitals Exchanging Information Electronically with Long-term Care Facilities .............................. 15

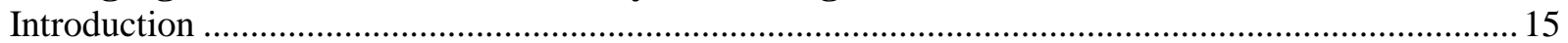

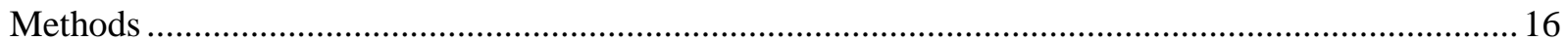

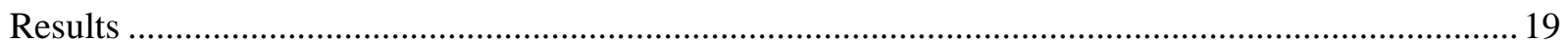

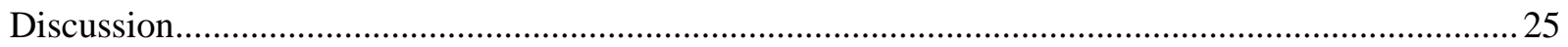

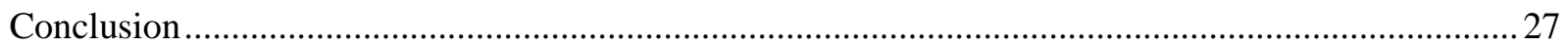

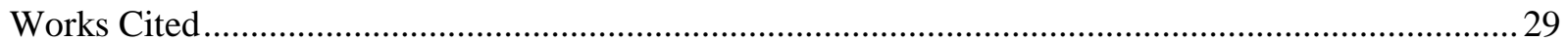

Chapter 2 : The Importance of Use and Usage Patterns in Assessing Potential for Health

Information Exchange to Improve Post-Acute Transitions of Care ........................................ 31

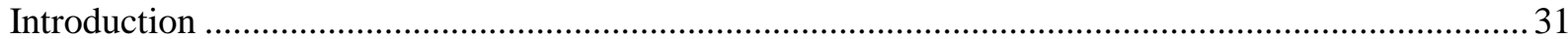

Objective.

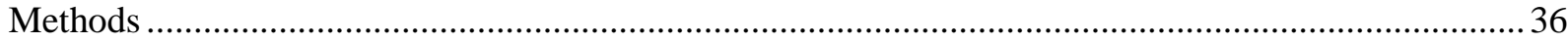

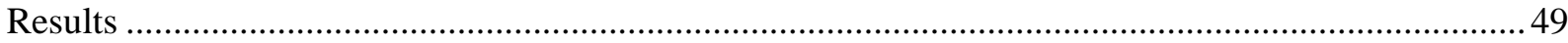

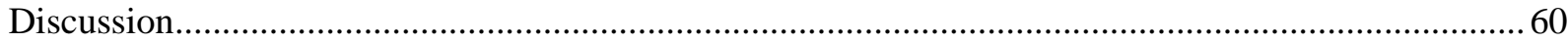

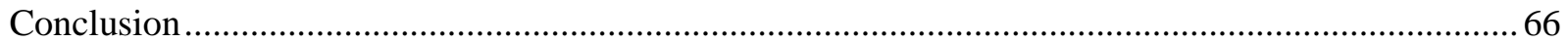

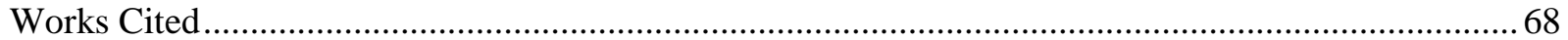

Chapter 3 : Opportunities and Challenges in Using Electronic Portals to Address

Information Discontinuity during Post-Acute Care Transitions ................................................ 71

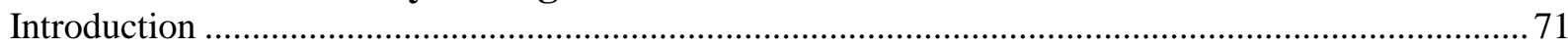

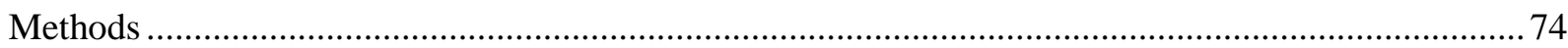

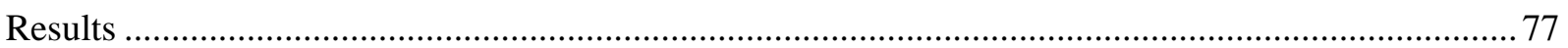

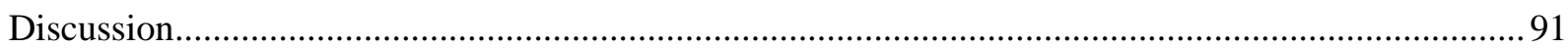

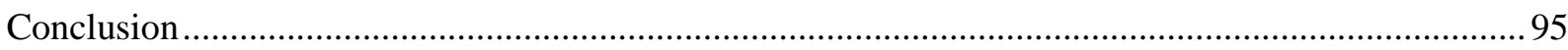

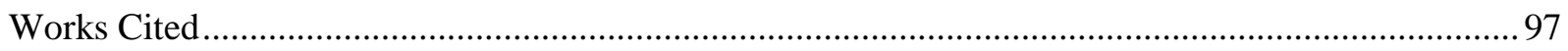


Conclusion 


\section{List of Tables}

Table 1.1: Percent of US Hospitals Routinely Exchanging Structured Summary of Care Records Electronically with LTC Providers [unweighted] .................................................................... 20 Table 1.2: Bivariate Analyses: Comparing LTC HIE activity across Hospital Characteristics

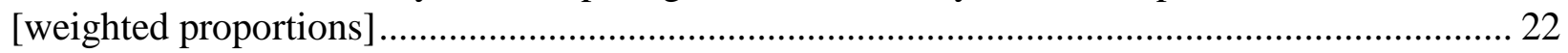

Table 1.3: Multivariate Analyses: Predicting LTC HIE Activity ………………......................... 23

Table 2.1 List of Information Usage Categories...................................................................... 37

Table 2.2 Descriptive Information, Treatment SNFs............................................................... 49

Table 2.3 Sample Characteristics of Patients in SNFs with and without ECL Access .................. 51

Table 2.4 Estimated Effects of HIE Portal Implementation on Likelihood of 30-day Hospital

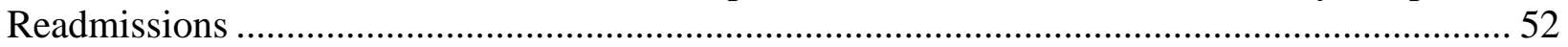

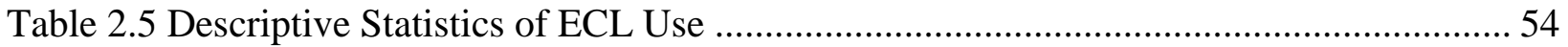

Table 2.6 Patient Drivers of ECL Use, by Facility (Bivariate Analyses) .................................... 55

Table 2.7 Patient Drivers of ECL Use (Multivariate Analyses) .................................................. 57

Table 2.8 Moderators of the Relationship between ECL Use and Outcomes ................................ 59

Table 3.1 Participating Organizations and Respondents ............................................................ 78

Table 3.2 Summary of Hospital-to-SNF Care Transition Processes ............................................ 80 


\section{List of Figures}

Figure i.1: Model of Integrative Care (Valentijn et al., 2010) ................................................... 5

Figure 2.1. Conceptual Model of Variation in Hospital-SNF HIE Use on Patient Outcomes ..... 33 


\section{List Appendices}

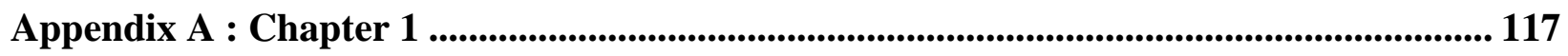

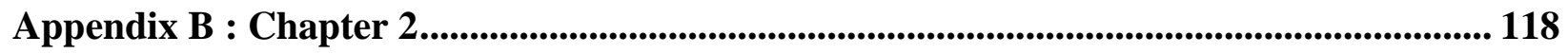




\section{List of Abbreviations, List of Acronyms, List of Symbols}

ACO - Accountable care organization

AHA - American Hospital Association

AVS - After-visit summary

BPCI - Bundled payment care initiative

CMS - Centers for Medicare and Medicaid Services

DON - Director of Nursing

EHR - Electronic health record

EIS - Electronic information sharing

HIE - Health information exchange

HIO - Health Information Organization

LTC - Long term care

PAC - Post-acute care

SCR - Summary of Care Record

SNF - Skilled nursing facility 


\begin{abstract}
Hospitals frequently transfer sick patients to skilled nursing facilities (SNFs) for post-acute care; information sharing between these settings is critical to ensure safe and effective care during and after this transition. Recent policy and payer initiatives have increased financial pressure on hospitals and SNFs to work together towards improving these care transitions, and associated patient outcomes such as avoidable re-hospitalizations. Exchanging information electronically, through health information exchange (HIE), can help facilitate information transfer, and has shown benefits to patient care in other contexts. But, it is unclear whether this evidence translates to the post-acute care context given the vulnerability of this patient population and complexities specific to coordination between acute and post-acute care settings.
\end{abstract}

Chapter One first estimates the national prevalence of hospital's engagement in HIE with postacute providers, and explores potential factors prompting this investment. $56 \%$ of hospitals report some level of HIE with post-acute care providers. This investment appears strategically to be more incidental than intentional; hospitals' overall level of sophistication and investment in electronic health records and HIE strongly predicts whether HIE is occurring in the post-acute transition context. However, we see some evidence of association between participation in delivery and payment reforms and hospital use of HIE with post-acute providers. This suggests that HIE may increasingly be considered part of a comprehensive strategy to improve coordination between hospitals and post-acute care providers, though may lack the customization necessary to extract meaningful value. 
Chapter Two utilizes a difference-in-differences approach to assess HIE impact on patient outcomes in the post-acute context, exploiting one focal hospital's selective implementation of HIE with just three partnering local SNFs. I find no measurable effect of HIE implementation on patient likelihood of re-hospitalization, relative to patients discharged to SNFs without HIE. However, log files that capture when and how these SNF providers use available HIE technology reveal significant variation in usage patterns. HIE was more often utilized following discharge situations where transitional care workflows may not be particularly robust, such as discharge from the ED or observation rather than an inpatient unit. However, the system was less likely to be used for more complex patients, and for patients discharged on the weekend - a time when SNFs operate at reduced staffing and may not have the bandwidth to leverage available technology. When we connect variation in usage patterns to likelihood of readmission, realizing any patient care benefits depended on the timing (relative to patient transfer) and intensity (depth of information retrieved) of use.

Chapter Three employs qualitative methods - semi-structured interviews with the focal hospital and five proximate SNFs - to better understand hospital-to-SNF transitions, and perceived opportunities and challenges in using HIE functionality to address information gaps. We capture five specific dimensions of information discontinuity reported by SNFs; utilizing IT to address these issues is hindered by lack of process optimization from a sociotechnical perspective. Some organizations lacked workflows to connect those with HIE access to the staff seeking information. Further, all facilities struggled with physician-centric transition processes that restricted availability of critical nursing and social work documentation, and promoted 
organizational changes that strengthened physician-to-physician handoff while unintentionally weakening inter-organizational transitional care processes.

HIE has the potential to address information discontinuity that compromises post-acute transitions of care. These findings facilitate targeted efforts to help hospitals and SNFs pursue HIE in ways that are most likely to result in improved care quality and patient outcomes. 


\section{Introduction}

Policymakers, providers, and payers are devoting substantial attention to improving patient care transitions from hospitals to post-acute care (PAC) settings. These transitions are frequent; 8 million patients (22\% of total inpatient stays) were discharged to PAC in 2013. (1) Nearly half of these patients were discharged to skilled nursing facilities (SNFs), the largest institutional provider of PAC. Despite the high volume of these transitions, numerous studies of hospital-SNF transitional care have found systemic deficits in quality and safety. (2-7) The result is worse patient outcomes in SNF settings (e.g., delayed care responsiveness, medical errors) and increased risk of readmission to the hospital. (8-11)

A key contributor to poor hospital-SNF transitions is the lack of robust information sharing. (3, 5, 10, 12-14) Informational continuity - having systematic processes that support the timely exchange of accurate, relevant and usable information - is a key element of coordination that supports integrated systems of care and, subsequently, improved outcomes. $(15,16)$ Communication processes between hospitals and SNFs, and information technology infrastructure to support care continuity in this context, are relatively immature due in part to a historical lack of financial incentives for hospitals and SNFs to work together on improving care transitions and associated outcomes. $(7,17)$ However, the rapidly changing healthcare environment, with unprecedented investment in health information technology over the past decade, creates the opportunity to improve communication and rectify poor information sharing through electronic health information exchange (HIE). When hospitals have electronic health 
record systems (EHRs) with HIE capabilities, they can create and electronically transmit information about the hospitalization to outside providers (i.e., push information), or make information about the hospitalization available for outside providers to access electronically (i.e., have outside providers view and/or pull information). Recent systematic reviews of the impact of HIE on quality and utilization outcomes reveal a small number of high-quality studies and mixed evidence of benefits $(18,19)$, with some evidence of reducing inefficient duplication of services $(20,21)$ and association of community-wide HIE with lower likelihood of patient rehospitalization. (22)

The challenge in applying this suggestive evidence of HIE benefit to the post-acute care transition context is that these findings focus almost exclusively on use of HIE to share information between hospitals, or to support transitional care between hospitals and ambulatory care providers when patients are discharged back to the community. There are unique features of hospital-SNF transitions that create uncertainty about whether existing evidence on HIE benefits translates to this context. First, because PAC providers were ineligible for federal EHR financial incentives, SNFs and other PAC providers lag in adoption of clinical EHR systems with the same meaningful use certification competencies as hospital and ambulatory provider systems. (23-26) When technology and use capabilities are mismatched between the "sender" (i.e., the hospital) and the "receiver" of information (i.e., the SNF), it may impede the value from HIE. Second, SNFs have information needs that differ from acute care settings.(27-29) For example, SNFs must manage residents' functional status and document extended rehabilitative care - types of documentation not systematically captured nor emphasized during hospitalizations. Therefore, it is not clear the extent to which hospitals make this information available, let alone customize 
HIE approaches to meet SNF information needs. Relatedly, hospitals and SNFs have different staffing models, workflows, reimbursement structures and cultural norms; these discrepancies may increase the difficulty of constructing shared handoff processes that fit the needs and preferences of both organizations. (30) Finally, patients experiencing care transitions to SNFs are older and have more complex healthcare needs than the average patient. $(17,31-33)$ Appropriately caring for this high-needs population is uniquely challenging for providers, as is designing robust and appropriate HIE support.

Dissertation Aim 1: Understand Hospital Decisions to Adopt HIE with PAC Providers In the absence of compelling evidence regarding the direct value of HIE, it is critical to understand whether and when hospitals and PAC providers have still chosen to pursue HIE as a strategy for addressing the unique features and complexity of post-acute transitional care. The availability of information sharing capabilities in this context relies mainly on decision-making by hospitals (or health systems) who have the clinical data systems and financial resources to make HIE a reality. The first part of my dissertation thus seeks to discover key organizational characteristics common among hospitals that have chosen to make this investment. Evidence on how providers behave under these circumstances (i.e. with no clear business case) is illustrative for understanding motivation(s) and organizational decision-making not just around IT, but delivery system changes more broadly. In Chapter One, I use aggregated national hospital survey data sources to estimate the extent to which hospital-LTC HIE is taking place, and identify key organizational factors associated with this investment. This analysis pits competing hypotheses against one another: Is hospital-LTC HIE essentially a byproduct of general hospital investment in IT capabilities, or are hospitals responding strategically to delivery reform 
initiatives that incentivize hospitals to focus on improved post-acute care transitions and associated patient outcomes? I find that over half of hospitals in 2014 report engaging in HIE with post-acute care providers, either send-only (33.9\%) or bidirectional (22.8\%) exchange. Hospitals' overall level of sophistication and investment in electronic health records and HIE strongly predicts whether HIE is occurring with post-acute care providers, suggesting that hospital-LTC HIE may be more incidental than intentional. But, we also find evidence that hospitals are more likely to report using HIE in this context when they also report some level of organizational affiliation with one or more post-acute care facilities. This indicates that some hospitals may also be pursuing HIE with post-acute providers more intentionally, reacting to shifting financial incentives that promote development of an integrated, comprehensive strategy to improve coordination between these care settings. Policymakers can thus continue to indirectly promote hospital-LTC HIE connectivity with initiatives that emphasize interorganizational coordination to control total cost of care (i.e. ACOs, bundled payments, etc). However, it is unclear whether these outcomes-based incentive structures are sufficient to spur adoption of HIE strategies with sufficient depth and tailoring to address the fundamental challenges plaguing PAC transitions. This merits further investigation, both to advance IT focused research as well as evaluation of delivery system reform more broadly.

Dissertation Aim 2: Understand the effect of hospital-PAC HIE adoption on patient outcomes Integrated care frameworks often depict the pursuit of care coordination as a nested model where functional and normative integrative processes take place from the level of the patient-provider clinical relationship all the way up to system-level policies and incentive structures (See Figure i.1). (34) In the context of post-acute care transitions, we continue to see changes on the outer 
rings of this framework - payment and delivery changes at the system level that incentivize coordination, as well as organizational tools and processes to address continuity issues.

Healthcare systems'

continued investment in

HIE infrastructure, despite

a lack of demonstrated

value, suggests providers'

implicit assumption that

these functional changes

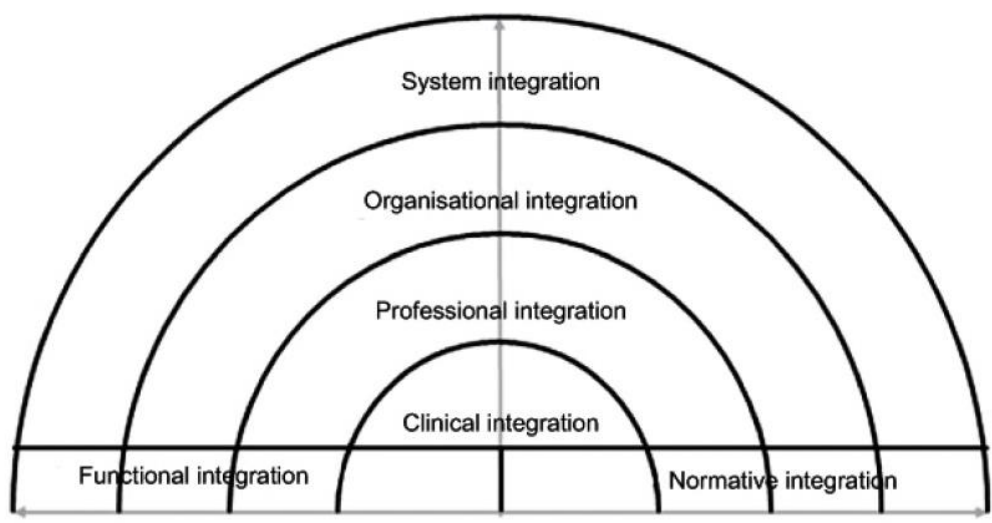

Figure i.1: Model of Integrative Care (Valentijn et al., 2010)

may overcome the known lack of normative integration in hospital-post-acute relationships. Testing this assumption empirically requires robust evaluation of the impact of hospital-PAC HIE connections on quality of care, in communities where they exist. This analysis not only addresses an important practical need for evidence to inform health IT policy, but would also strengthen our conceptual understanding of the relative strength of functional versus normative changes in care delivery and the interplay between micro-, meso- and macro- changes to promote care integration.

Thus, Chapter 2 delves locally, using patient-level data provided by one focal hospital that began investing selectively in HIE capabilities with three local SNFs ("partner SNFs") in June of 2014. The nature of this data, which captures all hospital-to-SNF discharges and spans the period before and after HIE was implemented with the partner SNFs, enables a robust difference-indifferences analysis of HIE impact on patient care. Specifically, we use the June 2014 implementation date as a cut-point to compare pre vs. post-period changes in the likelihood of 
30-day patient rehospitalization for patients discharged to one of the three partner SNFs, relative to changes in the same time frame for patient discharged to other SNFs that did not receive HIE capabilities. We use rehospitalization as our outcome of interest, as it represents an important and often-used indicator of poor transitional care. $(9,35,36)$ This analysis finds no measureable average effect of HIE implementation on rehospitalizations, adding to the growing body of evaluative health IT literature emphasizing that availability of enabling technology does not necessarily translate to use of the technology in ways that drive meaningful improvement in care delivery.

To better analyze whether HIE improves outcomes such as rehospitalizations that are sensitive to the quality of post-acute care transitions, we need data that captures the specifics of when and how it is used. (37-40) Adoption of HIE capability is an insufficient proxy for measuring use of information sharing systems to actively support transitional and post-acute patient care. The application of socio-technical systems (STS) theory is critical in understanding the jump from IT adoption to IT use, and anticipating the effects of use on patient care. STS theory considers the inter-relatedness of four key domains that together shape the nature and effectiveness of post-IT implementation care processes: environment, task, technology, and people. $(41,42)$

Applying an STS lens to coordination across hospitals and SNFs is particularly illustrative in thinking about potential gaps between the potential and reality of electronic information sharing when applied to both sides of the transition. We utilize a sociotechnical frame to hypothesize the following two constraints on achieving value from portal implementation: 
Hypothesis 1: Information made available to SNF providers at the time of transition is unlikely to consistently meet the specific informational needs of those providing post-acute care A sociotechnical framework predicts that technology will be maximally impactful only if embedded in ways that disrupt and seek to improve existing processes. The hospital's selection of a portal rather than other forms of information sharing reflects a decision not to touch the existing "people processes" of hospital discharge planning and the underlying beliefs about coordination role and responsibility underlying these processes. No change in documentation practices is required with use of a portal, nor extra effort in the discharge planning process. This lack of technology integration in to care practices represents a missed opportunity to better present informational needs of receiving providers to those providing and documenting care in hospitals.

Hypothesis 2: Integrating portal use in to SNF care will be difficult, and depends on perceived relevance of information, usability, and fit with existing workflows Unlike the hospital experience, use of the portal by SNFs requires active changes to existing workflow. New policies and processes must be established regarding who accesses information, when that information is accessed, and what information retrieval activity should take place. Any change in staff responsibilities and/or inter-dependencies between staff roles necessary to leverage the value of portal access requires re-negotiation of embedded norms and potential resistance to such change. The more significant the deviation required compared to pre-existing workflows, the less likely that implementation will be met with staff support. And, lack of perceived value in the early stages of use could decrease motivation to make new technologyenabled workflows a systematized feature of care. 
Thinking about portal use from the SNF organizational perspective, normative situational factors may disrupt the balance of sociotechnical systems in place and temporarily modify the perceived value of IT systems in carrying out information retrieval tasks (See Figure 2). For example, we might expect HIE use to serve as a substitute when information transfer via other traditional mechanisms is weak or disrupted (i.e. a weekend discharge, or discharge from a non-inpatient unit). In addition, likelihood of use could be driven by patient complexity, where more complex patients (i.e. longer length of stay, more diagnoses) require more information to maintain safe, effective care. These are situational drivers of use. Similarly, nuances in how information is retrieved - for example, information accessed in a more timely way relative to the timing of patient transfer, or accessing a greater volume of information - represents variation in the utility associated with portal use and may moderate the relationship between use and outcomes.

We investigate our hypotheses, and the moderating effects of situational drivers and information retrieval quality, using a mixed methods approach. Some a priori hypothesis can be tested with quantitative data that captures HIE usage patterns and patient outcomes. Qualitative data, however, is more useful for fleshing out interdependencies between the "people processes" and structures (staff role definition, workflows, organizational norms) and the IT-enabled retrieval capabilities. For example, understanding who has access to the information systems, and what workflows (if any) connect those individuals to frontline clinical staff, is a critical sociotechnical consideration for optimizing IT implementation and use. It is these interdependencies that shape the opportunities, challenges and ultimate potential of HIE to improve transitional care. We opted for an explanatory sequential mixed methods design that allowed our qualitative data 
collection to help confirm early findings, develop a better understanding of mechanisms underlying results we found counter-intuitive, and generate new hypotheses that will inform specifications of future data extraction requests.

To explore actual HIE usage patterns, I merge the patient-level data from the above differencein-differences analysis with audited log files from the hospital's electronic health record that capture every information retrieval action taken by a SNF provider through the HIE portal. These records are patient-identified and time-stamped, allowing me to link records and determine whether HIE was accessed for a patient, the timing of HIE access relative to the timing of discharge from hospital to SNF, and some detail about the type of information viewed. This unique assembled dataset then also enables analyses to determine the types of patients for whom HIE tends to be used, and associations between variation in usage patterns and likelihood of rehospitalization.

We observed significant variation in system use within and across the three SNF facilities. On average, HIE was utilized for $46 \%$ of patients for whom it was available. Access rates within the timeframe immediately surrounding transition from hospital to SNF - 48 hours before transition and up to 72 hours after - was only $29 \%$. HIE was more likely to be used in contexts where prior research has suggested traditional handoffs are weaker, such as when a patient is discharged from the ED rather than an inpatient unit. But, surprisingly, the system was less likely to be used for patients of greater complexity, even though these patients have more critical information relevant to care continuation and are at higher risk of readmission. (43) Finally, in cases where HIE was used for a patient, we find evidence in only one of the three HIE-enabled SNFs that 
accessing information in a timely way (relative to the timing of transition), and accessing more comprehensive information, is associated with a small but significant reduction in the likelihood of patient rehospitalization.

The complementary qualitative inquiry - semi-structured interviews with the same focal hospital and partner SNFs from Chapter 2, as well as two additional local SNF providers - shed light on how introducing new technology and technology-enabled processes in to existing workflows can have significant and sometimes unintended consequences on the efficiency, effectiveness, and safety of care delivery. (44-45) Chapter 3 enhances our sociotechnical understanding of postacute care transitions in three key ways. We first map out the workflows that support these handoffs, and identify key areas of information discontinuity creating pressure points in the process. We then explore specific ways in which HIE-enabled SNFs (via a hospital portal) have used available technology to address these challenges. Finally, we consider key challenges limiting the potential of HIE to improve transitional care.

We identify five distinct dimensions of discontinuity caused by missing (2), difficult-to-use (1), or delayed (2) information at the time of patient transfer. Facilities most often accessed information prior to patient discharge from the hospital, to help determine whether they could meet a patient's care needs and - once accepted for admission - to get a head-start on establishing a care plan and securing any specialized resources needed for that patient's care. We find significant workflow disconnect in some of the facilities between individuals using the portal and those directly responsible for patient care, weakening any potential association between HIE use and improved care delivery. We also find that transitional care remains a very 
physician-centric process; despite the critical role of nurses and social workers in SNF care delivery, the hospital limited the accessibility of documentation relevant to helping these providers carry out their roles most effectively.

Taken together, this body of work addresses key knowledge gaps related to what motivates investment in HIE to support post-acute transitions, as well as specific challenges and opportunities in using HIE to meaningfully change transitional care processes from an integrated sociotechnical perspective. Findings from these analyses will directly inform policies, organizational strategies and technology design to support improved coordination between hospital and SNFs, and ultimately better patient care. 
Works Cited

1. Tian W. An All-Payer View of Hospital Discharge to Postacute Care, 2013. Agency for Healthcare Research and Quality, Healthcare Cost and Utilization Project: May 2016.

2. Boockvar K, Vladeck BC. Improving the quality of transitional care for persons with complex care needs. Journal of the American Geriatrics society. 2004;52(5):855-6.

3. LaMantia MA, Scheunemann LP, Viera AJ, Busby-Whitehead J, Hanson LC. Interventions to improve transitional care between nursing homes and hospitals: a systematic review. Journal of the American Geriatrics Society. 2010;58(4):777-82.

4. Naylor MD, Brooten DA, Campbell RL, Maislin G, McCauley KM, Schwartz JS. Transitional care of older adults hospitalized with heart failure: a randomized, controlled trial. Journal of the American Geriatrics Society. 2004;52(5):675-84.

5. Popejoy L, Galambos C, Vogelsmeier A. Hospital to nursing home transition challenges: Perceptions of nursing home staff. Journal of nursing care quality. 2014;29(2):103-9.

6. Murray LM, Laditka SB. Care transitions by older adults from nursing homes to hospitals: Implications for long-term care practice, geriatrics education, and research. Journal of the American Medical Directors Association. 2010;11(4):231-8.

7. Naylor MD, Aiken LH, Kurtzman ET, Olds DM, Hirschman KB. The importance of transitional care in achieving health reform. Health affairs. 2011;30(4):746-54.

8. Tjia J, Bonner A, Briesacher BA, McGee S, Terrill E, Miller K. Medication discrepancies upon hospital to skilled nursing facility transitions. Journal of general internal medicine. 2009;24(5):630-5.

9. Mor V, Intrator O, Feng Z, Grabowski DC. The revolving door of rehospitalization from skilled nursing facilities. Health Affairs. 2010;29(1):57-64.

10. Georgiou A, Marks A, Braithwaite J, Westbrook JI. Gaps, disconnections, and discontinuities - the role of information exchange in the delivery of quality long-term care. The Gerontologist. 2013;53(5):770-9.

11. Gurwitz JH, Field TS, Avorn J, McCormick D, Jain S, Eckler M, et al. Incidence and preventability of adverse drug events in nursing homes. The American journal of medicine. 2000;109(2):87-94.

12. King BJ, Gilmore-Bykovskyi AL, Roiland RA, Polnaszek BE, Bowers BJ, Kind AJ. The consequences of poor communication during transitions from hospital to skilled nursing facility: a qualitative study. Journal of the American Geriatrics Society. 2013;61(7):1095102.

13. Shah F, Burack O, Boockvar KS. Perceived barriers to communication between hospital and nursing home at time of patient transfer. Journal of the American Medical Directors Association. 2010;11(4):239-45.

14. Gaskin S, Georgiou A, Barton D, Westbrook J. Examining the role of information exchange in residential aged care work practices-a survey of residential aged care facilities. BMC geriatrics. 2012;12(1):1.

15. Haggerty JL, Reid RJ, Freeman GK, Starfield BH, Adair CE, McKendry R. Continuity of care: a multidisciplinary review. BMJ. 2003 Nov 20;327(7425):1219-21. 
16. Van Walraven C, Oake N, Jennings A, Forster AJ. The association between continuity of care and outcomes: a systematic and critical review. Journal of evaluation in clinical practice. 2010 Oct 1;16(5):947-56.

17. Liu K, Garrett B, Eilertsen T, Epstein A, Long S, Kramer A, et al. Options for improving Medicare payment for skilled nursing facilities. Urban Institute, 2007 Contract No.: CMS Contract No. 500-00-0025.

18. Fontaine P, Ross SE, Zink T, Schilling LM. Systematic review of health information exchange in primary care practices. The Journal of the American Board of Family Medicine. 2010;23(5):655-70.

19. Rudin RS, Motala A, Goldzweig CL, Shekelle PG. Usage and effect of health information exchange: a systematic review. Annals of internal medicine. 2014;161(11):803-11.

20. Adler-Milstein J, Salzberg C, Franz C, Orav E, Newhouse J, Bates D. Effect of Electronic Health Records on Health Care Costs: Longitudinal Comparative Evidence From Community Practices. Annals of Internal Medicine. 2013.

21. Lammers EJ, Adler-Milstein J, Kocher KE. Does health information exchange reduce redundant imaging? Evidence from emergency departments. Medical care. 2014;52(3):227-34.

22. Vest JR, Kern LM, Silver MD, Kaushal R. The potential for community-based health information exchange systems to reduce hospital readmissions. Journal of the American Medical Informatics Association. 2014:amiajnl-2014-002760.

23. Kruse CS, Mileski M, Alaytsev V, Carol E, Williams A. Adoption factors associated with electronic health record among long-term care facilities: a systematic review. BMJ open. 2015;5(1):e006615.

24. Abramson EL, McGinnis S, Moore J, Kaushal R. A statewide assessment of electronic health record adoption and health information exchange among nursing homes. Health services research. 2014;49(1pt2):361-72.

25. Wang T, Biedermann S. Adoption and utilization of electronic health record systems by long-term care facilities in Texas. Perspect Health Inf Manag. 2012;9(1).

26. Park-Lee E, Rome V, Caffrey C. Characteristics of residential care communities that use electronic health records. The American journal of managed care. 2014;21(12):e669-76.

27. Cherry B, Carter M, Owen D, Lockhart C. Factors Affecting Electronic Health Record Adoption in Long-Term Care Facilities. Journal for healthcare quality. 2008;30(2):37-47.

28. Cherry BJ, Ford EW, Peterson LT. Experiences with electronic health records: early adopters in long-term care facilities. Health care management review. 2011;36(3):265-74.

29. Filipova AA. Electronic Health Records Use and Barriers and Benefits to Use in Skilled Nursing Facilities. Computers Informatics Nursing. 2013;31(7):305-18.

30. Cohen MD, Hilligoss B, Amaral ACK-B. A handoff is not a telegram: an understanding of the patient is co-constructed. Critical care. 2012;16(1):303.

31. Allen LA, Hernandez AF, Peterson ED, Curtis LH, Dai D, Masoudi FA, et al. Discharge to a skilled nursing facility and subsequent clinical outcomes among older patients hospitalized for heart failure. Circulation: Heart Failure. 2011;4(3):293-300. 
32. Naylor MD, Kurtzman ET, Grabowski DC, Harrington C, McClellan M, Reinhard SC. Unintended consequences of steps to cut readmissions and reform payment may threaten care of vulnerable older adults. Health Affairs. 2012:10.1377/hlthaff. 2012.0110.

33. Fried TR, Mor V. Frailty and Hospitalization of Long-Term Stay Nursing Home Residents. Journal of the American Geriatrics Society. 1997;45(3):265-9.

34. Valentijn PP, Schepman SM, Opheij W, Bruijnzeels MA. Understanding integrated care: a comprehensive conceptual framework based on the integrative functions of primary care. International journal of integrated care. 2013 Jan;13.

35. Rahman M, Foster AD, Grabowski DC, Zinn JS, Mor V. Effect of Hospital-SNF Referral Linkages on Rehospitalization. Health services research. 2013;48(6pt1):1898-919.

36. Jencks SF, Williams MV, Coleman EA. Rehospitalizations among patients in the Medicare fee-for-service program. New England Journal of Medicine. 2009;360(14):1418-28.

37. Vest JR, Jasperson JS. How are health professionals using health information exchange systems? Measuring usage for evaluation and system improvement. Journal of medical systems. 2012;36(5):3195-204.

38. Vest JR, Zhao H, Jaspserson J, Gamm LD, Ohsfeldt RL. Factors motivating and affecting health information exchange usage. Journal of the American Medical Informatics Association. 2011;18(2):143-9.

39. Everson J, Kocher KE, Adler-Milstein J. Health information exchange associated with improved emergency department care through faster accessing of patient information from outside organizations. Journal of the American Medical Informatics Association. 2016:ocw116.

40. Vest JR, Jasperson JS, Zhao H, Gamm LD, Ohsfeldt RL. Use of a health information exchange system in the emergency care of children. BMC medical informatics and decision making. 2011;11(1):1.

41. Leavitt HJ. Applied Organizational Change in Industry, Structural, Technological and Humanistic Approaches. Handbook of organizations. 1965;264.

42. Carayon P. Human factors of complex sociotechnical systems. Applied ergonomics. 2006 Jul 1;37(4):525-35.

43. Ouslander JG, Naharci I, Engstrom G, Shutes J, Wolf DG, Rojido M, Tappen R, Newman D. Hospital transfers of skilled nursing facility (SNF) patients within 48 hours and 30 days after SNF admission. Journal of the American Medical Directors Association. 2016 Sep 1;17(9):839-45.

44. Harrison MI, Koppel R, Bar-Lev S. Unintended consequences of information technologies in health care - an interactive sociotechnical analysis. Journal of the American medical informatics Association. 2007;14(5):542-9.

45. Sittig DF, Singh H. A new sociotechnical model for studying health information technology in complex adaptive healthcare systems. Quality and Safety in Health Care. 2010;19(Suppl 3):i68-i74. 


\section{Chapter 1 : Investing in Post-Acute Care Transitions: Factors Associated with Hospitals Exchanging Information Electronically with Long-term Care}

\section{Facilities}

$\underline{\text { Introduction }}$

Care transitions between hospitals and long-term care providers (LTC) involve vulnerable patients with complex care needs, high utilization and often diminished ability to actively participate in the transfer of their health information and care plan. [1-3] Poor transitions to LTC providers increase the risk of rehospitalization and result in negative long-term health outcomes. [1, 3-9] However, hospitals and LTC providers lack strong incentives and infrastructure to improve information transfer during transitions.[10, 11]

Recent policy initiatives have sought to improve transitions by encouraging stronger relationships between hospitals and LTC providers in two ways: through aligning incentives for better coordination and by promoting adoption of information technology to improve information sharing. Policies aimed at aligning incentives include bundled payment initiatives, updates to the SNF prospective payment system and a value based purchasing program for nursing homes intended to reduce readmissions.[11-13] Stages 2 and 3 of the Medicare and Medicaid EHR Incentive Programs, commonly referred to as Meaningful Use explicitly require electronic information sharing (health information exchange, or HIE) with other provider organizations during care transitions; while LTC providers were not eligible for Meaningful Use 
incentives and lag behind hospitals in both EHR and HIE adoption, there may be spillover effects in which hospital investment in EHRs and HIE spurs adoption in LTC settings. [14-16] Thus, both types of policy efforts may drive hospitals and LTCs to improve care transitions by investing in HIE.

However, little is known about hospital-LTC health information exchange across the nation. Understanding the extent to which such exchange is happening today, as well as what types of hospitals are making this investment, offer insight into how hospitals may view the value of investing in HIE with LTC providers. Such results are also useful for policymakers to inform future efforts to increase connectivity between hospitals and LTCs in support of improved care transitions. This is particularly timely given recently updated guidance from the Centers for Medicare and Medicaid Services (CMS) detailing the allowed use of 90 percent Federal matching funds to state Medicaid agencies to invest in increasing HIE with Medicaid providers including long-term care providers - that are ineligible for Meaningful Use incentives. [17] We therefore use the most recent national data on health IT adoption in U.S. hospitals to answer the following research questions: (1) What proportion of U.S. hospitals engage in electronic health information exchange with LTC providers? (2) What are the IT and policy characteristics associated with hospital engagement in HIE with LTC providers? And, (3) Are there characteristics that differentiate hospitals that only send information electronically to LTC providers versus those that engage in bidirectional exchange (i.e., sending and receiving)?

\section{$\underline{\text { Methods }}$}

Setting and Data: Our dataset is comprised of non-federal, acute-care hospitals in the fifty states and the District of Columbia. We combined five sources of data. First, we used the 2014 American Hospital Association (AHA) IT Supplement Survey to capture hospital HIE with LTC 
providers (our outcome of interest) and other hospital IT capabilities. 2014 was the first year in which the AHA IT Supplement Survey asked hospitals about HIE with LTC providers. Second, we used the 2014 American Hospital Association Annual Survey to capture additional hospital characteristics, including some measures of hospital incentives to engage in HIE with LTC providers (e.g., ACO participation). Finally, we used three types of data from the Center for Medicare and Medicaid Services (CMS) to capture (1) hospital Meaningful Use attestation status under the Medicare EHR Incentive Program, (2) all-cause, 30-day readmission rates by hospital, and (3) presence of Medicare bundled payment initiatives in the hospital service area that include post-acute care in the payment episode. Our final sample size was 1,991 hospitals. [18] (For comparison of our analytic sample to those who did not respond to the IT supplement, see Appendix A).

\section{Measures:}

Hospital-LTC HIE. We used responses from the IT Supplement Survey to create three binary indicators for hospital engagement in LTC HIE: (1) whether or not each hospital exclusively sends structured summary of care records (SCRs) to LTC providers routinely ("send-only"); [19] (2) whether or not each hospital exclusively receives structured SCRs from LTC providers routinely ("receive-only"); and (3) whether or not each hospital sends as well as receive structured SCRs with LTC providers routinely ("bidirectional" exchange). We used these indicators to create two variables to distinguish how our characteristics of interest related to: (1) "any hospital-LTC HIE" (i.e., hospitals that engage in send-only or bidirectional, compared to those that do neither) and (2) "bidirectional HIE" (i.e., hospitals that engage in bidirectional exchange compared to those that send-only). We exclude "receive-only" hospitals from analysis since there were only 10 . 
IT Capabilities to Support Hospital-LTC HIE. We created three measures to capture hospitallevel HIT capabilities under the hypothesis that these capabilities would increase a hospital's ability to create and transmit a SCR electronically during a care transition. First, we included a categorical measure for whether, as of May 2015, a hospital had (a) not attested to Meaningful Use, (b) attested to Stage 1 Meaningful Use only, or (c) attested up through Stage 2 of Meaningful Use. We also included an indicator for (2) whether a hospital participates in a health information organization (HIO) in their market [20], and (3) whether the hospital sends and/or receives SCRs with unaffiliated hospitals and/or ambulatory care providers.

Policy Motivators to Support Hospital-LTC HIE. We created four hospital-level variables that capture engagement with concurrent reforms and policy changes that we hypothesized would directly affect a hospital's financial motivation to invest in LTC HIE. First, we included each hospital's fiscal year 2013-2014 score for 30-day, all-cause readmissions, under the assumption that hospitals struggling with managing care transitions (for which they get financially penalized) may be more proactively seeking HIE with LTCs as an improvement strategy. Second, we included an indicator for presence of specific Medicare bundled payment initiatives in a hospital's market that encompass post-acute care as part of the care episode (using Dartmouth Atlas Hospital Service Areas as the definition of a market). We hypothesized that hospitals in these markets would be more likely to invest in LTC HIE to manage quality and cost for patients transitioning between these two settings. Following a similar logic, our third measure captures whether or not the hospital reported participating in an ACO. Finally, we created an indicator for whether or not the hospital owns, is affiliated with or is engaged in a joint venture with a skilled nursing facility (SNF). We focused on SNFs (excluding other LTC providers such as rehab facilities and long-term acute care hospitals) because (1) a greater volume of patients transition 
between hospitals and SNFs relative to other LTC providers, and (2) current policy efforts to improve care transitions and readmissions from post-acute care focus on SNFs.

Hospital Demographic Controls. We included measures of hospital characteristics that we expected might relate to both our focal characteristics and whether or not hospitals engage in HIE with LTC providers. These measures included size, ownership, teaching status and urban/rural location.

Analytic Approach: We first calculated the proportion of hospitals engaging in the different types of SCR exchange with LTC providers - none, send only, receive only, or send and receive. We report weighted proportions using non-response weights to produce nationally representative estimates. We next examined the bivariate relationships between hospital characteristics and any hospital-LTC HIE, and then bidirectional HIE to assess whether there were systematic differences between hospitals that engaged in bidirectional exchange versus send-only. We used chi-squared tests to assess statistical significance across categorical characteristics and t-tests to assess differences in means for continuous characteristics.

Finally, we used multivariate logistic regression models to examine the independent relationships between hospital characteristics and the same two dependent variables: any hospital-LTC HIE and bidirectional HIE. In our models, standard errors were adjusted for hospital clustering within markets (using Dartmouth Atlas hospital referral regions - HRRs) and we included nonresponse weights.

\section{$\underline{\text { Results }}$}

One-third (33.9\%) of hospitals exclusively sent information electronically to LTC settings, $0.5 \%$ exclusively received information electronically from LTC settings and $22.8 \%$ of hospitals 
engaged in bidirectional exchange. The remaining $42.8 \%$ of hospitals did not routinely engage in SCR exchange with LTC providers. (Table 1.1)

Table 1.1: Percent of US Hospitals Routinely Exchanging Structured Summary of Care Records Electronically with LTC Providers [unweighted]

\begin{tabular}{|l|l|}
\hline $\begin{array}{l}\text { Number of hospitals* } \\
\text { (with LTC HIE capability reported) }\end{array}$ & $\mathrm{N}=1,981 *$ \\
\hline No activity & $847(42.8 \%)$ \\
\hline Sending only & $671(33.9 \%)$ \\
\hline Receiving only & $10(0.5 \%)$ \\
\hline Sending and Receiving & $453(22.9 \%)$ \\
\hline
\end{tabular}

*Sample size includes general acute-care hospitals, as well as the following specialty hospitals likely to discharge patients to: cancer, heart, ENT, orthopedic, chronic disease and "other specialty"

\section{Hospital Characteristics Associated with LTC HIE Capability:}

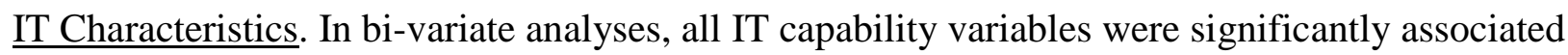
with hospitals engagement in any hospital-LTC HIE. Hospitals that had attested to Stage 1 only, or up through Stage 2 of Meaningful Use, were significantly more likely to engage in any SCR exchange with LTCs as compared to hospitals that had not attested $(53.2 \%$ and $59.7 \%$, respectively, versus $33.4 \%, \mathrm{p}<0.001)$. Hospitals that were participating in an HIO were more likely than those that were not to engage in LTC HIE $(61.0 \%$ versus $46.3 \%, \mathrm{p}<0.001)$ as were hospitals that engaged in HIE with other hospitals or ambulatory providers in the market $(64.0 \%$ versus $25.7 \%, \mathrm{p}<0.001)$. (Table 1.2)

In our multi-variate model, relative to hospitals that had not participated in any Meaningful Use attestation by May 2015, hospitals that had successfully attested to Stage 1 only were significantly more likely to be engaged in any hospital-LTC HIE ( $\mathrm{OR}=1.87 ; \mathrm{p}=0.01)$, as were hospitals that had attested to Stage $2(\mathrm{OR}=2.05 ; \mathrm{p}=0.003)$. (Table 1.3) Participation in an HIO was also significantly associated with increased odds of any hospital-LTC HIE $(\mathrm{OR}=1.34$; 
$\mathrm{p}=0.021$ ), as was a hospital engaged in HIE with other hospitals or ambulatory care providers $(\mathrm{OR}=4.54 ; \mathrm{p}<0.001)$. 
Table 1.2: Bivariate Analyses: Comparing LTC HIE activity across Hospital Characteristics [weighted proportions]

\begin{tabular}{|c|c|c|c|c|c|c|}
\hline & $\begin{array}{c}\text { Any LTC } \\
\text { HIE } \\
\text { Capability }\end{array}$ & $\begin{array}{c}\text { No LTC } \\
\text { HIE } \\
\text { Activity }\end{array}$ & $\begin{array}{l}\text { P Value } \\
\text { (Chi- } \\
\text { squared) }\end{array}$ & $\begin{array}{c}\text { Send and } \\
\text { Receive LTC } \\
\text { HIE } \\
\text { Capability }\end{array}$ & $\begin{array}{l}\text { Send-only } \\
\text { LTC HIE } \\
\text { Capability }\end{array}$ & $\begin{array}{l}\text { P Value } \\
\text { (Chi- } \\
\text { squared) }\end{array}$ \\
\hline & $\mathrm{N}=\mathbf{1 , 1 2 0}$ & $\mathbf{N}=847$ & & $\mathbf{N}=\mathbf{4 5 1}$ & $\mathrm{N}=669$ & \\
\hline \multicolumn{7}{|l|}{ IT Capabilities } \\
\hline \multicolumn{7}{|c|}{ Meaningful Use Attestation } \\
\hline None & 33.9 & 66.1 & \multirow[t]{3}{*}{$<0.001$} & 51.0 & 49.0 & \multirow[t]{3}{*}{0.196} \\
\hline Stage 1 Only & 53.3 & 46.7 & & 41.5 & 58.5 & \\
\hline Stage 1 and 2 & 59.6 & 40.4 & & 37.4 & 62.6 & \\
\hline \multicolumn{7}{|c|}{ Is participating in market $\mathrm{HIO}$} \\
\hline Yes & 61.1 & 38.9 & \multirow[t]{2}{*}{$<0.001$} & 38.8 & 61.2 & \multirow[t]{2}{*}{0.473} \\
\hline No & 46.3 & 53.7 & & 41.1 & 58.9 & \\
\hline \multicolumn{7}{|c|}{ Reports sending information electronically to other hospitals or ambulatory providers } \\
\hline Yes & 64.0 & 36.0 & \multirow[t]{2}{*}{$<0.001$} & 41.9 & 58.1 & \multirow[t]{2}{*}{$<0.001$} \\
\hline No & 26.1 & 73.9 & & 18.9 & 81.1 & \\
\hline \multicolumn{7}{|l|}{ Policy Motivators } \\
\hline \multicolumn{7}{|c|}{ Presence of BPCI in the market (HSA) } \\
\hline Yes & 61.1 & 38.9 & \multirow[t]{2}{*}{$<0.001$} & 39.0 & 61.0 & \multirow{2}{*}{0.755} \\
\hline No & 52.0 & 48.0 & & 39.9 & 60.1 & \\
\hline \multicolumn{7}{|l|}{ Involvement in $\mathrm{ACO}$} \\
\hline Yes & 63.1 & 36.9 & \multirow{2}{*}{$<0.001$} & 47.9 & 52.1 & \multirow[t]{2}{*}{$<0.001$} \\
\hline No & 53.1 & 46.9 & & 36.0 & 64.0 & \\
\hline \multicolumn{7}{|l|}{ Hospital } \\
\hline $\begin{array}{l}\text { Readmission Score, } \\
\text { FY } 13 / 14\end{array}$ & 15.29 & 15.15 & $<0.001$ & 15.29 & 15.31 & 0.747 \\
\hline Type of SNF & & & & & & \\
\hline Affiliation & & & & & & \multirow{3}{*}{0.664} \\
\hline No affiliation & 52.7 & 47.3 & \multirow{2}{*}{$<0.001$} & 40.0 & 60.0 & \\
\hline $\begin{array}{l}\text { SNF Ownership, } \\
\text { Affiliation or Joint } \\
\text { Venture }\end{array}$ & 61.1 & 38.9 & & 38.7 & 61.3 & \\
\hline \multicolumn{7}{|c|}{ Hospital Organizational Characteristics } \\
\hline \multicolumn{7}{|l|}{ Hospital Size } \\
\hline$<100$ & 46.9 & 53.1 & \multirow[t]{3}{*}{$<0.001$} & 37.3 & 62.7 & \multirow[t]{3}{*}{0.417} \\
\hline $101-399$ & 62.8 & 37.2 & & 40.7 & 59.4 & \\
\hline $400+$ & 68.1 & 31.9 & & 42.2 & 57.8 & \\
\hline \multicolumn{7}{|l|}{ Urban/Rural } \\
\hline Urban & 59.6 & 40.4 & $<0.001$ & 40.3 & 59.7 & 0.499 \\
\hline Rural & 50.4 & 49.6 & & 38.2 & 61.8 & \\
\hline Teaching Status & & & & & & \\
\hline Non-teaching & 52.3 & 47.7 & $<0.001$ & 37.3 & 62.7 & 0.017 \\
\hline Minor teaching & 62.9 & 37.1 & & 41.6 & 58.4 & \\
\hline Major teaching & 66.6 & 33.4 & & 51.7 & 48.3 & \\
\hline Ownership & & & & & & \\
\hline Public (state only) & 47.5 & 52.5 & $<0.001$ & 42.4 & 57.6 & 0.040 \\
\hline Non-govt, NFP & 59.9 & 40.1 & & 40.5 & 59.5 & \\
\hline Investor-owned, FP & 46.4 & 53.6 & & 28.6 & 71.4 & \\
\hline
\end{tabular}


When we examined whether these characteristics predicted which hospitals reported bidirectional HIE as compared to "send only", in bivariate analysis there were only significant differences for whether the hospital engaged in HIE with other hospitals or ambulatory providers (41.9\% versus $19.2 \%, \mathrm{p}<0.001)$. In multivariate analysis, this continued to be the only characteristic that differentiated hospitals engaged in bidirectional exchange compared to those doing send-only $(\mathrm{OR}=3.31 ; \mathrm{p}=0.001)$.

Table 1.3: Multivariate Analyses: Predicting LTC HIE Activity

\begin{tabular}{|c|c|c|c|c|}
\hline & \multicolumn{2}{|c|}{$\begin{array}{l}\text { Model 1: Any HIE } \\
\text { Activity }\end{array}$} & \multicolumn{2}{|c|}{$\begin{array}{c}\text { Model 2: Bidirectional } \\
\text { Exchange Compared to Send } \\
\text { Only }\end{array}$} \\
\hline \multicolumn{5}{|l|}{ Sample Size: $\mathbf{N = 1 , 9 6 7}$} \\
\hline Categorical Variables & Odds Ratio & SE & Odds Ratio & SE \\
\hline \multicolumn{5}{|l|}{ IT Characteristics } \\
\hline \multicolumn{5}{|l|}{ Meaningful Use Attestation } \\
\hline No attestation & Ref & & Ref & \\
\hline Stg. 1 MU Attestation Only & $1.82 * *$ & 0.24 & 0.69 & 0.47 \\
\hline $\begin{array}{l}\text { Stg. } 1 \text { and } 2 \mathrm{MU} \\
\text { Attestation }\end{array}$ & $1.98 * * *$ & 0.24 & 0.59 & 0.48 \\
\hline Participation in $\mathrm{HIO}$ & $1.35 * *$ & 0.13 & 0.76 & 0.18 \\
\hline $\begin{array}{l}\text { Reports exchange of } \\
\text { information with other } \\
\text { hospitals or ambulatory care } \\
\text { providers }\end{array}$ & $4.55 * * *$ & 0.18 & $3.27 * * *$ & 0.36 \\
\hline \multicolumn{5}{|c|}{ Hospital Organizational Characteristics } \\
\hline \multicolumn{5}{|l|}{ Hospital Size } \\
\hline 0-99 Beds & Ref & & Ref & \\
\hline 100-399 Beds & $1.63 * * *$ & 0.12 & 1.13 & 0.17 \\
\hline $400+$ Beds & $1.82 * *$ & 0.23 & 0.92 & 0.25 \\
\hline \multicolumn{5}{|l|}{ Location } \\
\hline Urban & Ref & & Ref & \\
\hline Rural & 1.05 & 0.15 & 1.02 & 0.19 \\
\hline \multicolumn{5}{|l|}{ Teaching Status } \\
\hline Not Teaching & Ref & & Ref & \\
\hline Minor Teaching & 0.95 & 0.13 & 1.17 & 0.18 \\
\hline Major Teaching & 0.73 & 0.25 & $2.04 * *$ & 0.29 \\
\hline Ownership & & & & \\
\hline
\end{tabular}




\begin{tabular}{|c|c|c|c|c|}
\hline Private, Non-Profit & Ref & & Ref & \\
\hline Public & $0.78^{*}$ & 0.14 & 1.16 & 0.21 \\
\hline Private, For-Profit & 0.83 & 0.19 & $0.58 * *$ & 0.27 \\
\hline \multicolumn{5}{|l|}{ Policy Motivators } \\
\hline $\begin{array}{l}\text { Presence of BPCI in the } \\
\text { market }\end{array}$ & 1.16 & 0.13 & 0.81 & 0.17 \\
\hline Involvement in $\mathrm{ACO}$ & 1.09 & 0.17 & $1.74 * * *$ & 0.18 \\
\hline $\begin{array}{l}\text { 30-day all-cause readmission } \\
\text { score }\end{array}$ & $1.20^{* *}$ & 0.07 & 0.91 & 0.09 \\
\hline $\begin{array}{l}\text { Own/affiliate/joint venture } \\
\text { with a SNF }\end{array}$ & $1.26^{*}$ & 0.12 & 0.91 & 0.17 \\
\hline
\end{tabular}

$\underline{\text { Policy Motivators. In bivariate analyses, all four factors related to hospital motivation to engage }}$ in HIE with LTC providers were positively related and statistically significant. Hospitals with a bundled payment initiative in their service area were significantly more likely engage in any hospital-LTC HIE (60.9\% versus 52.0\%, p<0.001), as were hospitals participating in an ACO (63.1\% versus $53.0 \%, \mathrm{p}<0.001)$. Hospitals that had a higher all-cause, 30 -day readmissions score were also more likely to engage in any hospital-LTC HIE (15.29 vs $15.15 ; \mathrm{p}<0.001)$. Hospitals that owned or were affiliated with a SNF were also more likely to engage in any hospital-LTC HIE (61.6\% versus $52.2 \%, \mathrm{p}<0.001)$.

In multivariate analysis, hospitals with a higher readmissions score were significantly more likely to engage in any hospital-LTC HIE $(\mathrm{OR}=1.19 ; \mathrm{p}=0.016)$. There was also a significant and positive relationship between hospitals with formal SNF relationships and hospital-LTC HIE $(\mathrm{OR}=1.29, \mathrm{p}=0.041)$. Neither ACO participation nor presence of a bundled payment initiative in the hospital service area was significantly associated with any hospital-LTC HIE.

Comparing bidirectional to send-only, hospitals participating in an ACO were significantly more likely to engage in bidirectional exchange ( $47.9 \%$ versus $36.1 \%$; $<<0.001)$. None of the other characteristics differentiated the two groups. In our multivariate regression, ACO participation 
persisted as the only significant predictor that distinguished bidirectional from send-only

$(\mathrm{OR}=1.73 ; \mathrm{p}=0.003)$.

\section{$\underline{\text { Discussion }}$}

Using 2014 national hospital survey data, we found that the majority of hospitals routinely engaged in electronic exchange (sending, receiving, or both) of structured summary of care records - a relatively advanced form of HIE - with long-term care providers. Just over one-third of hospitals engaged in send-only exchange and an additional one-quarter of hospitals engaged in bidirectional exchange. These findings contribute to the small body of empirical evidence on information exchange activity between hospitals and LTC providers, and are the first to provide national level estimates of hospital-reported exchange activity with LTCs. While it is encouraging that so many hospitals are investing in HIE with LTC providers despite lower rates of health IT adoption in this setting, it remains critical to achieve greater levels of uptake. Without ensuring that LTC providers are able to routinely engage in HIE, we will continue to struggle to support patient care across the continuum and fail to maximize the benefit from the recent increase in EHR adoption resulting from the meaningful use incentives.

As payment to LTC providers and hospitals increasingly emphasizes total patient care and paying for value, those leading these organizations have new incentives to pursue collaborative relationships. By improving information continuity, electronic health information exchange offers a valuable approach to improving transitions, and the associated quality and safety of care. Our findings inform LTC leaders on the current level of hospital engagement in such exchange, and help them identify which types of hospitals may be particularly motivated to pursue it specifically, hospitals with some existing technology infrastructure and HIE experience, as well as those with a compelling business case to invest in HIE with LTC providers. Going forward, 
ensuring that HIE between hospitals and LTC providers translates into improved care transitions will likely require additional work to understand and accommodate the different information needs in these two settings, and address health IT implementation challenges more acute among or specific to LTC providers, such as lack of devoted financial resources and an inadequate evidence base to support organizational change and system use in the LTC context. [21-24] Our findings also offer key insights for policymakers seeking to increase hospital-LTC HIE by suggesting what is motivating hospitals to invest in this capability. Specifically, hospitals that are investing appear to be doing so as part of broad investment in health IT capabilities with many types of trading partners, and in response to incentives to strengthen relationships with LTC providers - including readmission penalties and broader care delivery reforms. Therefore, future funding might be most effectively used by targeting LTC providers that do not have strong relationships with hospitals with advanced health IT capabilities, as well as LTC providers less engaged with hospitals under either formal affiliations or as partners in new models of care delivery. These are the LTC providers that hospitals appear less willing to connect with on their own, and therefore would represent a good use of public dollars to ensure broad connectivity. Ultimately, it will be critical to ensure not just "any" hospital-LTC HIE, but bidirectional exchange. Here, our finding that hospitals participating in an ACO were more likely to engage in bidirectional exchange suggests that these new payment models are having one of their intended effects with respect to driving HIE. [25] However, ACOs may incentivize bidirectional exchange only between select partners and therefore not ensure that LTC providers are connected to all hospitals from which they regularly receive patients.

Limitations: Our study uses self-reported survey data, and we were not able to verify the accuracy of responses. However, data from the AHA IT Supplement has been used extensively 
to measure national HIT adoption among hospitals. [26-28] Second, our measure of hospital SCR exchange with LTC providers is limited in three ways. SCR exchange is only one type of document that may be exchanged electronically and it is not clear whether hospitals that exchange SCRs also exchange other types of clinical data with LTC providers. However, SCRs were designed to include key types of clinical data (e.g., medication list, encounter diagnosis, lab results) that are important to care transitions. We also do not know about the breadth of LTC HIE activity (i.e. whether the hospital is exchanging with just one or a few LTC providers in the market, or many). This is a key limitation and prevents us from knowing the extent to which hospitals are engaging in HIE with the LTC providers with whom they share the majority of patients. Further, respondents could have differentially interpreted what it meant to engage in SCR exchange with LTC providers "routinely". Finally, 2014 was the first and currently only year in which the survey question on SCR exchange with LTC providers is available. As a result, we did not have the ability to examine change in hospital-LTC HIE over time and our findings reflect associational relationships.

\section{Conclusion}

As of 2014 , nearly $25 \%$ of hospitals were engaged in bidirectional information exchange with LTC providers, with another $34 \%$ engaged in send-only. Our findings suggest that hospitals are including LTC exchange in their overall EHR and HIE strategy, i.e. a "rising tide lifts all ships" dynamic, and that new payment incentives (i.e. readmission penalties, ACO incentive structures) are also driving hospital-LTC HIE. While the anticipated growth of these incentive programs may be sufficient to drive broad hospital-LTC HIE, and in particular, bidirectional exchange, policy efforts could speed progress by focusing support on LTC providers that hospitals are less likely to view as valuable exchange partners. Doing so would move us closer to the important 
goal of ensuring that our healthcare system has the capabilities in place to treat patients seamlessly across the care continuum. 


\section{$\underline{\text { Works Cited }}$}

1. LaMantia MA, Scheunemann LP, Viera AJ, Busby-Whitehead J, Hanson LC. Interventions to improve transitional care between nursing homes and hospitals: a systematic review. Journal of the American Geriatrics Society. 2010;58(4):777-782.

2. Liu K, Garrett B, Eilertsen T, et al. Options for improving Medicare payment for skilled nursing facilities. Urban Institute;2007.

3. King BJ, Gilmore-Bykovskyi AL, Roiland RA, Polnaszek BE, Bowers BJ, Kind AJ. The consequences of poor communication during transitions from hospital to skilled nursing facility: a qualitative study. Journal of the American Geriatrics Society. 2013;61(7):1095-1102.

4. Coleman EA, Smith JD, Raha D, Min S-j. Posthospital medication discrepancies: prevalence and contributing factors. Archives of internal medicine. 2005;165(16):1842-1847.

5. Boockvar K, Vladeck BC. Improving the quality of transitional care for persons with complex care needs. Journal of the American Geriatrics society. 2004;52(5):855-856.

6. Mor V, Intrator O, Feng Z, Grabowski DC. The revolving door of rehospitalization from skilled nursing facilities. Health Affairs. 2010;29(1):57-64.

7. Tilson S, Hoffman GJ. Addressing Medicare Hospital Readmissions. Congressional Research Service. 2012.

8. Roy CL, Poon EG, Karson AS, et al. Patient safety concerns arising from test results that return after hospital discharge. Annals of Internal Medicine. 2005;143(2):121-128.

9. Teno JM, Mitchell SL, Skinner J, et al. Churning: the association between health care transitions and feeding tube insertion for nursing home residents with advanced cognitive impairment. Journal of palliative medicine. 2009;12(4):359-362.

10. Bennett R, Tuttle M, May K, Harvell J, Coleman E. Health information exchange in postacute and long-term care case study findings: final report. Washington (DC): Department of Health and Human Services, Office of Disability, Aging and Long-Term Care Policy;2007. 11. Naylor MD, Kurtzman ET, Grabowski DC, Harrington C, McClellan M, Reinhard SC. Unintended consequences of steps to cut readmissions and reform payment may threaten care of vulnerable older adults. Health Affairs. 2012:10.1377/hlthaff. 2012.0110.

12. Zigmond J. Avoiding the penalty box. New rules on readmissions push hospitals, postacute providers into closer collaboration. Modern healthcare. 2012;42(5):38.

13. Medicare Program; Prospective Payment System and Consolidated Billing for Skilled Nursing Facilities (SNFs) for FY 2016, SNF Value-Based Purchasing Program, SNF Quality Reporting Program, and Staffing Data Collection. Final Rule. Centers for Medicare and Medicaid Services , HHS;2015. 0097-6326.

14. Zhang N, Lu SF, Xu B, Wu B, Rodriguez-Monguio R, Gurwitz J. Health Information Technologies: Which Nursing Homes Adopted Them? Journal of the American Medical Directors Association. 2016;17(5):441-447.

15. Health IT in Long-Term and Post-Acute Care Issue Brief. Washington, DC: US Department of Health and Human Services; Office of the National Coordinator for Health IT; 2013.

16. Wolf L, Harvell J, Jha AK. Hospitals Ineligible For Federal Meaningful-Use Incentives Have Dismally Low Rates Of Adoption Of Electronic Health Records. Health Affairs. March 1, 2012 2012;31(3):505-513. 
17. Availability of HITECH Administrative Matching Funds to Help Professionals and Hospitals Eligible for Medicaid EHR Incentive Payments Connect to Other Medicaid Providers. In: Services CfMM, edFebruary 29, 2016.

18. Arriving at the final sample: 2,745 hospitals from the AHA main file matched with IT supplement data. We then removed 658 hospitals from the analysis that did not respond to any part of the IT supplement survey section on information exchange. Finally, we removed 97 hospitals from the sample that did not have any readmissions data. This left us with a complete dataset of 1,991 hospitals. This number includes the 10 "receive-only" hospitals that were ultimately excluded from analysis.

19. A Summary of Care Record (SCR) contains key data elements, specified in the Meaningful Use certification criteria, that are believed to be necessary for the next care provider to be informed about patient status and prior care received.

20. Health Information Organizations (HIOs) are community-level efforts bring together stakeholders to enable HIE and may include LTC providers; in recent national data collected on HIOs, $40 \%$ of operational HIOs reported that they have LTC providers contributing information, and half had LTC providers receiving information. (Source: Painter MW, Jha AK. Health Information Technology in the United States, 2015: Transition to a Post-HITECH World (Executive Summary). Mathematica Policy Research; 2015.)

21. Cherry BJ, Ford EW, Peterson LT. Experiences with electronic health records: early adopters in long-term care facilities. Health care management review. 2011;36(3):265-274.

22. Filipova AA. Electronic Health Records Use and Barriers and Benefits to Use in Skilled Nursing Facilities. Computers Informatics Nursing. 2013;31(7):305-318.

23. Kruse CS, Mileski M, Alaytsev V, Carol E, Williams A. Adoption factors associated with electronic health record among long-term care facilities: a systematic review. BMJ open. 2015;5(1):e006615.

24. Degenholtz HB, Resnick A, Lin M, Handler S. Development of an applied framework for understanding health information technology in nursing homes. Journal of the American Medical Directors Association. 2016;17(5):434-440.

25. Buntin MB, Jain SH, Blumenthal D. Health information technology: laying the infrastructure for national health reform. Health Affairs. 2010;29(6):1214-1219.

26. Charles D, King J, Patel V, Furukawa MF. Adoption of electronic health record systems among US non-federal acute care hospitals: 2008-2012. Office of the National Coordinator for Health Information Technology; 2013.

27. Adler-Milstein J, DesRoches CM, Kralovec P, et al. Electronic Health Record Adoption In US Hospitals: Progress Continues, But Challenges Persist. Health Affairs. 2015:10.1377/hlthaff. 2015.0992.

28. Jha AK, Burke MF, DesRoches C, et al. Progress toward meaningful use: hospitals' adoption of electronic health records. The American journal of managed care. 2011;17(12 Spec No.):SP117-124. 


\section{Chapter 2 : The Importance of Use and Usage Patterns in Assessing Potential for Health Information Exchange to Improve Post-Acute Transitions of Care $\underline{\text { Introduction }}$}

Hospitals are devoting substantial attention to improved discharge planning and transitions of care. The Medicare Readmission Reduction Program, as well as delivery system reforms such as accountable care organization and bundled payments, provide financial incentives for providers to coordinate services across the care continuum. In spite of this, poor handoffs and lack of information continuity continue to compromise patient care. These concerns are particularly acute for patients transitioning from hospitals to skilled nursing facilities (SNFs), the largest institutional provider of post-acute care. More than four million Medicare patients are discharged to a SNF annually; these patients tend to be older and have more complex conditions, thus they are more vulnerable to breakdowns in care processes. (1) Indeed, numerous studies of hospital-SNF transitional care have found systemic deficits in quality and safety. (2-7) These deficits result in worse patient outcomes in SNF settings (e.g., delayed care responsiveness, medical errors) and average rates of readmission to the hospital as high as $25 \% .(8-11)$

A key contributor to poor hospital-SNF transitions is the lack of robust information sharing. This often results in missing, delayed, or difficult-to-use information received by SNF providers that then compromises their ability to deliver safe and effective care. $(3,6,10,12-14)$ Electronic 
information sharing offers potential to improve key dimensions of information quality (e.g. completeness, accuracy, timeliness, and standardization of content) that could enhance care transition processes. $(15,16)$ Indeed, the promise of electronic health information exchange (HIE) was a key driver of the unprecedented investment in health information technology over the past decade through the HITECH Act and corresponding organizational and regional investments. (17)

There is, however, significant uncertainty about if and how HIE supports hospital-SNF transitions.. Evidence linking HIE to improved patient care is sparse and restricted to the context of hospitalto-hospital or hospital-to-primary care transitions. (18) This limited evidence may not translate to transitions between hospitals as acute care providers and SNFs as post-acute care providers. Unlike hospitals in hospital-to-hospital transitions, the providers in hospital-SNF transitions have different informational needs. For example, SNFs are concerned about continuity in rehabilitation therapies and improvements to functional status; these are not points of emphasis during an acute hospitalization. Hospitals and SNFs also maintain different staffing models, workflows, reimbursement structures and cultural norms; these discrepancies may increase the difficulty of constructing shared handoff processes that fit the needs and preferences of both organizations. (19, 20) Finally, unlike hospitals and primary care providers, post-acute care providers were ineligible for Meaningful Use payments under the EHR Incentive Programs established by HITECH. Though post-acute care providers continue to invest in technology to support care practices and documentation needs, they lag in adoption of systems with clinical delivery features that match the systems certified and used by eligible (i.e. hospital and ambulatory care) providers under Meaningful Use criteria. (21) These differences pose an additional barrier to achieving seamless interoperability. (22) 
Understanding the impact of HIE on hospital-SNF transitional care requires assessing not just whether HIE is used but the specifics of how it is used. Prior work reveals substantial variation in the level of HIE use in hospitals and ambulatory settings, resulting in uneven impact on care. (2326) Since there has been no empirical evaluation of the relationship between hospital-SNF HIE and patient outcomes, there has also been no critical analysis of variation in HIE usage patterns and how this variation may illuminate what types of usage patterns benefit patient outcomes. This knowledge is critical if we are to advance targeted policy and organizational strategies that have the greatest likelihood of improving post-acute transitional care.

\section{Objective}

In this paper, we sought to determine whether HIE between hospitals and SNFs has a measureable impact on patient care and to understand what approaches to HIE use are associated with greater benefits. Estimating an overall treatment effect via "intent to treat" - whether a system was implemented between two providers - over time enables robust longitudinal analyses for causal interpretation (See Figure 2.1; Research Question (RQ) 1). Exploring cross-sectional variation in actual use - in when and how SNF providers access available hospital information - provides a more nuanced understanding of the mechanisms that may be driving the relationship between HIE availability and outcomes (RQ2 \& RQ3).

Figure 2.1. Conceptual Model of Variation in Hospital-SNF HIE Use on Patient Outcomes 


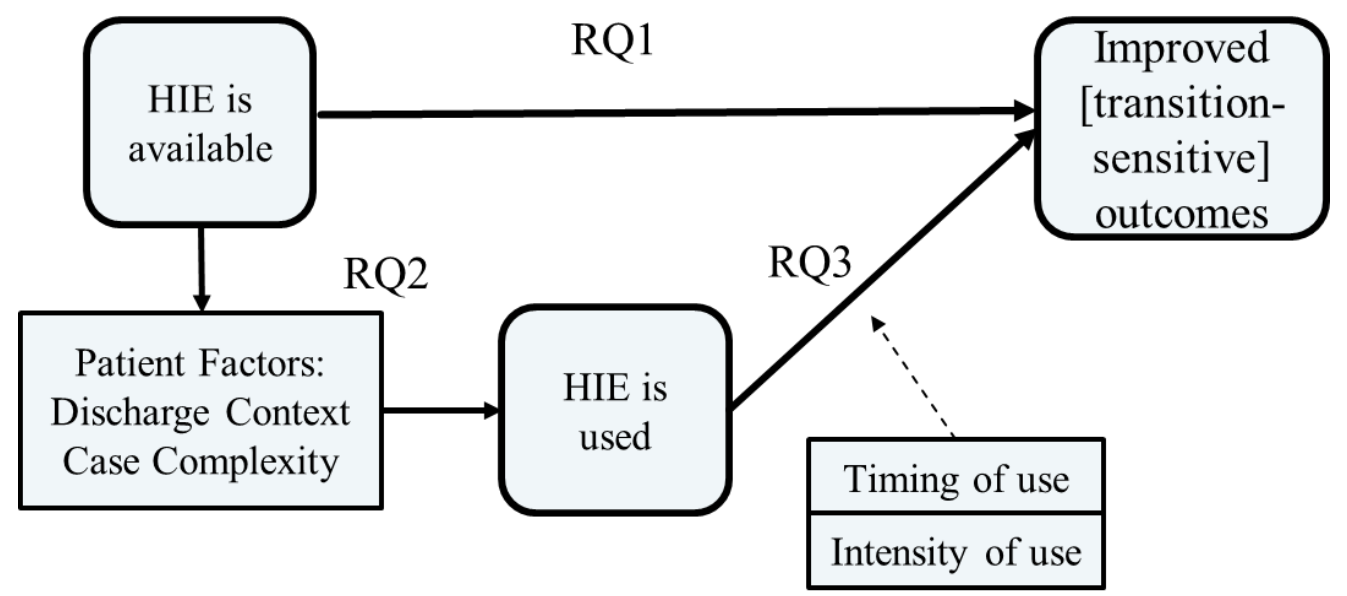

Once systems that enable HIE are implemented, the factors that shape how the system is used to support post-acute care processes are unknown. First, electronic information retrieval may not be equally useful for all patients. If this were the case, we would expect to find systematic variation in the type of patient for whom HIE systems are used. Patients with higher case complexity - more conditions, more concurrent medications, etc. - have more intensive care needs. Care for these patients requires complex medical decision-making, which may affect informational needs and change the perceived utility for SNF providers of engaging in retrieval via HIE. Context surrounding the patient handoff from hospital to SNF - for example, whether the patient is being discharged off-shift and/or back to a SNF where they were already residing - may also affect the rigor of information sharing practices during transition.

Information systems can only be expected to measurably improve transitional care if they are used in ways that address known shortcomings in the quality of information transfer. Two dimensions of information quality are particularly relevant as moderators of the relationship between use of HIE and improved patient outcomes. First, timing of system use helps to illustrate the primary purpose with which SNF providers approach use of health information exchange (HIE). More prompt use of the system relative to the time of patient discharge would indicate transition-focused 
information retrieval to support handoffs and patient care planning. $(26,27)$ Use outside of the care transition window may relate more to information needs for billing documentation or, if use occurs with little predictability, may indicate unplanned provider use of the system prompted by a decline in patient condition (i.e. acute informational need). Second, intensity of system use - the breadth as well as depth of data retrieved from hospital records via HIE - may be driven by standard information retrieval processes, or by the specific information needs based on patient condition. Retrieving a greater volume of information may better support transitional and postacute care processes via more complete information availability; however, this relationship may vary based on the timing - and, relatedly, the primary purpose - of system use.

This analysis thus takes a novel approach to answer the following research questions:

Research Question 1: Does electronic information sharing between hospitals and SNFs improve the quality patient post-acute care transitions, as measured by a reduction in rate of 30-day readmissions?

Research Question 2: Are there specific patient level factors related to the individual's case complexity or the context surrounding discharge that are associated with whether SNF providers utilize available HIE technology?

Research Question 3: Does variation in the timeliness and/or intensity of system use modify the extent to which effects of HIE on patient care can be detected?

Findings from this study can inform the design and implementation of HIE systems that maximize improved hospital-SNF transitions. 


\section{$\underline{\text { Methods }}$}

Setting and Data: The study was conducted at the 550- bed adult hospital of a large academic health system that implemented an Epic electronic health record in 2012, and in June 2014, selectively extended EpicCare Link (ECL) to three SNFs in the local community. ECL is a "viewonly" portal feature that enables outside providers to access internal patient records for assigned patients. This resource was offered for supplemental use in addition to other discharge summary or continuity of care documentation sent as part of standard care transfer. A comprehensive timestamped record of every information retrieval action taken by an authorized user for a patient via ECL is captured in a "log file" of audited actions; this audit trail is required under HIPAA and maintained by the health system's IT support services. Physicians who see patients in the SNF have their own direct log-in to the Epic EHR and do not use ECL. Therefore, our audit record captures information retrieval by SNF administrators and floor nurses - those most directly and continuously responsible for implementing post-transitional care processes.

We merged two data files to create the analytic dataset. First, we pulled records for all patients discharged from the hospital to a SNF between January 1, 2013 (18 months prior to ECL implementation) and March 31, 2017 (30 months post-implementation). These records, which came from fields in the EHR, included the following data: patient medical record number, timestamp for hospital admission and discharge, age, gender, race, reason(s) for hospitalization, current diagnoses, current medications, and name of SNF to which the patient was discharged. If the patient was readmitted to the focal hospital within the 30 days following hospital discharge, this was indicated along with the number of days between discharge and readmission. 
Second, we retrieved all records of activity within ECL by users whose access rights are associated with one of the three ECL-enabled SNFs. These audit-log records span from mid-June 2014 (the time of system implementation) to March 31, 2017. Specific data fields contain: user ID, facility ID, patient medical record number, timestamp of action, and specific action taken. One hundred seventeen different action types were captured during the data collection period. These actions were then collapsed into 10 different categories based on the type of information retrieved (See Table 2.1), in addition to a eleventh summary screen which is the default landing page for the majority of system uses.

Table 2.1 List of Information Usage Categories

\begin{tabular}{|l|}
\hline Patient Summary Screen \\
\hline Inpatient Notes \\
\hline Ambulatory Notes \\
\hline ED Notes \\
\hline Problem List \\
\hline Orders and Results (labs and imaging) \\
\hline Patient History \\
\hline Medications \\
\hline Consults/Referrals \\
\hline Health Maintenance/Immunization Records \\
\hline Patient Demographics \\
\hline
\end{tabular}

For the 30-month timeframe following ECL implementation, we used patients' medical record number and the timestamps associated with patient discharge as well as ECL system actions to match patient-specific ECL use to the corresponding index hospitalization. ECL records were matched to a hospitalization if the action took place within a defined 16-day window: (1) up to 48 hours pre-hospital discharge (window not to extend earlier than timestamp of inpatient admission); and (2) up to fourteen days post-hospital discharge or until the time of subsequent hospital readmission, whichever occurred first. We hypothesized that this window would capture 
preparatory activity in anticipation of discharge, up through the deadline for submitting key Medicare reporting requirements - the Minimum Data Set and Care Area Assessment.

Analytic Approach: We first generate a descriptive table comparing changes in the summary statistics of patients in the treatment facilities, pre vs. post-ECL implementation. These include demographic statistics (age, gender, race), characteristics of the hospital stay (length of stay, number of active diagnoses, number of medication classes present on medication list), and detail regarding readmissions (30-, 14-, and 7-day readmission rates, time until readmission, length of readmission stay). We compare that to changes in the same summary statistics of patients in nontreatment facilities, to test the parallel trends assumption of our chosen analytic approach. To create a more similar group for comparison to our treatment facility patients, we also generate similar statistics and changes pre/post for patients discharged only to other non-treatment SNFs geographically proximate to the focal hospital. We expect this group to be more similar in composition to treatment group patients at baseline than other control group patients whose SNF placement (presumably close to their home) is an hour away or more from the focal hospital. Exploring characteristics of this alternate control group also provides some indication of whether the focal hospital's referral patterns changed (in terms of average complexity of patients referred to treatment vs. non-treatment SNFs) pre vs. post implementation. We ultimately choose to present both sets of results, comparing the treatment group to both the full non-treatment group and only geographically proximate non-treatment facilities.

\section{Analysis 1: Difference in Difference and Difference in Trend}

To answer our first research question - whether electronic information sharing improves patient outcomes following post-acute care transitions from hospital to SNF - we use an intent to treat 
approach with a classic difference-in-differences (DiD) model. We also analyze differences in the rate of change in readmission likelihoods over time with a supplemental difference-in-trend (DiT) analysis.

\section{$\underline{\text { Measures }}$}

Dependent Variable: The primary outcome used for all analyses presented in this study is incidence of hospital readmission. Likelihood of patient readmission is sensitive to the quality of care transfer and possible breakdown in information continuity. $(9,28)$ Thirty-day readmission rates, in particular, have been used in numerous quality improvement and pay-for-value reform initiatives as a salient indicator of care quality due to system costs and patient/family burden. For each patient-hospitalization, we created a binary indicator from the EHR hospitalization data as to whether a 30-day readmission occurred to the focal hospital following discharge to SNF. We also created two additional binary indicators of shorter readmission windows - 7-day and 14-day readmissions - as alternate outcomes that may be more sensitive to quality of care transfer processes. Due to the nature of our dataset, we do not capture readmissions to other hospitals. This is noted further in our limitations. However, we don't have reason to suspect that the rate of readmission from these SNFs back to the focal hospital (versus other hospitals) changed throughout our study period; because this issue is time-invariant, our chosen analytic approach allows us to mitigate its potentially confounding effects.

Independent Variables: For DiD and DiT analyses, we created two relevant binary indicators that allowed us to identify observations of patients experiencing a discharge from hospital to SNF for which HIE was available during the care transition. The first is a "treatment" variable, and takes a value of one if the patient was discharged to one of the three SNFs that was ultimately granted ECL access rights. The second is a "Pre/Post" time variable that relates to ECL implementation; 
this indicator takes a value of one if the patient was discharged after ECL was implemented. Patients with a value of one for both of these indicators experienced a transition for which HIE was available. For DiT analyses only, we created a third monthly time variable that takes a value from 1 to 48, covering the duration of the study period.

\section{DiD Approach:}

Equation 1: Difference-in-Differences Model Specification

$$
Y_{i t}=\beta_{0}+\beta_{1} F_{i}+\beta_{2} T_{t}+\beta_{3}[F * T]_{i t}+\beta_{4} X_{i t}+\varepsilon_{i t}
$$

The quasi-experimental DiD approach includes estimates for the two covariates defined above: a facility indicator for whether a patient $(i)$ was discharged to one of the three treatment SNFs $\left(\mathrm{F}_{\mathrm{i}}\right)$ and a time indicator for whether that discharge took place pre vs. post implementation $\left(\mathrm{T}_{\mathrm{i}}\right)$. The marginal effect of the interaction term $\left(\left[\mathrm{F}^{*} \mathrm{~T}\right]\right.$ it $)$ allows us to estimate the change in likelihood of readmission for patients discharged to the treatment SNFs, before and after ECL implementation, net of the change in readmission rates during that same time for patients sent to non-treatment SNFs. We also include a vector of patient condition covariates $\left(\mathrm{X}_{\mathrm{i}}\right)$ likely to be associated with readmissions. While we have no reason to suspect dissimilar changes in the patient population served by treatment vs. non-treatment SNFs around the time of ECL implementation (i.e. potential threats to the parallel trends assumption of DiD), including these readmission-associated patient indicators increases the precision of our estimate of our primary marginal probability effect (that of the IT implementation). These covariates include patient characteristic measures similar to those used in other analyses that explore the relationship between patient complexity and readmissions such as patient age, gender, length of hospitalization, total number of diagnoses, number of 
medication classes on current medication list. (29) We also include primary health condition related to reason for hospitalization, categorized based on the Clinical Classification Software used by the Agency for Healthcare Research and Quality. (30)

Estimating the independent marginal probability effects of discharge to a treatment $\operatorname{SNF}\left(\mathrm{F}_{i}\right)$ and discharge in the pre vs. post implementation time frame $\left(\mathrm{T}_{t}\right)$ through a DiD approach offers a number of key advantages that improve our estimation of treatment effect. The former, $\mathrm{F}_{i}$, captures time-invariant differences between patient care in treatment and non-treatment SNFs, which is important for two key reasons. First, the academic health system we studied has the closest relationship with these three SNFs; these SNFs are geographically most proximate, and receive the greatest proportion of the hospital's patients. Therefore, the inter-organizational processes and relationships between the hospital and these three SNFs are likely better-developed than those with non-treatment SNFs. Second, our data only captures readmissions if they occurred at the focal hospital. Patients discharged to the three treatment SNFs are much more likely to be readmitted to our study hospital because it is their local hospital; patients discharged to a non-treatment SNF over an hour away, for example, may be readmitted to a smaller community hospital closer to home, which we would not capture. This artificially inflates the readmission rate for patients discharged to treatment SNFs, relative to non-treatment. Including an independent estimated marginal probability effect of time pre/post implementation, $\mathrm{T}_{t}$, allows us to control for general time trends that span the implementation of ECL. Because of intense policy and payment reform focus, organizations have been engaged in numerous efforts to reduce hospital readmissions. These efforts have occurred in parallel with efforts to improve information continuity via ECL. By estimating the marginal effect of $\mathrm{T}_{t}$, we are able to control for the effect of other readmission- 
reduction initiatives during this time period that affect patients in both treatment and non-treatment SNFs.

In addition to our primary model, we also run two robustness checks. First, we allow for a "learning" period, where we remove data from the first 3 months post-implementation from analysis. This timeframe is likely to reflect a period of organizational change where ECL use processes have not yet been normalized and we would not expect to see any systematic relationship with outcomes. (31) Second, we also present our results with the non-treatment SNF group restricted to only include other SNFs that are geographically proximate to the focal hospital and received at least 100 patients from the focal hospital during the study period. This natural cutpoint emerged from the data, and creates a comparison group of facilities and patients likely to be more similar to our treatment group. Finally, as a sensitivity analysis, we rerun our primary model specifications using our alternate 7- and 14-day outcome variables. For all analyses, we use probit models due to the binary nature of our dependent variable. Because of known complications using interaction terms in non-linear models, we report treatment effect on the treated rather than average treatment effect. (32-34)

\section{Difference in Trend Approach:}

We also estimate a Difference-in-Trend (DiT) model to determine whether the rate of change in likelihood of readmissions for patients discharged to treatment SNFs, pre versus post-ECL implementation, differs from the rate of change in likelihood of readmissions for patients discharged to non-treatment SNFs during the same timeframe. These models use the same measures and follow a similar approach to the DiD model already explained, but include the 
addition of a monthly time variable that takes a value from 1 to 48 , covering the duration of the study period (see Equation 2). This monthly count variable, $\mathbf{M}$, is included as an independent covariate to estimate monthly readmission rate slope in the pre period for the non-treatment group, as well as interacted with existing covariates to estimate the marginal index effect of pre-period changes for the treatment group $\left(\beta_{5}\right)$ and post-period changes for the control group $\left(\beta_{6}\right)$.

Equation 2: Difference-in-Trend Model Specification

$Y_{i t}=\beta_{0}+\beta_{1} F_{i}+\beta_{2} T_{t}+\beta_{3}[F T]_{i t}+\beta_{4} M_{i t}+\beta_{5}[F M]_{i t}+\beta_{6}[T M]_{i t}+\beta_{7}[F T M]_{i t}+\beta_{8} X_{i t}+\varepsilon_{i t}$

The computed marginal effect of the three-way interaction term ([FTM $\left.]_{\text {it }}\right)$ represents the estimated difference in monthly rate of change in likelihood of readmissions for patients discharged to treatment SNFs, post versus pre-ECL implementation, net of the difference observed in the same timeframe for patients discharged to non-treatment SNFs. We conduct the same robustness checks and sensitivity analyses for our DiT models as specified for the initial DiD analysis.

\section{Analysis 2: Understanding, Predicting ECL Use}

Following intent-to-treat analysis, we then explore characteristics of actual ECL usage data. By assembling descriptive statistics of ECL use, across all treatment SNFs and by individual facility, we can identify key areas of variation in when and how HIE is being utilized to support post-acute transitional care. Key descriptive measures include: patient-level system access rate (overall and by year), average time to first view of the ECL system, relative to hospital discharge, median number of information retrieval actions taken per patient, average number of information categories accessed, and percent of sessions initiated within 24 hours of readmission (as a potential indicator of use prompted by patient decline). We also define a "transition window" of use, a more narrowly defined window around the time of patient transition from hospital to SNF (see below) 
that is a subset of total system use. Using this definition, we additionally calculate the percent of total uses that occur within this window, and average number of categories of information accessed when use occurs in this timeframe.

After this initial synthesis of usage data, we then seek to explore for which patients the ECL system is more likely to be used within the 16-day window defined above. We suspect that both patient and SNF organizational factors affect likelihood of use; however, the nature of our data limits us to only exploring associations between patient-level factors and ECL use. We thus explore characteristics of our patient observations within two domains that may help illustrate when SNF providers perceive greater utility in using available HIE technology: factors that speak to the context in which that patient was handed off from hospital to SNF, and those that speak to overall patient complexity.

\section{$\underline{\text { Measures }}$}

Dependent Variable: The primary outcome in this analysis is a binary indicator for whether the ECL system was accessed for a discharged patient within the 16-day window of transitional and initial post-acute care period. We also constructed a second, more narrow "transition window" indicator at the patient-observation level. This indicator takes on a value of one if first use of the ECL system falls between 48 hours prior to discharge and up to 72 hours after the hospital timestamp of patient discharge to the SNF.

Independent Variables: We include three variables that are related to the context in which the patient was transitioned from hospital to SNF. More specifically, these measures are intended to capture situations where workflows supporting transitional care may deviate from standard 
practices and create information discontinuity. First, we generated a binary indicator for whether the patient was discharged on a weekend day, as reduced weekend staffing at both institutions might compromise handoff processes and affect informational needs and/or information-seeking behavior. (35) Second, we created an indicator for whether the patient was discharged to a SNF to which they were already a resident prior to hospitalization. We include this variable because hospital providers may anticipate the SNF having fewer information needs for returning patients with whom they are already familiar, and adjust the rigor of their discharge documentation accordingly. Finally, we include an indicator for whether the index hospitalization was an ED visit or observational stay rather than an inpatient hospitalization. Discharges from an ED or observational unit often lack the designated discharge planning staff and the more robust transitional care processes (i.e. nurse-to-nurse handoff call) of an inpatient unit, putting patients at increased risk. (36)

We then also employ a second set of patient characteristic measures expected, in aggregate, to give some indication of patient complexity at the time of hospital discharge. The measures used here are similar to those used in other analyses that explore the relationship between patient complexity and likelihood of re-hospitalization (29), and should roughly capture our construct of interest, which is the relative informational needs for a particular patient's care. These include patient age, gender, length of hospitalization, total number of diagnoses, number of medication classes on current medication list, and primary health condition related to reason for hospitalization, categorized based on the Clinical Classification Software used by the Agency for Healthcare Research and Quality. (30) 


\section{Predictors of Use Approach:}

To determine which patient-specific factors may be responsible for driving ECL use, we first conduct bivariate analyses that compare descriptive statistics on all available patient-level covariates described above across ECL use and non-ECL use patients. We compare both the "no ECL use" patient group to the "any ECL use" group, as well as comparing patients for whom ECL was first used during the defined transition window versus those for whom it was first used after this window expired (these latter results presented in the appendix). We then select the variables with significant differences across the two groups and include them in the multivariate analysis. We use probit models to regress ECL use (overall as well as use specifically within the transition window) on all selected patient-level covariates. We run these models pooled (with facility level fixed-effects) as well as individually for each facility to allow for the possibility that use patterns may differ across SNFs with respect to which patient factors drive use, and the strength of these associations.

\section{Analysis 3: Understanding Variation in Use, and Association with Outcomes}

Finally, we seek to understand variation in how the ECL system is used during information retrieval, with the expectation that this variation might drive differential impact of ECL use on patient care decision-making and ultimately patient outcomes. More specifically, we are interested in two characterizations of use that map to dimensions of information quality at the time of retrieval: timing of system use, and intensity of system use.

\section{Measures:}

Dependent Variable: The outcome used for this analysis is whether the patient was readmitted back to the focal hospital within 30 days of discharge from the index hospitalization. 
Independent Variables: To capture timeliness of system use, we use the indicator for whether ECL was accessed for a patient within the transition window of care. Activity within this window is important as it is more likely to capture information retrieval associated with care handoff processes. To capture intensity of system use, we created two types of summary use measures related to the depth of information retrieval via ECL. This was operationalized as (1) the total number of audited information retrieval actions taken, and (2) binary indicators for whether "basic" and/or "advanced" information seeking took place. Advanced information seeking was defined based on cut-points in the data, using overall access rates for each of the ten categories of information defined in the data. Accessing inpatient or ambulatory notes were far more common actions, and considered basic activity. All other much less frequent categories of information retrieval, aside from demographics and immunization information (as they are not obviously relevant to transitional care needs), were considered advanced actions. We chose to collapse data and define "depth of information seeking" in these two ways due to limitations in the data. Despite greater available richness in how an ECL action is audited (117 different action types), there is significant variation in the consistency between how audited actions within ECL are recorded and what the provider actually sees on-screen. For example, when a provider "Views inpatient provider note" six consecutive times according to the ECL audit file, it is unclear whether that provider viewed the same note six times, or viewed six separate notes. Similarly, the content of these notes vary and we cannot necessarily know how many categories of information - as we have defined them - may be contained in any one note. One note may just contain post-operative surgical notes; another may contain key information regarding medication administration, lab results and wound care instructions. Given these uncertainties, we chose a lenient approach to counting number of 
actions (duplicates count as two separate retrieval actions); and, we chose not to use more granular measures of information categories in evaluating intensity of system use.

Variation in Use Approach:

This analysis is restricted only to patients discharged to a treatment SNF in the post-ECL implementation period (June 2014 to March 2017). To explore potential moderators of the estimated effect of ECL on patient care, we use multivariate probit analyses that regress our readmission outcome on the independent and interacted effects of our timeliness and intensity-ofuse measures. We first conduct this analysis with data pooled across all three treatment SNFs, including facility-level fixed-effects. We then run the regression separately for each facility to determine whether variation in organizational use patterns drive differences in discernible effect on patient care across the three facilities. For example, if ECL use within the transition window is common practice in one organization and rare in another, we might expect different outcomes for patients who had their information accessed within this timeframe across the two organizations. In the former, use would be consistent with standard IT workflows and we can understand effects of variation in use in a larger, more heterogeneous, and closer to randomly selected patient population; in the latter, we have a more acute endogeneity problem. When system use is unexpected within this transition window, it is more likely to have been triggered by a decline in patient status or troubled handoff process. Understanding the association between nuanced variation in use patterns and patient outcomes for this non-random group of patients is then likely to be dwarfed by the fact that the patient condition prompting use of the system is closely associated with increased risk of readmission, our outcome of interest. 


\section{$\underline{\text { Results }}$}

The final dataset contained 16,623 discharges; 4,144 of these discharges (24.9\%) took place in the 18 months prior to ECL implementation and 12,479 in the 2.5-year post-implementation period. $41.1 \%$ of patients throughout the study period were discharged to one of the three SNFs that ultimately received ECL access (i.e. "treatment SNFs"). Summary detail for each of the three treatment SNFs, in relation to county and statewide averages, are listed in Table 2.2.

Table 2.2 Descriptive Information, Treatment SNFs

\begin{tabular}{|c|c|c|c|c|c|}
\hline & SNF 1 & SNF 2 & SNF 3 & $\begin{array}{c}\text { County } \\
\text { Average } \\
(\mathrm{N}=9)\end{array}$ & $\begin{array}{c}\text { State } \\
\text { Average } \\
(\mathrm{N}=431)\end{array}$ \\
\hline Size (beds) & 161 & 180 & 71 & 132 & 108 \\
\hline Average Age & 81 & 74 & 76 & 76 & 78 \\
\hline Percent Dual Eligible Beneficiaries & $11.5 \%$ & $26.4 \%$ & $19.6 \%$ & $27.1 \%$ & $32.4 \%$ \\
\hline Average LOS & 23.1 & 23.1 & 24.2 & 28 & 26.9 \\
\hline Average HCC Score & 2.05 & 2.69 & 2.75 & 2.65 & 2.64 \\
\hline $\begin{array}{l}2017 \text { Adjusted rehospitalization rate, short- } \\
\text { stay residents (<101 days) }\end{array}$ & $23.3 \%$ & $21.7 \%$ & $27.0 \%$ & $\begin{array}{c}22.5 \% \\
\text { (weighted) }\end{array}$ & $\begin{array}{c}21.5 \% \\
\text { (weighted) }\end{array}$ \\
\hline Ownership & $\begin{array}{l}\text { Non-Profit } \\
\text { Corporation } \\
\end{array}$ & $\begin{array}{c}\text { For-Profit } \\
\text { Corporation } \\
\end{array}$ & $\begin{array}{c}\text { For-Profit } \\
\text { Corporation }\end{array}$ & & \\
\hline Distance to focal hospital & $3 \mathrm{mi}$ & $3 \mathrm{mi}$ & $2.2 \mathrm{mi}$ & & \\
\hline
\end{tabular}

Table 2.3 shows pre-to-post comparison of summary statistics for the treatment group, full control group, and control group patients discharged to a non-treatment SNF geographically proximate to the focal hospital. The only significant changes pre-vs. post-implementation for the treatment group include a reduction in the percent of patients that were white $(-1.2 \% ; \mathrm{p}=0.005)$ and an increase in the average length of stay for readmission hospitalizations $(+0.6$ days; $\mathrm{p}=0.02)$. The full control group and the geographically proximate control group both saw significant increases, comparing pre- to post-period, in the percent of patients that were white $(+2.6 \%$ full, $\mathrm{p}=0.002$; $+2.8 \%$ proximate, $\mathrm{p}=0.014$ ), as well as reductions in the average length of index hospitalization 
(-1.1 days full, $\mathrm{p}<0.001 ;-0.6$ days proximate, $\mathrm{p}=0.003)$, number of active diagnoses $(-1.3$ diagnoses full, $\mathrm{p}<0.001 ;-0.7$ diagnoses proximate, $\mathrm{p}=0.014)$, and 30 -day readmission rates $(-2.3 \%$ full, $\mathrm{p}=0.011 ;-4.7 \%$ proximate, $\mathrm{p}=0.010)$. The geographically proximate group also saw a significant reduction across the two periods in 14-day readmission rates $(-5.5 \% ; \mathrm{p}=0.002)$. Because length of stay and number of diagnoses are indicators of complexity, these summary statistics give some indication that the reduction in readmission rates over time in the control groups may be due to reduced complexity of patients hospitalized and discharged to these non-primary facilities. Measures of complexity for the treatment group are not significant but trend in the opposite direction, towards increasing complexity; these factors can be controlled for in modeling approaches, but bias our results towards a null finding. 
Table 2.3 Sample Characteristics of Patients in SNFs with and without ECL Access

\begin{tabular}{|c|c|c|c|c|c|c|c|c|c|c|}
\hline & \multicolumn{2}{|c|}{ Treatment SNFs } & \multirow{3}{*}{$\begin{array}{l}\text { Change } \\
\text { (absolute), } \\
\text { Pre to Post }\end{array}$} & $\begin{array}{l}\text { All } \\
\text { Discharges }\end{array}$ & \multicolumn{2}{|c|}{ Non-Treatment SNFs } & \multirow{3}{*}{$\begin{array}{c}\text { Change } \\
\text { (absolute), } \\
\text { Pre to Post }\end{array}$} & \multicolumn{2}{|c|}{$\begin{array}{c}\text { Proximate Non-Treatment } \\
\text { SNFs } \\
\end{array}$} & \multirow{3}{*}{$\begin{array}{c}\text { Change } \\
\text { (absolute), } \\
\text { Pre to Post }\end{array}$} \\
\hline & Pre-ECL & Post-ECL & & $\begin{array}{l}\text { Full Study } \\
\text { Period }\end{array}$ & Pre-ECL & Post-ECL & & Pre-ECL & Post-ECL & \\
\hline $\begin{array}{l}\text { No. of patient } \\
\text { encounters }\end{array}$ & 1350 & 5487 & & 16,623 & 2794 & 6992 & & 560 & 1428 & \\
\hline Age & $70.1(14.5)$ & $69.7(14.2)$ & -0.4 & $69.8(14.4)$ & $69.4(14.6)$ & $70.0(14.4)$ & +0.6 & $72.7(13.6)$ & $73.0(12.8)$ & +0.3 \\
\hline$\%$ Male & $43.7 \%$ & $45.7 \%$ & $+2.0 \%$ & $45.0 \%$ & $43.8 \%$ & $45.2 \%$ & $+1.4 \%$ & $41.8 \%$ & $43.0 \%$ & $+1.2 \%$ \\
\hline$\%$ White & $79.8 \%$ & $78.6 \%$ & $-1.2 \% * *$ & $82.7 \%$ & $83.5 \%$ & $86.1 \%$ & $+2.6 \% * *$ & $84.8 \%$ & $87.6 \%$ & $+2.8 \% *$ \\
\hline $\begin{array}{l}\text { Avg. length of hospital } \\
\text { stay }\end{array}$ & $9.0(10.1)$ & $10.3(12.8)$ & +1.3 & $9.5(10.8)$ & $9.9(10.9)$ & $8.8(9.2)$ & $-1.1 * * *$ & $9.2(10.3)$ & $8.6(7.8)$ & $-0.6^{*}$ \\
\hline Number of diagnoses & $20.0(9.2)$ & $20.4(9.2)$ & +0.4 & $19.2(9.3)$ & $19.3(9.7)$ & $18.0(9.2)$ & $-1.3^{* * * *}$ & $21.0(9.4)$ & $20.3(8.3)$ & $-0.7^{*}$ \\
\hline 30-day readmit rate & $32.3 \%(46.7)$ & $28.4 \%(45.1)$ & $-3.9 \%$ & $24.7 \%(43.1)$ & $23.2 \%(42.2)$ & $20.9 \%(40.7)$ & $-2.3 \% *$ & $\begin{array}{l}28.9 \% \\
(45.4) \\
\end{array}$ & $\begin{array}{l}24.2 \% \\
(42.9) \\
\end{array}$ & $-4.7 \% *$ \\
\hline Time until readmission & $10.5(7.9)$ & $10.4(7.5)$ & -0.1 & $10.7(7.8)$ & $10.8(7.8)$ & $10.9(7.9)$ & +0.1 & $9.7(7.4)$ & $10.6(7.9)$ & +0.9 \\
\hline $\begin{array}{l}\text { Avg length of } \\
\text { readmission stay }\end{array}$ & $5.0(8.0)$ & $5.6(7.4)$ & $+0.6^{*}$ & $5.6(7.6)$ & $5.8(7.2)$ & $5.7(7.8)$ & -0.1 & $5.0(6.5)$ & $6.2(8.7)$ & +1.2 \\
\hline 14-day readmit rate & $22.4 \%(41.7)$ & $19.8 \%(39.9)$ & $-2.6 \%$ & $17.0 \%(37.6)$ & $15.8 \%(36.5)$ & $14.3 \%(34.9)$ & $-1.5 \%$ & $\begin{array}{l}22.0 \% \\
(41.4)\end{array}$ & $\begin{array}{l}16.5 \% \\
(37.2)\end{array}$ & $-5.5 \% * *$ \\
\hline 7-day readmit rate & $14.1 \%(34.8)$ & $11.7 \%(32.1)$ & $-2.4 \%$ & $10.0 \%(30.0)$ & $9.1 \%(28.8)$ & $8.3 \%(27.7)$ & $-0.8 \%$ & $\begin{array}{l}12.1 \% \\
(32.7)\end{array}$ & $\begin{array}{l}10.3 \% \\
(30.4)\end{array}$ & $-1.8 \%$ \\
\hline
\end{tabular}

${ }^{*} \mathrm{p} \leq 0.05 ;{ }^{* *} \mathrm{p} \leq 0.01 ; * * * \mathrm{p} \leq 0.001$ 


\section{Difference in Differences and Difference in Trend:}

The results from the difference-in-difference analyses are presented in Table 2.4. The estimated marginal probability effect of the key "Treatment*Post" interaction term - describing the change in average likelihood of readmission for treatment facilities, pre/post, net of the change in control SNFs - is insignificant $(-0.1 \% ; \mathrm{p}=0.990)$. This result holds across models that allow for a learning period, as well as restricting the control group to only geographically proximate SNFs. The latter eliminates the significance of time-invariant differences between treatment and control.

Exploring Difference in Trend, the marginal effect of our Treatment*Post*Time interaction term that captures the difference in the rate of change of likelihood of readmission for treatment SNFs, pre/post, net of changes in the non-treatment SNFs, is again insignificant $(-0.2 \% ; \mathrm{p}=0.556)$. In our alternate specifications, the effect of this interaction term remains negative and insignificant.

Table 2.4 Estimated Effects of HIE Portal Implementation on Likelihood of 30-day Hospital Readmissions

\begin{tabular}{|c|c|c|c|c|c|c|}
\hline & \multicolumn{3}{|c|}{$\begin{array}{c}\text { Model: Marginal Effects } \\
\text { Identification: Difference in Differences }\end{array}$} & \multicolumn{3}{|c|}{$\begin{array}{c}\text { Model: Marginal Effects } \\
\text { Identification: Difference in Difference of Slope } \\
\text { (Difference in Trend) }\end{array}$} \\
\hline & Overall & $\begin{array}{c}\text { 3-month } \\
\text { learning } \\
\text { period }\end{array}$ & $\begin{array}{l}\text { Control } \\
\text { group: } \\
\text { Proximate } \\
\text { SNFs only }\end{array}$ & Overall & $\begin{array}{c}\text { 3-month } \\
\text { learning } \\
\text { period }\end{array}$ & $\begin{array}{l}\text { Control } \\
\text { group: } \\
\text { Proximate } \\
\text { SNFs only }\end{array}$ \\
\hline Treatment Facility & $\begin{array}{c}0.071^{* * *} \\
(0.015)\end{array}$ & $\begin{array}{c}0.089 * * * \\
(0.015)\end{array}$ & $0.028(0.022)$ & $0.064 *(0.026)$ & $\begin{array}{c}0.068^{* *} \\
(0.022)\end{array}$ & $-0.006(0.030)$ \\
\hline $\begin{array}{l}\text { Post (After ECL } \\
\text { implementation) }\end{array}$ & $-0.027 *(0.011)$ & $-0.021 *(0.10)$ & $-0.052 *(0.024)$ & $\begin{array}{c}-0.049 * * \\
(0.018)\end{array}$ & $-0.027(0.022)$ & $-0.032(0.040)$ \\
\hline Treatment*Post & $-0.001(0.017)$ & $-0.006(0.016)$ & $0.020(0.027)$ & $0.035(0.035)$ & $-0.012(0.026)$ & $0.014(0.037)$ \\
\hline Time & & & & $0.001(0.001)$ & $-0.001(0.002)$ & $-0.005(0.004)$ \\
\hline Treatment*Time & & & & $0.001(0.003)$ & $0.002(0.001)$ & $0.003(0.002)$ \\
\hline Post*Time & & & & $0.0003(0.003)$ & $0.001(0.002)$ & $0.003(0.004)$ \\
\hline Treatment*Post*Time & & & & $-0.002(0.003)$ & $-0.001(0.001)$ & $-0.002(0.002)$ \\
\hline
\end{tabular}

$* \mathrm{p} \leq 0.05 ; * * \mathrm{p} \leq 0.01 ; * * * \mathrm{p} \leq 0.001$

‡Other patient-level parameters included but not shown include: age, gender, length of hospitalization, total number of diagnoses, number of medication classes on current medication list and primary health condition related to reason for hospitalization, categorized based on the Clinical Classification Software used by the Agency for Healthcare Research and Quality 


\section{Understanding ECL Use:}

When hospitalization records were merged with the audit file of ECL use, we observed 2,525 patients discharged from the focal hospital during the post-implementation study period (June 2014 - March 2017) for whom there was corresponding ECL use in the defined 16-day window. This represents an overall access rate of $46.0 \%$, with a range across the three treatment SNFs of 37.6-49.8\% (Table 2.5). Two SNFs experienced increased rates of system use over time, while the third saw use drop throughout the study period. Median number of actions taken within the system ranged from 5 to 9; on average, providers sought two or more categories of information during use for a particular patient.

If and when the system was used within the transition window also varied significantly across the three SNFs. The average "time to first look" at patient information within the ECL system was 3.1 days post-discharge. By facility, however, we see that only Facilities 2 and 3 had an average timing of use within the transition window ( 0.7 days and 2.2 days post-discharge, respectively). The average "time to first look" for patients in Facility 1 was 7.4 days post-transition. Overall, ECL was accessed during the defined transition timeframe for 1,585 patients; this represents $63 \%$ of total patient cases for which ECL was used. Facility 1 had only $10 \%$ of use occur within the transition window, compared to nearly $70 \%$ in Facility 2. Interestingly, a significant amount of transition window use occurred prior to the patient leaving the hospital, ranging from $54 \%$ in Facility 3 up to $85 \%$ of transition window use in Facility 2. Overall rates of use of the system within 24 hours of patient readmission (if applicable) - which may indicate ECL use prompted by a decline in patient status - were only $2.7 \%$ on average, though almost double that rate in Facility 
$3(5.3 \%)$. The average number of information categories viewed only seemed to differ across different timing of use in Facility 3, with a greater breadth of information sought during the transition window compared to the overall 16-day window.

Table 2.5 Descriptive Statistics of ECL Use

\begin{tabular}{|c|c|c|c|c|}
\hline & Pooled & Glacier & Heartland & Regency \\
\hline Number of post-ECL admitted patients & 5487 & 1586 & 2397 & 1504 \\
\hline $\begin{array}{l}\text { Total number of patient case uses } \\
\text { (within full } 16 \text { day window) }\end{array}$ & \begin{tabular}{|l|l|}
2525 \\
$(46.0 \%)$ \\
\end{tabular} & $\begin{array}{l}766 \\
(48.3 \%) \\
\end{array}$ & $\begin{array}{l}1194 \\
(49.8 \%)\end{array}$ & $\begin{array}{l}565 \\
(37.6 \%) \\
\end{array}$ \\
\hline Percent use, 2014 & $42.8 \%$ & $8.3 \%$ & $81.5 \%$ & $36.0 \%$ \\
\hline Percent use, 2015 & $54.3 \%$ & $43.2 \%$ & $78.0 \%$ & $36.6 \%$ \\
\hline Percent use, 2016 & $69.0 \%$ & $78.9 \%$ & $77.6 \%$ & $50.0 \%$ \\
\hline Percent use, 2017 & $66.1 \%$ & $75.7 \%$ & $70.9 \%$ & $49.3 \%$ \\
\hline Median number of information retrieval actions taken & 7 & 6 & 9 & 5 \\
\hline Average number of categories of information accessed, overall & $1.76(1.10)$ & $1.62(0.92)$ & $1.86(1.04)$ & $1.77(1.43)$ \\
\hline 1 category & $8.0 \%$ & $4.2 \%$ & $3.0 \%$ & $19.7 \%$ \\
\hline 2 categories & $47.7 \%$ & $54.4 \%$ & $49.7 \%$ & $32.1 \%$ \\
\hline 3-5 categories & $42.1 \%$ & $40.8 \%$ & $45.6 \%$ & $41.1 \%$ \\
\hline $6+$ categories & $2.2 \%$ & $0.6 \%$ & $1.7 \%$ & $7.1 \%$ \\
\hline $\begin{array}{l}\text { Number of sessions initiated within } 24 \text { hours of readmission (as a } \\
\text { percent of total uses) }\end{array}$ & $69(2.7 \%)$ & $10(1.3 \%)$ & $29(2.4 \%)$ & $30(5.3 \%)$ \\
\hline Average time to first view (SD) & $\begin{array}{|ll|}3.1 & \text { days } \\
(4.6) & \\
\end{array}$ & $\begin{array}{ll}7.4 & \text { days } \\
(3.9) & \end{array}$ & $\begin{array}{ll}0.7 & \text { days } \\
(3.3) & \\
\end{array}$ & $\begin{array}{ll}2.2 & \text { days } \\
(3.4) & \end{array}$ \\
\hline $\begin{array}{l}\text { No. first uses that occur within transition window ( } 2 \text { days before to } \\
\text { three days after hospital discharge) (\% of total use cases) }\end{array}$ & \begin{tabular}{|l|l|}
1585 \\
$(62.8 \%)$
\end{tabular} & $\begin{array}{l}148 \\
(10.0 \%)\end{array}$ & $\begin{array}{l}1052 \\
(68.7 \%)\end{array}$ & $\begin{array}{l}385 \\
(29.1 \%) \\
\end{array}$ \\
\hline $\begin{array}{l}\text { Percent of transition window use that occurs before hospital } \\
\text { discharge }\end{array}$ & $75.4 \%$ & $60.8 \%$ & $85.3 \%$ & $54.3 \%$ \\
\hline $\begin{array}{l}\text { Average number of categories of information accessed, transition } \\
\text { window }\end{array}$ & \begin{tabular}{|l|}
$1.86(1.14)$ \\
\end{tabular} & $1.66(0.91)$ & $1.84(1.03)$ & $1.99(1.46)$ \\
\hline
\end{tabular}

The bivariate analyses comparing descriptive information for patients in treatment SNFs for whom ECL was versus was not used can be found in Table 2.6. Comparing "No ECL use" to "Any ECL use", we find that these patient populations differ significantly in both contextual and complexity factors. Patients with ECL use were less likely to be discharged on a weekend compared to patients for whom ECL was not used (11.6\% vs. $14.7 \%$; $\mathrm{p}=0.001)$, and more likely to be a new rather than returning SNF resident ( $89.2 \%$ vs. $81.4 \%$; $\mathrm{p}<0.001)$; they are also more likely to have been at the hospital for an ED visit or observational stay rather than an inpatient hospitalization (12.4\% inpatient stays vs. $5.6 \%$; $\mathrm{p}<0.001)$. We also see, in terms of patient condition, that ECL patients 
are slightly older (70.3 vs. $69.2 ; \mathrm{p}=0.005)$ but had shorter length of index hospital stay ( 8.7 days vs $11.5 ; \mathrm{p}<0.001)$ and fewer active diagnoses on their problem list (19.2 vs. $21.5 ; \mathrm{p}<0.001)$. Results comparing patients for whom ECL was first used during the transition window versus those for whom it was first used after this window expired are presented in the Appendix. These results provide additional intuition, indicating that among the population of patients for whom ECL was used, the sub-population for whom ECL was accessed in a more timely way tended to be more complex (longer length of stay, more active diagnoses).

Table 2.6 Patient Drivers of ECL Use, by Facility (Bivariate Analyses)

\begin{tabular}{|c|c|c|c|c|c|}
\hline & \multicolumn{2}{|c|}{$\begin{array}{l}\text { No ECL Use } \\
\qquad N=2,962\end{array}$} & \multicolumn{2}{|c|}{$\begin{array}{l}\text { Any ECL Use } \\
\qquad \begin{array}{l}\mathrm{N}=2,525 \\
\end{array}\end{array}$} & $\begin{array}{c}\text { T-test difference } \\
\text { in means }(\mathrm{P}- \\
\text { value })\end{array}$ \\
\hline \multicolumn{6}{|c|}{ Context Factors } \\
\hline Weekend discharge & \multicolumn{2}{|c|}{$14.7 \%$} & \multicolumn{2}{|c|}{$11.6 \%$} & 0.001 \\
\hline $\begin{array}{l}\text { Patients that are new } \\
\text { (rather than returning) } \\
\text { SNF residents }\end{array}$ & \multicolumn{2}{|c|}{$81.4 \%$} & \multicolumn{2}{|c|}{$89.2 \%$} & $<0.001$ \\
\hline $\begin{array}{l}\text { Patients admitted to } \\
\text { SNF following ED or } \\
\text { observational stay only }\end{array}$ & \multicolumn{2}{|c|}{$5.6 \%$} & \multicolumn{2}{|c|}{$12.4 \%$} & $<0.001$ \\
\hline \multicolumn{6}{|c|}{ Complexity Factors } \\
\hline Age at discharge & \multicolumn{2}{|c|}{$69.2(14.2)$} & \multicolumn{2}{|c|}{$70.3(14.2)$} & 0.005 \\
\hline Gender & \multicolumn{2}{|c|}{$45.6 \%$} & \multicolumn{2}{|c|}{$45.7 \%$} & 0.946 \\
\hline Non-white race & \multicolumn{2}{|c|}{$21.6 \%$} & \multicolumn{2}{|c|}{$21.2 \%$} & 0.710 \\
\hline Length of stay (days) & \multicolumn{2}{|c|}{$11.5(15.4)$} & \multicolumn{2}{|c|}{$8.7(8.6)$} & $<0.001$ \\
\hline $\begin{array}{l}\text { Number of conditions } \\
\text { on current problem list }\end{array}$ & \multicolumn{2}{|c|}{$21.5(9.3)$} & \multicolumn{2}{|c|}{$19.2(8.8)$} & $<0.001$ \\
\hline $\begin{array}{c}\text { Number of medication } \\
\text { classes }\end{array}$ & \multicolumn{2}{|c|}{$9.5(5.1)$} & \multicolumn{2}{|c|}{$9.4(5.2)$} & 0.597 \\
\hline \multirow{5}{*}{$\begin{array}{l}\text { Most Frequent Patient } \\
\text { Conditions }\end{array}$} & $\begin{array}{c}\text { ADP } \\
\text { Admit* }\end{array}$ & $17.6 \%$ & $\begin{array}{l}\text { ADP } \\
\text { Admit }\end{array}$ & $18.5 \%$ & \\
\hline & $\begin{array}{c}\text { Signs/ } \\
\text { Symptoms }\end{array}$ & $15.8 \%$ & $\begin{array}{c}\text { Signs/ } \\
\text { Symptoms }\end{array}$ & $14.9 \%$ & \\
\hline & Respiratory & $10.7 \%$ & Respiratory & $8.8 \%$ & \\
\hline & Behavioral & $8.8 \%$ & Falls & $8.1 \%$ & \\
\hline & $\begin{array}{l}\text { Cardio- } \\
\text { vascular }\end{array}$ & $7.2 \%$ & Behavioral & $7.7 \%$ & \\
\hline
\end{tabular}

ADP Admit= same day outpatient surgery

In multivariate analysis, we see further evidence that patient-level factors related to discharge context may be driving decisions to utilize available HIE (Table 2.7). In predicting ECL use at any 
time during the full 16-day window, patients discharged on a weekend are less likely to have ECL utilized for their care $(-4.3 \% ; \mathrm{p}=0.036)$. They are more likely to be new rather than returning SNF patients $(+3.8 \%$; $\mathrm{p}=0.001)$ and have been at the hospital for an ED or observational stay rather than inpatient admission (+6.8\%; $\mathrm{p}=0.027)$. We also see some evidence of a relationship between case complexity and ECL use, with ECL more likely to be utilized for less complex patients. A longer length of index hospitalization and greater number of active diagnoses on the problem list were both associated with reduced likelihood of ECL Use (-0.4\% per day of hospitalization; $\mathrm{p}<0.001$; $0.3 \%$ per additional active diagnosis; $\mathrm{p}<0.001)$.

Similar patterns hold for estimating likelihood of ECL use during the transition window (from two days pre-discharge up through three days post-discharge). Being a new SNF resident no longer had a significant effect, but weekend discharge was still associated with reduced likelihood of ECL use $(-10.7 \% ; \mathrm{p}<0.001)$, and an ED or observational stay were associated with an increased likelihood of ECL use $(+11.9 \%$; $\mathrm{p}<0.001)$. These indicators suggest SNF conditions such as staffing during normal vs. "off" business hours may affect whether ECL is used to support transitional care. Similarly, differences in use based on the type of hospital encounter preceding SNF admission suggests that there could be variation in the robustness of handoff processes from the hospital side that affects whether ECL is needed to support a patient's transitional care. Finally, similar to overall ECL use, lower case complexity was also still associated with likelihood of ECL use in the transition window, with a longer length of index hospitalization and greater number of active medication classes on the medication list both negatively associated with likelihood of 
transition window ECL use $(-0.5 \%$ per day of hospitalization; $\mathrm{p}<0.001 ;-0.5 \%$ per additional medication class; $\mathrm{p}<0.001)$.

Table 2.7 Patient Drivers of ECL Use (Multivariate Analyses)

\begin{tabular}{|l|l|l|l|l|l|}
\hline & $\begin{array}{l}\text { Pooled, All } \\
\text { ECL Use }\end{array}$ & $\begin{array}{l}\text { Pooled, } \\
\text { Transition } \\
\text { window use }\end{array}$ & $\begin{array}{l}\text { Transition } \\
\text { window } \\
\text { Facility 1 }\end{array}$ & $\begin{array}{l}\text { Transition } \\
\text { window } \\
\text { Facility 2 }\end{array}$ & $\begin{array}{l}\text { Transition } \\
\text { window } \\
\text { Facility 3 }\end{array}$ \\
use- \\
\hline Sample Size & 5487 & 5487 & 1586 & 2397 & 1504 \\
\hline Context Factors & & & & & \\
\hline $\begin{array}{l}\text { Weekend Discharge } \\
\text { Ref: Weekday discharge) }\end{array}$ & $-.043(.021)^{*}$ & $-.107(.020)^{* * *}$ & $-.062(.023)^{* *}$ & $-.185(.034)^{* * *}$ & $-.025(.035)$ \\
\hline $\begin{array}{l}\text { Patient is a new SNF resident } \\
\text { Ref: Returning SNF resident) }\end{array}$ & $.038(.012)^{* * *}$ & $.006(.010)$ & $-.028(.023)$ & $.056(.042)$ & $.010(.043)$ \\
\hline $\begin{array}{l}\text { Patient discharged following } \\
\text { ED or observational stay } \\
\text { Ref: Inpatient hospitalization) }\end{array}$ & $.068(.031)^{*}$ & $.119(.025)^{* * *}$ & $.051(.038)$ & $.167(.043)^{* * *}$ & $.164(.069)^{*}$ \\
\hline Patient Complexity Factors & & & & & \\
\hline Age & $.0001(.001)$ & $.001(.001)$ & $-.001(.001)$ & $.002(.001)^{*}$ & $.0003(.001)$ \\
\hline Male Gender (ref: F) & $-.003(.015)$ & $.002(.013)$ & $.030(.015)^{*}$ & $-.003(.022)$ & $-.020(.024)$ \\
\hline Length of Hospital Stay & $-.004(.001)^{* * *}$ & $-.005(.001)^{* * *}$ & $-.002(.001)$ & $-.010(.001)^{* * *}$ & $.003(.002)$ \\
\hline Num. of Medication Classes & $.001(.002)$ & $-.005(.001)^{* * *}$ & $.0002(.002)$ & $-.010(.002)^{* * *}$ & $-.002(.003)$ \\
\hline Num. of Active Diagnoses & $-.003(.001)^{* * *}$ & $-.0001(.001)$ & $-.001(.001)$ & $.002(.001)$ &.$- .003(.002)$ \\
\hline R & .078 & .130 & .068 & .056 & .027 \\
\hline $\begin{array}{l}\text { Chi }{ }^{2} \text { Test Statistic, Likelihood } \\
\text { Ratio test }\end{array}$ & $411.3 * * *$ & $749.7 * * *$ & $55.6 * * *$ & $155.4 * * *$ & $40.44 *$ \\
\hline Facilities (reference: Fac 1) & & & & & \\
\hline Fac 2 & $.226(.01)^{* * *}$ & $.377(.014)^{* * *}$ & & & \\
\hline Fac 3 & $-.056(.019)^{* * * *}$ & $.173(.014)^{* * *}$ & & & \\
\hline
\end{tabular}

All models also include binary indicator for each of the top 15 listed reasons for index hospitalization

$* \mathrm{p} \leq 0.05 ; * * \mathrm{p} \leq 0.01 ; * * * \mathrm{p} \leq 0.001$

When we look at predictors of ECL use in the transition window across individual facilities, we notice significant variation. SNF 3, in particular, had the least variation in ECL use predicted by specified patient-level factors - either contextual or case complexity characteristics. Only SNF admission following an ED or observational stay was a significant predictor in this facility, with a $16.9 \%$ increased likelihood of use within the transition window compared to patients coming from an inpatient hospitalization $(\mathrm{p}=0.017)$. Facility 1 , which had the lowest rate of transitional window ECL use across all facilities, also had very few significant patient-level predictors of this use. Patients discharged from hospital to SNF on a weekend had reduced likelihood of use within the 
transition window $(-6.2 \% ; \mathrm{p}=0.007)$. Interestingly, male patients had a $3 \%$ higher likelihood of ECL used during transitional care compared to female patients in this facility $(\mathrm{p}=0.049)$. This could be spurious, but may be indicative of targeted ECL use for conditions that only affect men, such as prostate care. Patterns of use for Facility 2 were most similar to pooled analyses, with reduced likelihood of transitional window use associated with a weekend discharge $(-18.5 \%$; $p<0.001)$ and an ED or observation stay rather than inpatient hospitalization preceding SNF admission $(+16.7 \%$; $\mathrm{p}<0.001)$. We also see reduced likelihood of use with increasing patient case complexity, indicated by the relationship with longer lengths of stay $(-1.0 \%$ per additional day; $p<0.001)$ and number of active medication classes in the current medication list (-1.0\% per additional medication class; $\mathrm{p}<0.001)$. Counter to these findings, we do see a positive relationship between age and use; older patients in Facility 2 have a slightly higher likelihood of having ECL utilized during their transitional care $(+0.2 \%$ per year of age; $\mathrm{p}=0.033)$.

\section{Moderating effects of timeliness and completeness:}

Multivariate analyses exploring patient-level predictors of ECL use revealed variation in how the system is used across the three treatment SNFs. Therefore, in analyzing the moderating effects of timing and intensity of use on the relationship between ECL use and patient likelihood of readmission, we run the models pooled and separately for each facility. These results are presented in Table 2.8. In pooled analyses, when using patients for whom ECL was never accessed as a reference group, we see that accessing only basic patient information during the transition window of care -48 hours prior to hospital discharge and up to 72 hours post-discharge - is associated with a $5.5 \%$ increased likelihood of 30 -day readmission $(\mathrm{p}=0.048)$. This association does not exist 
for patients for whom ECL was first accessed after the transition window expired. The number of information retrieval actions taken, our measure of usage intensity, also has no significant effect. Finally, we consider the interacted effects of timing and intensity. Neither our indicator of advanced information being accessed during transitional care, nor the number of overall information retrieval actions taken during the transition window, were significantly associated with likelihood of readmission.

Table 2.8 Moderators of the Relationship between ECL Use and Outcomes

\begin{tabular}{|c|c|c|c|c|}
\hline \multirow[t]{2}{*}{ (Outcome: 30-day readmission) } & \multicolumn{4}{|c|}{ Average marginal effects } \\
\hline & Pooled & Facility 1 & Facility 2 & Facility 3 \\
\hline \multicolumn{5}{|l|}{$\begin{array}{l}\text { Timing of System Use } \\
\text { (reference: no ECL use) }\end{array}$} \\
\hline $\begin{array}{l}\text { Transition window use - basic } \\
\text { information only }\end{array}$ & $0.055(.028)^{*}$ & $0.202(.082)^{*}$ & $0.006(.039)$ & $0.108(.057)$ \\
\hline Post- transition window ECL use & $-0.016(.025)$ & $-0.044(.051)$ & $-0.013(.037)$ & $0.024(.053)$ \\
\hline \multicolumn{5}{|l|}{ Intensity of System Use } \\
\hline $\begin{array}{l}\text { Count of ECL actions } \\
\text { (centered at median of 7) }\end{array}$ & $0.0004(.001)$ & $-0.003(.003)$ & $-.001(.002)$ & $.006(.003)^{*}$ \\
\hline \multicolumn{5}{|l|}{ Timing and Intensity of System Use } \\
\hline $\begin{array}{l}\text { Advanced information retrieval } \\
\text { within the transition window }\end{array}$ & $0.001(.036)$ & $0.226(.132)$ & $-0.055(.049)$ & $0.053(.078)$ \\
\hline $\begin{array}{l}\text { Interaction: Count of actions when } \\
\text { use is within the transition } \\
\text { window }\end{array}$ & $0.002(.002)$ & $-0.003(.008)$ & $0.006(.002)^{*}$ & $-0.011(.005)^{*}$ \\
\hline \multicolumn{5}{|l|}{ Facility-level Effects (ref: Facility 1) } \\
\hline Facility 2 & $0.065(.021)^{*}$ & & & \\
\hline Facility 3 & $0.090(.025)^{* * *}$ & & & \\
\hline
\end{tabular}

Patient condition controls included

${ }^{*} \mathrm{p} \leq 0.05 ; * * \mathrm{p} \leq 0.01 ; * * * \mathrm{p} \leq 0.001$

When we look at facility-specific analyses, we observe different relationships between patterns of use and patient outcomes. For Facility 1, we observe a large 20.2\% increased likelihood of 30-day readmission when just basic information is accessed during the transition window $(\mathrm{p}=0.013)$. Because use within the transition window is atypical for this facility, we suspect this association is being driven by a small amount of endogenous ECL use prompted by instability in patient condition soon after transfer, and that this instability is not well-predicted by our available patient 
control variables. Similar to pooled analyses, this association does not exist for ECL use that takes place outside of the transition window, nor do we detect any association between intensity of use (overall or in the transition window) and readmissions. In Facility 2, the only significant association observed is a higher likelihood of readmission when a higher volume of information was retrieved during the transition window $(+0.6 \%$ increase per action within the transition window; $\mathrm{p}=0.012$ ). Interestingly, when we look at the volume of ECL information retrieval in Facility 3 within this designated transition window, we see a reversed effect. During transitional care for patients discharged to Facility 3, each additional information retrieval actions taken within this window is associated with a $1.2 \%$ reduced likelihood of patient readmission $(\mathrm{p}=0.045)$.

\section{$\underline{\text { Discussion }}$}

Understanding the role health IT might play in improving information continuity and handoff during post-acute care transitions is a timely and critical issue for policymakers, provider organizations, payers, and patients. Yet, evaluating the impact of electronic information sharing in this context has hardly been studied, and analysis of HIE more generally has yielded mixed and often marginal results. This study is the first of its kind, using log files that capture audited use of an information sharing system in the context of post-acute transitional care. With these data, we can explore the determinants, timing, and nature of electronic information retrieval to support post-acute transitional care processes, and begin to intuit whether there are particular patterns of use that are most likely to results in improved patient care. 
In this study, our first research aim sought to determine whether electronic information sharing capability improves the quality of post-acute care transitions, as measured by a reduced patient likelihood in 30-day hospital readmissions. We used a difference in difference analyses to explore whether the selective implementation of EpicCare Link (ECL) - a portal-enabled form of HIE - between a large, academic hospital and three local skilled nursing facilities impacted transition-sensitive patient outcomes (30-day readmissions), relative to patients transitioned to non-ECL equipped facilities. We found no measureable net effect of portal implementation, adding to the growing body of evidence in health IT research - and implementation research more broadly - demonstrating that availability of new care processes or technologies does not necessarily translate to effective use of these tools in ways that improves care delivery and associated outcomes.

Our second and third research aims explored variation in when and how HIE functionality was used by skilled nursing facility providers to support transitional and post-acute care. We observe significant variation, suggesting that contextual factors may be moderating encounter-level decisions regarding whether to access the system, and the depth of information retrieval initiated. On average, ECL was only utilized for $46 \%$ of patients for whom it was available. Patient-level factors related to both measures of case complexity as well as the context surrounding handoff proved to be significant predictors of use, but counter to expectation. We first anticipated that patients of greater medical complexity would be more likely to have ECL utilized to support their care, as more information would be needed for providers to make complicated medical decisions. Instead, more complex patients had lower likelihood of ECL use, both overall and 
during the transition window. We also expected that ECL would be more likely utilized in situations where workflows supporting transitional care may deviate from standard practices and create information discontinuity. This includes a patient being discharged on the weekend (35), or admitted to the SNF directly from the ED or an observational bed. (36) Here, we find conflicting evidence; ECL use is more likely to be used for hospital-to-SNF transitions that bypass an inpatient unit, but is less likely to be utilized on weekends rather than weekdays.

Taken together, these results suggest that the portal may currently serve as a substitute coordination mechanism in the absence or insufficiency of existing non-technical communication platforms, and provide compelling evidence for studying HIE use and impact with consideration for the broader sociotechnical context in which care is being delivered. For example, patients of greater complexity - as indicated by condition or type of index hospitalization - experience lower ECL use on average, which could be appropriate if it's due to these patients receiving more robust handoff care and more timely visits by the hospital-employed sub-acute physicians responsible for their SNF care. If this is the case, increasing use and value of portal-enabled information retrieval requires hospitals and SNFs to think about how the portal can be leveraged to deliver utility that is complementary to (rather than competing with) other coordination processes. Promoting use of the portal to retrieve nursing and social work documentation that is more relevant to supporting the care that SNF providers deliver may be one such " 2.0 " use case. However, this more intentional and systematized use would require a SNF environment with aligned and enabling workflows to facilitate its use in the context of transitional care. The fact that ECL use is dampened on weekends suggests that use is being driven by management and 
perhaps other ancillary team members that are typically only present during normal business hours. If this is true, this should drive organizational thinking around how to integrate technologies and workflows in ways that create opportunity for improved care. For all of these findings, qualitative inquiry is critical to developing better insights into the specific information challenges perceived by SNFs, how HIE is currently used, and how HIE could better support their needs during care transitions.

When we explore how timeliness and intensity of system use moderated the overall null effect on patient outcomes, we found slight evidence in one of the three facilities that retrieving more information during the transition window of care was associated with a reduced likelihood of readmission. Understanding why there's a relationship between ECL use and improved outcomes in this facility, and not the other two, generates some new hypotheses regarding how organizational-level factors impact whether HIE use can be expected to drive improvement in patient care. For example, staffing and management structures may dictate whether and when an organization has the capacity to incorporate HIE in to standard workflows. HIE value may also be contingent upon familiarity with its design, and consistency of use; these factors would depend in part on the average percent of a SNF's patient census received from the hospital offering HIE functionality. Unfortunately, we cannot test these ideas empirically with a small sample of only three facilities and one referring hospital. Scaling up this type of log-file analysis to the level of HIE operating at a regional level would enable more robust multi-level modeling to partition and explore drivers of variation at the patient, organizational, and even hospital-SNF dyad level. 
Overall, these findings have important implications for understanding the role that HIE-mediated information transfer can and perhaps should play in the greater context of information continuity during handoffs. Our evidence points to the conclusion that current patterns of HIE use by SNFs, which are relatively perfunctory, should not be expected to drive significant improvements in post-acute transitional care. Ultimately, SNF providers will not take the time to access these platforms during such a critical care window if there is little perceived value. Both hospitals and SNFs need to work together to think about data elements most useful for transitional and postacute care delivery; hospitals must then be willing to adapt their infrastructure to increase SNFrelevant information accessibility if they are to realize return on investment of this technology infrastructure. For example, a more customized portal interface or summary page for post-acute care providers might direct users to information most relevant to their care delivery tasks; this information may currently be buried and require numerous clicks to retrieve. Similarly, use patterns may differ not only by patient complexity but also particular conditions or treatment regimens that drive specific informational needs. This study only scratched the surface of understanding variation in information seeking based on patient factors; data mining techniques could leverage these audit files to understand, for example, what information needs to be prioritized when a patient is discharged on anti-psychotic medications or when a patient has ongoing wound care needs post-surgery. Incorporating flexibility and customization in to system functionality will be an important area of continued innovation to help providers better leverage HIE for improved care transitions and patient outcomes. 
This study has several key limitations. First, in the difference-in-difference analysis, we fail to capture our key outcome of patient readmission if a patient was readmitted to a hospital other than the focal hospital of our analyses. Though this limitation should be addressed through the nature of a DiD modeling approach, we also attempt to address this issue by creating a more geographically proximate control group and find no difference in results with these supplemental analyses. Changing local patterns of discharges to SNFs (by hospitals) or hospital referrals (by SNFs) around the time of ECL implementation may affect our parallel trends assumption and limit the interpretation of our findings, though we don't have clear evidence to suggest this as an issue.

Second, as discussed in the methods, the audit logs used to understand when and how ECL is used to support post-acute care only capture actions taken by SNF nurses and administrators. Physicians who visit patients in the SNF have their own direct access to the hospital electronic health record and do not use the ECL platform. Therefore, though we do have a comprehensive look at information retrieval by the full time staff responsible for SNF patient care, we do not know whether the physicians are accessing and providing the nursing team with additional information retrieved electronically from the hospital records. This is particularly salient given our findings that ECL is less likely to be used for more complex patients. Combining records of information retrieval by all providers responsible for post-acute care, doctors as well as nurses and administrators, would provide a necessary and more complete picture of information transfer to support post-acute transitional care. 
Third, $\log$ file data is novel and significantly broadens opportunities for health IT evaluation, but is not a source of data created nor intended for research purposes. We conducted significant data cleaning and data validation to ensure that we could responsibly use this data, but consider our findings to be suggestive and hypothesis-generating for further research. For example, due to the lack of complete specificity in what the audit record captures, we must be careful not to overinterpret the nature and depth of information retrieval based on number of actions or types of actions recorded. The relative value of viewing two different inpatient notes cannot be considered equally since we do not know the richness of information each might contain. A better understanding of the precise content of current information retrieval practices is critical if we are to understand and advance ideal use of HIE to support post-acute transitional care.

Finally, in terms of external validity, the study took place within a single academic medical center and three local skilled nursing facilities that used one type of electronic information sharing within one vendor system. This limited our ability to conduct statistical analyses of organizational factors affecting technology use and impact. Our results are preliminary and suggestive; recreating this analysis at larger scale within a regional information exchange effort would increase robustness and generalizability.

\section{$\underline{\text { Conclusion }}$}

Electronic information sharing between hospitals and local independent skilled nursing facilities may prove to be a useful tool for coordinating patient care across organizational boundaries, but currently does not demonstrate measurable impact on improving patient care. Our study provides suggestive evidence that understanding the contextual drivers of system use (patient condition, 
fidelity of non-IT based communication mechanisms), and the quality of HIE-enabled information retrieval (timeliness, depth of detail) will help providers extract greater value from HIE investments. Ultimately, realizing potential benefits requires leveraging the unique advantages of HIE-enabled retrieval to complement other processes that support information continuity, and building systems that provide customization and flexibility for prioritizing the specific information needed to support robust transitional care in this context. Having integrated tools and processes that promote information continuity will be critical moving forward in determining chances for success in the numerous finance and delivery reforms aimed at improving the quality, safety, and value of post-acute patient care. 


\section{$\underline{\text { Works Cited }}$}

1. Tian W. An All-Payer View of Hospital Discharge to Postacute Care, 2013. Agency for Healthcare Research and Quality, Healthcare Cost and Utilization Project; May 2016.

2. Boockvar K, Vladeck BC. Improving the quality of transitional care for persons with complex care needs. Journal of the American Geriatrics society. 2004;52(5):855-6.

3. LaMantia MA, Scheunemann LP, Viera AJ, Busby-Whitehead J, Hanson LC. Interventions to improve transitional care between nursing homes and hospitals: a systematic review. Journal of the American Geriatrics Society. 2010;58(4):777-82.

4. Naylor MD, Brooten DA, Campbell RL, Maislin G, McCauley KM, Schwartz JS. Transitional care of older adults hospitalized with heart failure: a randomized, controlled trial. Journal of the American Geriatrics Society. 2004;52(5):675-84.

5. Naylor MD, Aiken LH, Kurtzman ET, Olds DM, Hirschman KB. The importance of transitional care in achieving health reform. Health affairs. 2011;30(4):746-54.

6. Popejoy L, Galambos C, Vogelsmeier A. Hospital to nursing home transition challenges: Perceptions of nursing home staff. Journal of nursing care quality. 2014;29(2):103-9.

7. Murray LM, Laditka SB. Care transitions by older adults from nursing homes to hospitals: Implications for long-term care practice, geriatrics education, and research. Journal of the American Medical Directors Association. 2010;11(4):231-8.

8. Tjia J, Bonner A, Briesacher BA, McGee S, Terrill E, Miller K. Medication discrepancies upon hospital to skilled nursing facility transitions. Journal of general internal medicine. 2009;24(5):630-5.

9. Mor V, Intrator O, Feng Z, Grabowski DC. The revolving door of rehospitalization from skilled nursing facilities. Health Affairs. 2010;29(1):57-64.

10. Georgiou A, Marks A, Braithwaite J, Westbrook JI. Gaps, disconnections, and discontinuities - the role of information exchange in the delivery of quality long-term care. The Gerontologist. 2013;53(5):770-9.

11. Gurwitz JH, Field TS, Avorn J, McCormick D, Jain S, Eckler M, et al. Incidence and preventability of adverse drug events in nursing homes. The American journal of medicine. 2000;109(2):87-94.

12. King BJ, Gilmore-Bykovskyi AL, Roiland RA, Polnaszek BE, Bowers BJ, Kind AJ. The consequences of poor communication during transitions from hospital to skilled nursing facility: a qualitative study. Journal of the American Geriatrics Society. 2013;61(7):1095-102.

13. Shah F, Burack O, Boockvar KS. Perceived barriers to communication between hospital and nursing home at time of patient transfer. Journal of the American Medical Directors Association. 2010;11(4):239-45.

14. Gaskin S, Georgiou A, Barton D, Westbrook J. Examining the role of information exchange in residential aged care work practices-a survey of residential aged care facilities. BMC geriatrics. 2012;12(1):1.

15. Weiskopf NG, Weng C. Methods and dimensions of electronic health record data quality assessment: enabling reuse for clinical research. Journal of the American Medical Informatics Association. 2013;20(1):144-51. 
16. Lee YW, Strong DM, Kahn BK, Wang RY. AIMQ: a methodology for information quality assessment. Information \& management. 2002;40(2):133-46.

17. Buntin MB, Jain SH, Blumenthal D. Health information technology: laying the infrastructure for national health reform. Health Affairs. 2010;29(6):1214-9.

18. Hersh WR, Totten AM, Eden KB, Devine B, Gorman P, Kassakian SZ, et al. Outcomes from health information exchange: systematic review and future research needs. JMIR medical informatics. 2015;3(4).

19. Cohen MD, Hilligoss B, Amaral ACK-B. A handoff is not a telegram: an understanding of the patient is co-constructed. Critical care. 2012;16(1):303.

20. Clark B, Baron K, Tynan-McKiernan K, Britton M, Minges K, Chaudhry S. Perspectives of Clinicians at Skilled Nursing Facilities on 30-Day Hospital Readmissions: A Qualitative Study. Journal of hospital medicine. 2017;12(8):632-8.

21. Kruse CS, Mileski M, Alaytsev V, Carol E, Williams A. Adoption factors associated with electronic health record among long-term care facilities: a systematic review. BMJ open.

2015;5(1):e006615.

22. Holmgren AJ, Patel V, Charles D, Adler-Milstein J. US hospital engagement in core domains of interoperability. Am J Manag Care. 2016;22(12):e395-402.

23. Vest JR, Jasperson JS. How are health professionals using health information exchange systems? Measuring usage for evaluation and system improvement. Journal of medical systems. 2012;36(5):3195-204.

24. Vest JR, Jasperson JS, Zhao H, Gamm LD, Ohsfeldt RL. Use of a health information exchange system in the emergency care of children. BMC medical informatics and decision making. 2011;11(1):1.

25. Vest JR, Zhao H, Jaspserson J, Gamm LD, Ohsfeldt RL. Factors motivating and affecting health information exchange usage. Journal of the American Medical Informatics Association. 2011;18(2):143-9.

26. Everson J, Kocher KE, Adler-Milstein J. Health information exchange associated with improved emergency department care through faster accessing of patient information from outside organizations. Journal of the American Medical Informatics Association. 2016:ocw116.

27. Johnson KB, Unertl KM, Chen Q, Lorenzi NM, Nian H, Bailey J, et al. Health information exchange usage in emergency departments and clinics: the who, what, and why. Journal of the American Medical Informatics Association. 2011;18(5):690-7.

28. Rahman M, Foster AD, Grabowski DC, Zinn JS, Mor V. Effect of Hospital-SNF Referral Linkages on Rehospitalization. Health services research. 2013;48(6pt1):1898-919.

29. Hebert C, Shivade CP, Foraker RE, Wasserman J, Roth C, Mekhjian HS, et al.

Diagnosis-specific readmission risk prediction using electronic health data: a retrospective cohort study. BMC Med. Inf. \& Decision Making. 2014;14:65.

30. Elixhauser A, Steiner C, Palmer L. Clinical Classifications Software (CCS). US Agency for Healthcare Research and Quality, 2014. 2014.

31. Adler-Milstein J, Daniel G, Grossmann C, Mulvany C, Nelson R, Pan E, et al. Return on Information: A Standard Model for Assessing Institutional Return on Electronic Health Records. Institute of Medicine, Washington, DC (2014. 2014.

32. Ai C, Norton EC. Interaction terms in logit and probit models. Economics letters. 2003;80(1):123-9. 
33. Karaca-Mandic P, Norton EC, Dowd B. Interaction terms in nonlinear models. Health services research. 2012;47(1pt1):255-74.

34. Puhani PA. The treatment effect, the cross difference, and the interaction term in nonlinear "difference-in-differences" models. Economics Letters. 2012;115(1):85-7.

35. Cloyd JM, Chen JC, Ma Y, Rhoads KF. Is weekend discharge associated with hospital readmission? Journal of hospital medicine. 2015;10(11):731-7.

36. Samuels-Kalow ME, Stack AM, Porter SC. Effective discharge communication in the emergency department. Annals of emergency medicine. 2012 Aug 1;60(2):152-9. 


\section{Chapter 3 : Opportunities and Challenges in Using Electronic Portals to}

Address Information Discontinuity during Post-Acute Care Transitions

$\underline{\text { Introduction }}$

Care continuity remains a ubiquitous and salient challenge, as patients' total healthcare needs frequently require services across multiple provider types and care settings. $(1,2)$ These concerns are particularly critical for patients requiring post-acute care services following hospitalization. In 2013, 8 million patients (22\% of all total inpatient stays) required post-acute services; over $40 \%$ of these patients were discharged to skilled nursing facilities (SNFs), the largest institutional provider of post-acute care. (3) Patients experiencing transition to a SNF are older and more vulnerable than an average discharged patient, often with multiple chronic comorbidities and less ability to participate in coordinating their own care.(4-6) High rates of rehospitalization following discharge to SNF - estimated at nearly $25 \%$ - suggest that this complexity amplifies known challenges inherent in coordinating handoffs and effectively communicating continuation of a patient's care plan across time and location. $(7,8)$ Indeed, key quality of care issues in SNFs (i.e. delayed care responsiveness, medical errors, care fragmentation) as well as increased risk of readmission, have been largely attributed to compromised (i.e. missing, delayed or inaccurate) information during handoffs.(7, 9-16) 
Prior literature is notably sparse in understanding the specific informational needs and workflows that support effective hospital-to-SNF transitional care processes.(11) Thoughtful innovations such as the Transitional Care Model (5) or Project RED (Re-Engineered Discharge) (17) articulate roles, responsibilities and resources required for managing transitions after hospitalization, but do not account for the unique challenges of institution-to-institution handoffs. Transitions to SNFs - facilities governed by patient rehabilitation responsibilities, assessment standards, and organizational norms distinct from those of acute care providers such as hospitals - tend to surface issues of ambiguity in role definition and accountability in the postdischarge period. (18) Different care priorities also means that hospital-to-SNF transitions suffer not only from standard information management issues that compromise handoff quality (i.e. incomplete or inaccurate orders, omitted prescriptions), but also that the type of information conveyed isn't sufficient for the nature of services provided in the SNF setting (i.e. lack of information on functional status or psychosocial history). $(11,16)$

One strategic approach used by hospitals to improve handoffs is to shore up communication gaps by investing in health information exchange (HIE) with outside providers. With IT-enabled information transfer, hospitals can create and electronically transmit information about the hospitalization to outside providers (i.e., push information), or make information about the hospitalization available for outside providers to access electronically (i.e., have outside providers view or pull information). While most HIE investment to-date has focused on other transitional care contexts (i.e. discharge to home or hospital-to-hospital transfer), hospitals are increasingly engaged in via electronic information sharing to also improve transitional care with 
post-acute providers such as SNFs. (19) HIE is thought to have considerable potential to facilitate hospital-to-SNF transitions, yet perceived use cases in this context are still largely hypothetical. $(9,13,20)$ We know very little about how HIE can or should fit within the broader context of information transfer and other processes supporting handoff from hospital to SNF. Exploring current examples of HIE use between hospitals and SNFs can generate key insights in to how HIE adds unique value to transitional care processes, and where systems are falling short of potential. Importantly, introducing new technology and technology-enabled processes in to existing workflows can have significant and sometimes unintended consequences on the efficiency, effectiveness, and safety of care delivery. $(21,22)$ Exploring how technology use in this context alters, and is altered by, the complex social processes that also support transitional care can help providers better anticipate and address consequences and tradeoffs of future HIT design and implementation efforts.

To maximize efforts to improve post-acute transitions of care with HIE, we need to identify where use of IT can reshape processes that currently fall short of potential value, reinforce existing social systems of care that enhance quality and safety, and be redesigned to minimize unanticipated effects on handoff practices and patient care. Doing so requires a fundamental understanding of how hospital and SNF providers view information continuity challenges in this specific transitional care context. We thus conduct deep qualitative inquiry regarding transitional care practices between one focal hospital and local SNF providers, guided by the following three research questions. First, what key information gaps do SNF providers perceive in the context of receiving a patient following hospitalization? Second, how do practices operationalize the role of 
IT in supporting transitional care activities? And finally, what socio-technical considerations shape the perceived challenges and ultimate potential of using IT to alleviate information discontinuity during hospital-to-SNF transitions? Synthesizing specific HIE use cases in the post-acute transition context, and understanding complementary [inter-]organizational processes that facilitate impactful use, provides key guidance to providers looking to leverage IT investment for improved continuity of care for a vulnerable and complex patient population.

\section{$\underline{\text { Methods }}$}

Research Design and Sample: This qualitative study used semi-structured interviews to explore the role of IT-enabled information sharing in the broader context of processes and interactions that support hospital-to-SNF patient care transitions. To achieve analytic depth, data collection was restricted to a single large academic medical center in the Midwest, and SNFs in close geographic proximity to this focal hospital. The focal hospital uses an online referral management system (AllScripts) for pre-discharge communication and information transfer involved in coordinating patient SNF placement. And, in 2014, the hospital also began extending view-only portal access for SNFs to view the hospital's EHR data. We selected five SNF locations in which to conduct interviews; these facilities receive the large majority of this hospital's referrals. Importantly, these five SNFs vary in terms of the availability of IT-enabled information retrieval capabilities and timing of implementation, as well as variation in key organizational characteristics, such as patient demographics and strength of affiliation with the focal hospital. 
Data Collection: Interviews took place in February and March of 2018, and were conducted inperson, recorded, and transcribed. Hospital interviews were all conducted one-on-one, while SNF interviews were conducted in a group setting, with a minimum of 2 respondents per facility. Speaking with multiple respondents per site offered a range of perspectives based on role (i.e. clinical versus administrative) and organizational tenure. Individual interviews lasted 30-40 minutes, and group interviews ranged from 45 to 60 minutes in length. Protocols were designed narratively, to walk respondents through each stage of transitional care (pre-discharge, discharge, post-discharge). Using a socio-technical framing, respondents were asked to describe all relevant processes, interactions, and artifacts of transfer (i.e. an emailed referral document, a paper discharge summary), and the technical systems that supported these workflows (See Appendix for full protocol). Special attention was paid to the specific information elements deemed important at each stage of the transition, whether those elements were included in existing transfer processes, and the primary mechanism of transfer. Respondents were asked to reflect upon factors that introduce variation in these processes - both situational (due to patient condition or complexity) as well as temporal (due to changing IT capabilities or interorganizational relationships) - and how they responded to changing needs or altered contexts of care delivery. This study was reviewed and determined exempt by the Insititutional Review Board.

Analysis: Data collection was guided by an intent to use grounded dimensional analysis to deconstruct interactions and interpret meaning in a complex social situation. $(11,23,24) \mathrm{We}$ sought to first understand how hospital and SNF providers viewed their responsibilities in the 
context of transitional care, and the current socio-technical processes established to carry out these roles. By emphasizing the specific informational needs generated by each of these articulated responsibilities, we could determine where key issues of information discontinuity existed, the extent to which IT was or could be used to meet these challenges, and specific ways in which IT use reinforced, altered, or was inhibited by existing social processes of care. The nested structure of data collection - multiple respondents within an organization, across multiple care sites - enabled synthesis of findings based on different levels of comparison. (25) Interview responses were organized by role and by organization to explore variation and convergence of themes within each organization, across organizations, and within role type across organizations.

To carry out these analytic goals, we used a three-stage coding process. $(26,27) \mathrm{We}$ first developed provisional codes to sort out processes based on timing (pre, during or post-transfer) and type of informational need (standard versus supplemental). We then applied a second layer of modifier codes to identify perceived problems with respect to information quality (i.e. missing, delayed, unusable, or lack of context-relevant information) and process fidelity (i.e. identified facilitators and barriers to standard care practices). These first two rounds of coding allowed us to identify specific domains of information discontinuity that created pressure points throughout the transitional care process. At this stage, transcripts were then re-read in full and assessed for presence or absence of each identified challenge to ensure that strong opinions from one organization did not occlude differing but weak viewpoints of other organizations. (28) 
We then applied a third and final set of codes specific to the potential of using IT to solve identified problems, and sociotechnical considerations that facilitated or hindered IT use. Data segments describing aspects of information discontinuity were coded based on whether respondents (1) described ways they used available HIE to address the challenge; (2) identified a potential but not currently operationalized role for HIE to address the issues; or (3) were unable to conceive how HIE technology might address the identified information deficit. We also coded whether specific aspects of IT design or implementation enhanced or hindered the consequences of its use. Analyzing the co-occurrence of process and technology codes in the context of specific post-acute transition pressure points enabled robust understanding of opportunities to advance the role of IT in supporting care continuity from an integrated sociotechnical perspective. (22)

\section{$\underline{\text { Results }}$}

We spoke to a total of 18 respondents, 3 from the hospital and 15 from across our SNF settings (See Table 3.1). Hospital respondents included an attending hospitalist physician, director of the hospital case management and discharge planning team, and a hospital-employed care manager embedded at a local SNF. SNF respondents included a mix of facility administrators (4), admissions staff (5), directors of nursing (4) and floor nursing staff (2). Participating SNFs ranged in size (71 to 215 beds) and populations served, with variation in average patient risk score (1.98 to 2.75$)$ and assumed medical/social complexity based on insurance coverage type (7.5-26.4\% dual eligibles). All five facilities had long-standing access to the online AllScripts referral management system. Three of the five facilities received portal access beginning June 
2014. A fourth facility received access in September of 2017, and the fifth facility continues to maintain only fax and paper-based information exchange with the focal hospital. Finally, our sample included two practices with strong affiliation to the focal hospital, two with a moderate affiliation, and one with a weak relationship with the focal hospital. Affiliation strength was assessed qualitatively based on percent of patient referrals each facility received from the focal hospital as well as the extent to which the hospital had invested in relationships and resources (i.e. embedded care management, extent of hospital-employed physician presence and integration in to SNF care processes) across the SNFs.

Table 3.1 Participating Organizations and Respondents

\begin{tabular}{|l|l|l|l|l|l|l|l|}
\hline Organization & $\begin{array}{l}\text { Size } \\
\text { (beds) }\end{array}$ & $\begin{array}{l}\text { Average } \\
\text { Patient } \\
\text { Risk } \\
\text { Score } \\
\text { (HCC) }\end{array}$ & $\begin{array}{l}\text { Percent of } \\
\text { patients that } \\
\text { are dual } \\
\text { beneficiaries }\end{array}$ & $\begin{array}{l}\text { Has } \\
\text { portal } \\
\text { access? }\end{array}$ & $\begin{array}{l}\text { Date of } \\
\text { activation }\end{array}$ & $\begin{array}{l}\text { Strength } \\
\text { of } \\
\text { affiliation } \\
\text { with focal } \\
\text { hospital }\end{array}$ & Participants \\
\hline Hospital & 550 & & & & & & $\begin{array}{l}\text { Hospitalist } \\
\text { Case Management/ } \\
\text { Discharge Planning } \\
\text { Director } \\
\text { Embedded SNF Care } \\
\text { Manager }\end{array}$ \\
\hline SNF A & 161 & 2.05 & $11.5 \%$ & Yes & $6 / 2014$ & Moderate & $\begin{array}{l}\text { Administrator } \\
\text { Admissions } \\
\text { Floor Nurse }\end{array}$ \\
\hline SNF B & 180 & 2.69 & $26.4 \%$ & Yes & $6 / 2014$ & Strong & $\begin{array}{l}\text { Administrator } \\
\text { Director of Nursing } \\
\text { Admissions } \\
\text { Floor Nurse }\end{array}$ \\
\hline SNF C & 71 & 2.75 & $19.6 \%$ & Yes & $6 / 2014$ & Strong & $\begin{array}{l}\text { Administrator } \\
\text { Director of Nursing } \\
\text { Admissions }\end{array}$ \\
\hline SNF D & 215 & 2.17 & $11.5 \%$ & Yes & $9 / 2017$ & Moderate & $\begin{array}{l}\text { Administrator } \\
\text { Director of Nursing } \\
\text { Admissions }\end{array}$ \\
\hline SNF E & 85 & 1.98 & $7.5 \%$ & No & N/A & Weak & $\begin{array}{l}\text { Director of Nursing } \\
\text { Admissions }\end{array}$ \\
\hline
\end{tabular}




\section{Workflow to Transition Patients from Hospital to SNF}

Respondents described a fairly standard set of workflow processes surrounding hospital discharge of patients to a SNF (See Table 3.2). This care transition involves two major timeframes in which information is transferred: (1) Communication associated with hospital efforts to place a patient in an appropriate SNF; and (2) Information that moves from hospital to SNF at the time of patient transfer. 
Table 3.2 Summary of Hospital-to-SNF Care Transition Processes

\begin{tabular}{|c|c|}
\hline \multicolumn{2}{|l|}{ Prior to discharge (3-4 days pre-transfer): } \\
\hline $\begin{array}{l}\text { 1. Case manager and hospitalist, in } \\
\text { consultation with physical and occupational } \\
\text { therapists, determine patient's needs for sub- } \\
\text { acute rehabilitation and skilled nursing } \\
\text { services } \\
\text { 2. Case manager uses AllScripts to send out } \\
\text { initial referral request to SNFs that meet } \\
\text { patient preference \& insurance coverage } \\
\text { 3. SNF admissions team reviews patient } \\
\text { documentation received to determine whether } \\
\text { they can accommodate the patient, requests } \\
\text { additional information needed to make } \\
\text { admission decision } \\
\text { 4. SNF hospital nurse liaison meets with } \\
\text { patient, reviews information to answer } \\
\text { questions and determine fit } \\
5 . \text { Physicians on service begin building draft } \\
\text { version of discharge summary }\end{array}$ & $\begin{array}{l}\text { Standard Information Elements: } \\
\text { - } \quad \text { Demographics, diagnosis, insurance } \\
\text { - } \quad \text { History and Physical (H\&P) } \\
\text { - } \quad \text { Initial Op note } \\
\text { - } \quad \text { Initial PT assessment } \\
\text { - } \text { Medication list or 3-day MAR } \\
\text { - } \text { Recent progress notes } \\
\text { - } \quad \text { Recent chest X-ray } \\
\text { Supplemental Information Elements: } \\
\text { - Recent therapy notes } \\
\text { - Nursing Notes } \\
\text { - Special care instructions for complex patients } \\
\text { - } \quad \text { State evaluation forms for mental and } \\
\quad \text { behavioral health concerns }\end{array}$ \\
\hline \multicolumn{2}{|l|}{ Day of Discharge: } \\
\hline $\begin{array}{l}\text { 6. Physician uses EHR navigator tool to } \\
\text { complete discharge summary } \\
\text { 7. Discharge summary and other key patient } \\
\text { documents printed in duplicate, one for SNF } \\
\text { and one for patient. } \\
\text { 8. Nurse-to-nurse transition phone call } \\
\text { completed } \\
\text { 9. Patient travels via ambulance to SNF; floor } \\
\text { nurse receives brief verbal handoff, paper } \\
\text { discharge documentation } \\
\text { 10. Nurse conducts thorough patient intake } \\
\text { assessment; manually inputs medication } \\
\text { regimen in to internal standalone eMAR or } \\
\text { EHR system from hospital medication list* } \\
\text { 11. Discharge summary used to establish } \\
\text { treatment plans and special care instructions, } \\
\text { such as isolation precautions or tube feeding } \\
\text { needs. } \\
\text { 12. Orders confirmed with treating physician }\end{array}$ & $\begin{array}{l}\text { Standard Information Elements: } \\
\text { - } \quad \text { Discharge summary (reconciled medication } \\
\text { - } \text { list, plan for follow-up care) } \\
\text { - } \quad \text { MAR (3-day) } \\
\text { - } \quad \text { Recent PT/OT notes } \\
\text { - Progress notes } \\
\text { - } \text { Orders } \\
\text { - } \quad \text { Consultations } \\
\text { - } \quad \text { Paper prescriptions for Schedule II narcotics } \\
\text { - } \quad \text { Patient After-Visit Summary }\end{array}$ \\
\hline
\end{tabular}


Document transfer via AllScripts, pre-discharge, represents information sharing by the hospital to help SNF admission staff determine whether they can accept a patient given their insurance coverage and medical needs. Standard information provided by the hospital includes the initial history and physical (H\&P), operative report (Op note), and therapy assessments (physical and occupational) from the start of a patient's hospitalization; the hospital also includes recent progress notes and a 3-day medication administration record (MAR) to help assess current patient needs. These documents were sent via email-like attachments by the hospital, as directed by the case manager and executed by discharge planning assistants. The SNF is able to message back and request additional information to determine whether they can take a patient, such as more recent therapy notes or additional documentation on special care needs for particularly complex patients, such as those with advanced wounds, a tracheostomy, or a feeding tube.

At the time of discharge, the patient should leave the hospital with a paper discharge packet that includes the completed discharge summary as well as a printout of most documents already sent via AllScripts (H\&P, medication administration record, progress and therapy notes). This packet also includes discharge orders, all specialist consultative notes, and any required paper prescriptions for Schedule II narcotic medications. Importantly, the discharge summary includes the reconciled medication list, which is used by the SNF nurses as the medication orders to be executed upon admission. The hospital additionally includes the patient-facing After-Visit Summary (AVS), which also includes a discharge medication list. Hospital respondents noted this was sent as a precaution given occasional discrepancies between the two medication lists. 


\section{Domains of Information Discontinuity}

Respondents described five key domains in which information transfer was insufficient to support post-acute care delivery needs, with gaps due to missing (2), difficult to use (1), or delayed (2) information. The first missing information component relates to the longitudinal dimension of healthcare information, and lacking access to the historical context of patient care. By sending static documents via AllScripts pre-discharge, and a paper discharge packet at the time of transfer, SNF nurses struggled to provide effective care for a patient's current health episode due to unanswered questions about previous health events. Respondents described needing more temporal information most often for immunization records, lab and imaging, records of infectious disease treatment, and previous fractures/evidence of falls. As one nurse respondent noted, "Sometimes, immunization history will just say "none recorded". Well that just means none recorded for that hospital stay...I need the history of immunizations." But, sending more comprehensive paper records at discharge was not considered a helpful solution. She went on to exclaim "We certainly don't want them to send the patient's entire chart, though - that stack is already big enough!"

The second missing component of information was detail related to patients' social history and needs. Information transfer, as described by both hospital and SNF respondents, was focused on continuation of medical care needs. SNF respondents described a general hesitation for the hospital to share too much information during the referral process related to a patient's social determinants such as nature of family support or food and housing security, as well as behavioral risk factors. Even at the time of receiving a patient post-hospital discharge, these information 
elements were rarely made available. Hospital case management described an extensive assessment process done for at-risk patients during hospitalization, one that captured functional status, changes in activities of daily living, and key social determinants of care. These assessments were not shared at the point of transfer, even though SNFs emphasized how critical this information was in (1) providing high-quality service from the moment of receiving the patient, and (2) proactively planning a safe transition to home following the SNF stay. As one nurse respondent explained, "We get them for 2 weeks, maybe 3 weeks, sometimes less than that. It is very hard to get to know family dynamics, the person themselves, what their preferences are... [you're] having to make decisions in a vacuum without knowing the person". A Director of Nursing echoed a similar sentiment, saying "Knowing a little bit of a social history at the time they come from the hospital would be really helpful. If we know what's coming in the door, we can have a team of people ready to meet them. We can help that transition be smoother for all involved...[But], there's not a lot of psych-social assessment being documented. Those conversations are probably happening in the hospital, there's still that disconnect [in the information not coming to us]."

Third, SNFs described difficulty with the usability of received information at the time of discharge. As noted above, patients commonly arrived at the SNF with a substantial amount of paper documentation. When floor nurses were looking for particular pieces of information not immediately identifiable in the discharge summary (such as the medication list), some respondents noted frustration with the disorganized and difficult-to-navigate stack of information. As one floor nurse explained, "The [paper discharge packets] have everything you 
need in them, but you're sifting through a lot of information. They may include 30 days' worth of labs drawn, not in any particular order. When you get a running document of everything jumbled together [from the hospital]...it's hard to narrow down if you're looking for something specific. It has a lot of repeated information in there so you have to kind of dig."

The fourth domain in which SNF respondents described challenges with information receipt from the hospital related to the timing of when clinical staff learned about a patient, and how that limited their ability to prepare in advance for patient arrival. Most advance information about a patient would come to the SNF through document exchange in AllScripts, which is managed by the admissions team, or by way of the SNF-employed nurse liaison who interacts with patients in the hospital. However, some SNFs didn't have clear processes established for admissions to communicate knowledge gleaned through AllScripts to the clinical staff directly responsible for patient care. Floor nurses noted that they often didn't see any information until the patient was brought in to the facility by emergency medical services. This sometimes led to an environment "operating in chaos", as one respondent described, with the nurses flipping through extensive paper documentation to get medications entered and a care plan established. These challenges were compounded when delays in the hospital discharge and transfer process sometimes pushed SNF intake to occur late in the evening, after most other SNF staff had gone home for the day and shift change had occurred at the hospital. This scenario made it more difficult to call back to the hospital to secure necessary, potentially time-sensitive information. 
Finally, respondents from the SNFs explained challenges in accessing information generated after the time of hospital discharge. Sometimes, SNFs received patients discharged without a completed summary; the summary was then completed and sent via AllScripts 6 to 24 hours post-transfer. Once patients were in the care of the SNF, nurses and managers also noted difficulty in keeping track of pending consultations and appointments, as well as obtaining the documentation relevant to those visits. Respondents noted that it was important to know when the patient would be out of the facility, as it interfered with scheduling therapy sessions, and that receiving reports from these doctors' visits were important for updating nursing and therapy care plans.

\section{Using Portal-Enabled HIE to Address Information Discontinuity}

Despite shared perceptions of information challenges, the portal was implemented and used quite differently across the HIE-enabled SNFs. Differences in which staff actually used the system, and when it was used relative to the timing of transfer, drove organizational perceptions of the portal's utility and importance in the context of transitional care.

The portal appeared to play a meaningful role in supporting transitional care processes within two of the four facilities with access (SNFs C and D). The primary system users in these facilities were on-site nursing management staff, which enabled a wide variety of use cases. Facility D used the portal for every patient they received from the focal hospital; the portal was used primarily to facilitate retrieval of pertinent information that would help staff more proactively meet patient needs at the time of admission. The Director of Nursing described use as part of a systematized, organizational process for determining patients' risk level and 
establishing patient care plans, but only once the patient physically entered the facility. As she explained, "The portal is used as part of the process for [establishing a] general plan of care when the patient arrives. We get the LACE score [a calculated patient complexity score] and [patient] case details through the portal, so we can make sure that appropriate care conferences are being scheduled, and that physicians are getting in quickly to see the more critical patients." Though this information should be contained in the discharge summary, the printed summary was sometimes delayed in being completed and sent. And, the DON's portal access allowed her to carry out these planning processes in parallel with the admission nurse using the paper records to conduct initial assessment and intake.

In addition to this operationalized portal use, the DON at SNF D described additional situations that prompted additional ad-hoc portal use for about $25 \%$ of patients. This includes addressing two of the other established information gaps described above. First, she described using the system to access historical information not present in the paper discharge packet. This included examples such as seeking evidence of a history of fractures, as well as an abnormal lab result prompting searches for a more longitudinal record of lab values. Second, this facility emphasized how difficult the extensive paper records were to use, and noted use of the portal as an easier way to retrieve information technically available, but buried in the discharge documentation. When asked what prompted electronic information retrieval, the DON noted "The nurses will come to me if there's something questionable, and I'll do some research on it. For example, why does this patient have a hole in their belly? Is it from a laparoscopy? Did they have a feeding tube? I can do some digging... That information is probably in there [the discharge packet] 
somewhere. Often, though, I'll say "look, rather than you dig through 75 pages to try to find X piece of information, I'll just going to pull it up [through the portal]. It's much easier for me to just go in and scroll through to the [right] note."

Facility $\mathrm{C}$ had a similar approach to using the portal in terms of primary intent and user type, but differed in that they sometimes accessed patients' information prior to physical arrival to get a head-start on preparing to meet their care needs. The DON explained, "Often, the hospital will already have the patient's discharge info in their system before they get here. So, the nurse unit managers or I can go in and look at their discharge and make sure everything's ready for them in the room before they get here... do they need oxygen? What kind of tube feeding are they on? If they need isolation, we can make sure we have that auth[orization]. That makes for an easier transition for the patient...so that they're not in the room waiting while you're running around [preparing]." In addition to proactive care planning, respondents at SNF C also noted that they sometimes used the portal during the care transition period to access (1) a more historical informational perspective (with respect to labs and images), and (2) documentation generated from patient follow-up specialty appointments post-SNF admission.

The other two interviewed SNFs (A and B) reported portal availability as having a negligible effect on transitional care activity. Nursing management staff in these facilities had access to the portal, but rarely utilized it. Instead, the staff members that utilized the portal in these facilities had no direct patient care responsibilities within the SNF. One of the primary users was the hospital nurse liaison, the individual responsible for engaging and sharing information about the 
SNF with patients while they're still in the hospital. This use supported the referral process for patient SNF placement, complementing the admissions team's AllScripts-enabled communication with discharge planning staff. Nurse liaisons used the portal to view information regarding patients' condition complexity and care needs. This information was then communicated back to the SNF admissions team to help determine whether the facility was able to accept that patient. The other portal users in SNFs A and B were members of the Minimum Data Set (MDS) documentation team. These staff used the portal several days after SNF admission to gather needed patient information for reporting requirements under policies set by the Centers for Medicare and Medicaid Services and other payers.

\section{Barriers and Sociotechnical Challenges Affecting Integration of HIE in to Workflow}

SNFs A and B, who utilized the portal minimally to support transitional care workflows, experienced two key barriers not evident in the other facilities. First, these facilities cited a lack of any initial or ongoing training at the time portal access was made available as a key inhibitor of use. This led to confusion among designated users regarding how to navigate the system. As one Administrator from SNF B explained, "We're not familiar with it. We get in there and we're like “whoa, where do we go?"” The DON from this facility further elaborated, "I don't even remember my password [to log in to the portal]. I didn't have a training on it, so I don't have a clue how to operate it. I'm intimidated by it. We were originally pushing it, like "yeah we want access"... but then [never used it]."

The second challenge is that these organizations never established reliable workflows to leverage HIE capability responsively to the acute information needs of SNF staff with direct patient care 
responsibilities. Floor nurses at both of these facilities, when asked, saw value in on-demand electronic information retrieval. Yet, the widespread problem of high nurse staffing turnover at SNFs seemed to complicate efforts to secure access rights for these individuals. This created challenges in connecting access to need. The nurse liaisons who actively used the portal did so relatively far in advance of actual patient transition. Their role was to support SNF decisions about admission, rather than to assist floor nurses with addressing information challenges during care transitions. SNF A described an email handoff that sometimes took place between the liaison and SNF nurses conducting patient intake, but this asynchronous "push" style of communication couldn't accommodate real-time information needs as identified by those with direct care responsibility. Nursing management staff in these SNFs, in contrast, could have leveraged their portal access to more directly support transitional care processes. However, these individuals did not cognitively associate their access with the potential to play a role in bridging information gaps during handoff.

Two additional barriers to realizing value from portal use were identified that affected all facilities with access. First, both hospital and SNF respondents noted that handoff between facilities remained a very physician-centric process. This affected the nature and prioritization of information that was made available by hospitals; even with the portal, SNFs reported significant challenges in locating key nursing and social work documentation to seamlessly continue addressing patient needs within these domains. Hospital respondents confirmed that this information was made available summarily or not at all. Facilities continued to rely on the nurse- 
to-nurse handoff phone call as well as reports from their hospital nurse liaisons (who saw the patient in the hospital) to identify and prepare for patients in this regard.

The final barrier to use represents more of a convenient alternative to portal use rather than a limitation of the portal itself, but has significant implications for the quality of patient handoff during transitions. All facilities with the portal also had patient coverage through the sub-acute care practice of physicians employed by the focal hospital. Even the facility without portal access had patients discharged from the focal hospital seen by a hospital-owned family medicine practice. These physicians were responsible for post-hospital discharge care for patients in the SNF, and worked alongside the SNF nursing staff. The physician presence in the SNF created a parallel pathway in to the hospital's records, as these doctors completed their charting via full and direct access in to the hospital's EHR. Thus, rather than utilize the portal, SNF nurses noted that they often would ask an on-site doctor or advanced care practitioner (e.g. nurse practitioner, physician's assistant) to make inquiries in to patient records on their behalf. One administrator noted, "We hardly ever log in to [the portal] because the physician presence from the hospital here is so strong. They're here seven days a week. So, if we have a question, we prefer to just turn around and ask the physician here.” This facility, which didn't use the portal, relied on access through the sub-acute care team to address many of the information gaps for which the other facilities used the portal. However, even in facilities using the portal, the physician presence still provided an often-used workaround that lessened the need for true handoff between hospital providers and SNF staff. The DON at one of these facilities explained, "We always have a nurse practitioner or physician in the building. So, we don't necessarily have to go back and 
look at anything. They take over the case... [and], if the docs here have any questions about the case, things they need to do, they just communicate through the chart with the docs at the hospital. We don't have anything to do with it."

\section{$\underline{\text { Discussion }}$}

Hospitals and post-acute care providers such as skilled nursing facilities (SNFs) are actively seeking strategies to improve coordination and transitions of care, in response to escalating policy pressure to improve quality and manage total patient care costs. While the ability to share information electronically through various mechanisms of health information exchange (HIE) has demonstrated some benefits in other transitional care contexts, little is known about whether and how HIE can deliver value for transitions from hospital to post-acute care. Interviews with eighteen respondents across one focal hospital and five proximate SNFs that regularly receive this hospital's referrals reveal key areas of information discontinuity that create pressure points during post-acute care transitions. Understanding how existing workflows and processes both create and restrict opportunities for IT to facilitate coordination during these handoffs offers key insights in to how hospital-SNF HIE can be better designed and implemented to deliver real value during the transitional care process.

Only two of the four facilities with electronic portal access in to the hospital's EHR had active users within the SNF to support transitional care processes. These two facilities used the portal primarily to support more proactive care planning and efficient preparation for patient care needs. Notably, these facilities differed in their understanding of when the portal could be used 
to retrieve information. One facility derived utility in using the portal to access information before the patient entered the facility, while the other did not access information until the patient was present and admitted. To better support this particular use case, hospitals need to meet with SNFs and establish clear access guidelines that consider the nature and timing of informational needs for optimal care transitions. Further, hospital efforts to provide more accurate estimates of the timing of transfer - and for these transfers to happen earlier in the day - would facilitate more efficient SNF staff workflows for gathering and processing information needed to optimize patient intake processes. (29)

Importantly, there was no real difference in the types of information discontinuity experienced, nor significance of the challenges this discontinuity posed across facilities that did and did not use the portal. In the two facilities that did not use the portal to support transitional care, the lack of perceived usefulness stemmed from insufficient training as well as a workflow disconnect between individuals with portal access and those who were directly responsible for patient care post-discharge. Use by hospital nurse liaisons during the referral process for admissions provides some opportunity to glean pertinent information that would facilitate transitional care, but communication pathways to the admitting SNF floor nurses - if they occur at all - are diffuse, asynchronous, and one-way. From a strategic organizational perspective, establishing workflows that have nurse managers within the SNF using the portal to support patient intake processes provides more timely and responsive information retrieval that can meaningfully improve transitional care and associated outcomes. 
A key challenge affecting all SNFs was the extent to which hospital-to-SNF handoff remains a very physician-centric process. While this may make sense in other care transition contexts, nurses and social workers play a dominating role in SNF care delivery. SNFs rarely received the type of documentation that helped them provide an optimal patient experience from a nursing perspective in the SNF, nor proactively address social determinants of care that may prevent a safe discharge home. And, this information seemed to be either unavailable or extremely difficult to find even through the portal. Hospitals are understandably concerned about sharing information that may make certain patients difficult to place in to post-acute care settings. However, SNFs are still ultimately concerned with filling beds. And, increasing alignment and selective partnerships under new payment models create a disincentive for SNFs to engage in behavior that may jeopardize their preferred status. Policymakers could play a role in addressing this information gap by requiring key nursing and social work data elements in continuity of care documentation and summary of care records generated by certified EHRs. However, even in the absence of increased regulation, there's strategic imperative for hospitals to voluntarily make nursing and social work documentation available. Inadequately representing a patient's complete medical and social complexity may create a mismatch between a SNF's capabilities and patient needs, increasing risk of re-hospitalization. (30)

Finally, changing healthcare dynamics have dramatically altered how post-acute care is delivered. Patients in SNFs are increasingly cared for by sub-acute physicians employed by the 
discharging health system and who work almost exclusively within the SNF setting (i.e. "SNFists"). (31) While this integration appears to have significant benefits to care coordination and associated outcomes $(32,33)$, little attention has been paid to how this shift may impact handoff processes and continuity of information from the perspective of SNF nursing staff and management. Increased SNF staff reliance on hospital-employed providers and their direct access to hospital records to retrieve needed information lessens motivation to address systemic issues of information discontinuity across these settings. SNF staff are still experts in managing the interdependent physical, social, and behavioral health needs of their patients, and play a major role in the care and rehabilitation of patients. (34) Under new inter-organizational models of post-acute care, health systems need to think critically about how to maintain organization-toorganization handoffs alongside physician-focused transition processes. These delivery system changes otherwise risk compromising the ability of non-physician SNF providers to deliver timely and effective care with sufficient autonomy and workflow efficiency.

There are two main limitations to this study. First, I did not directly observe any SNF providers' admissions workflows, nor use the portal to retrieve patient information. By relying only on providers' self-report of individual and/or facility usage, we can't objectively confirm the frequency with which different types of information discontinuity arose, or the extent to which portal use maps to each of these areas of need. We attempted to address this issue by conducting SNF interviews in groups, allowing multiple respondents within an organization to discuss any areas of disagreement with respect to common processes and challenges. We also probed 
respondents to think about each identified challenge relative to others experienced, to discern a relative ranking of salient challenges and use strategies.

Second, we conducted a narrow set of interviews with just one large academic medical center and a subset of SNFs in the same local community. Though we attempted to interview SNFs with varying levels of affiliation with the hospital, data collection and subsequent analysis are skewed towards understanding transitional care processes between a hospital and SNFs that are closely aligned. Relatedly, the focal hospital has tremendous market power and advanced resources to support post-acute transitions outside of HIE capabilities - such as its embedded care managers and employed group of sub-acute care physicians - which many hospitals across the country do not have. While this limits generalizability, the analytic depth of this type of data collection facilitates key insights and hypotheses regarding how organizations can leverage a sociotechnical understanding of post-acute care transitions to improve processes and outcomes.

\section{$\underline{\text { Conclusion }}$}

Improving post-acute transitions of care between hospitals and skilled nursing facilities is critical to advancing patient care quality, safety, and value. This study identifies key dimensions of information discontinuity affecting hospital-to-SNF transitions, and explores the opportunities and challenges of using portal-enabled HIE to address these issues. Translating HIE investment in this context in to meaningful changes in care delivery requires addressing the interdependent nature of social and technical systems that support patient care. Modifications to system design and information accessibility, complemented by thoughtful restructuring of enabling 
organizational workflows within and across settings, are both critical to helping hospitals and SNFs improve coordination and patient experience. 


\section{$\underline{\text { Works Cited }}$}

1. Coleman EA, Berenson RA. Lost in transition: challenges and opportunities for improving the quality of transitional care. Annals of internal medicine. 2004;141(7):533-6.

2. Boockvar K, Vladeck BC. Improving the quality of transitional care for persons with complex care needs. Journal of the American Geriatrics society. 2004;52(5):855-6.

3. Tian W. An All-Payer View of Hospital Discharge to Postacute Care, 2013. Agency for Healthcare Research and Quality, Healthcare Cost and Utilization Project; May 2016.

4. Liu K, Garrett B, Eilertsen T, Epstein A, Long S, Kramer A, et al. Options for improving Medicare payment for skilled nursing facilities. Urban Institute; 2007.

5. Naylor MD, Brooten DA, Campbell RL, Maislin G, McCauley KM, Schwartz JS. Transitional care of older adults hospitalized with heart failure: a randomized, controlled trial. Journal of the American Geriatrics Society. 2004;52(5):675-84.

6. Murray LM, Laditka SB. Care transitions by older adults from nursing homes to hospitals: Implications for long-term care practice, geriatrics education, and research. Journal of the American Medical Directors Association. 2010;11(4):231-8.

7. Mor V, Intrator O, Feng Z, Grabowski DC. The revolving door of rehospitalization from skilled nursing facilities. Health Affairs. 2010;29(1):57-64.

8. Kind AJ, Smith MA, Frytak JR, Finch MD. Bouncing back: patterns and predictors of complicated transitions 30 days after hospitalization for acute ischemic stroke. Journal of the American Geriatrics Society. 2007;55(3):365-73.

9. Georgiou A, Marks A, Braithwaite J, Westbrook JI. Gaps, disconnections, and discontinuities - the role of information exchange in the delivery of quality long-term care. The Gerontologist. 2013;53(5):770-9.

10. Tjia J, Bonner A, Briesacher BA, McGee S, Terrill E, Miller K. Medication discrepancies upon hospital to skilled nursing facility transitions. Journal of general internal medicine. 2009;24(5):630-5.

11. King BJ, Gilmore-Bykovskyi AL, Roiland RA, Polnaszek BE, Bowers BJ, Kind AJ. The consequences of poor communication during transitions from hospital to skilled nursing facility: a qualitative study. Journal of the American Geriatrics Society. 2013;61(7):1095102.

12. Gurwitz JH, Field TS, Avorn J, McCormick D, Jain S, Eckler M, et al. Incidence and preventability of adverse drug events in nursing homes. The American journal of medicine. 2000;109(2):87-94.

13. Gaskin S, Georgiou A, Barton D, Westbrook J. Examining the role of information exchange in residential aged care work practices-a survey of residential aged care facilities. BMC geriatrics. 2012;12(1):1.

14. Shah F, Burack O, Boockvar KS. Perceived barriers to communication between hospital and nursing home at time of patient transfer. Journal of the American Medical Directors Association. 2010;11(4):239-45.

15. LaMantia MA, Scheunemann LP, Viera AJ, Busby-Whitehead J, Hanson LC. Interventions to improve transitional care between nursing homes and hospitals: a systematic review. Journal of the American Geriatrics Society. 2010;58(4):777-82. 
16. Popejoy L, Galambos C, Vogelsmeier A. Hospital to nursing home transition challenges: Perceptions of nursing home staff. Journal of nursing care quality. 2014;29(2):103-9.

17. Jack BW, Chetty VK, Anthony D, Greenwald JL, Sanchez GM, Johnson AE, et al. A reengineered hospital discharge program to decrease rehospitalization: a randomized trial. Annals of internal medicine. 2009;150(3):178-87.

18. Schoenborn NL, Arbaje AI, Eubank KJ, Maynor K, Carrese JA. Clinician roles and responsibilities during care transitions of older adults. Journal of the American Geriatrics Society. 2013;61(2):231-6.

19. Cross DA, Adler-Milstein J. Investing in Post-Acute Care Transitions: Electronic Information Exchange Between Hospitals and Long-Term Care Facilities. Journal of the American Medical Directors Association. 2016.

20. Alexander G, Rantz M, Galambos C, Vogelsmeier A, Flesner M, Popejoy L, et al. Preparing Nursing Homes for the Future of Health Information Exchange. Appl Clin Inform. 2015;6(2):248-66.

21. Harrison MI, Koppel R, Bar-Lev S. Unintended consequences of information technologies in health care - an interactive sociotechnical analysis. Journal of the American medical informatics Association. 2007;14(5):542-9.

22. Sittig DF, Singh H. A new sociotechnical model for studying health information technology in complex adaptive healthcare systems. Quality and Safety in Health Care. 2010;19(Suppl 3):i68-i74.

23. Kools S, McCarthy M, Durham R, Robrecht L. Dimensional analysis: Broadening the conception of grounded theory. Qualitative Health Research. 1996;6(3):312-30.

24. Bowers B, Schatzman L. Dimensional analysis. Developing grounded theory: The second generation. 2009:86-126.

25. Boeije H. A purposeful approach to the constant comparative method in the analysis of qualitative interviews. Quality and quantity. 2002;36(4):391-409.

26. Miles MB, Huberman AM. Qualitative data analysis: An expanded sourcebook: sage; 1994.

27. Feldman MS. Strategies for interpreting qualitative data: Sage; 1995.

28. Booth A, Carroll C, Ilott I, Low LL, Cooper K. Desperately seeking dissonance: identifying the disconfirming case in qualitative evidence synthesis. Qualitative health research. 2013;23(1):126-41.

29. Goins Jr TW. Transitions to and from nursing facilities. North Carolina medical journal. 2012;73(1):51.

30. Clark B, Baron K, Tynan-McKiernan K, Britton M, Minges K, Chaudhry S. Perspectives of Clinicians at Skilled Nursing Facilities on 30-Day Hospital Readmissions: A Qualitative Study. Journal of hospital medicine. 2017;12(8):632-8.

31. Teno JM, Gozalo PL, Trivedi AN, Mitchell SL, Bunker JN, Mor V. Temporal trends in the numbers of skilled nursing facility specialists from 2007 through 2014. JAMA internal medicine. 2017;177(9):1376-8.

32. Katz PR, Karuza J, Lima J, Intrator O. Nursing home medical staff organization: Correlates with quality indicators. Journal of the American Medical Directors Association. 2011;12(9):655-9. 
33. Lima JC, Intrator O, Karuza J, Wetle T, Mor V, Katz P. Nursing home medical staff organization and 30-day rehospitalizations. Journal of the American Medical Directors Association. 2012;13(6):552-7.

34. Harrington C, Carrillo H, Garfield R, Squires E. Nursing Facilities, Staffing, Residents and Facility Deficiencies, 2009 Through 2016. Henry J Kaiser Family Foundation; 2018. 


\section{Conclusion}

High rates of readmission for patients discharged to a skilled nursing facility (SNFs) following hospitalization suggest critical deficits in the quality and safety of these transitions. Weak information sharing processes are a key challenge plaguing effective coordination during handoff; resulting information discontinuity makes it difficult for SNF providers to seamlessly and effectively continue addressing a patient's total care needs in the post-acute care (PAC) setting. Healthcare organizations looking to strengthen post-acute transitional care processes are actively experimenting to see whether and how strategies used to strengthen continuity of care in other contexts (i.e. hospital to hospital transitions, or hospital to primary care) can be adapted for this purpose. Key among these strategies is investing in health information exchange (HIE) to promote electronic sharing and retrieval of patient information. Evidence to-date on whether HIE improves outcomes associated with transitional care, such as near-term, avoidable rehospitalizations, is not particularly robust, but is considered to have great potential. For HIE to meaningfully change care delivery, systems must be designed to deliver sufficient value such that it promotes implementation, and implemented with the appropriate supporting workflows to facilitate consistent and effective use. We have, at best, sparse knowledge regarding how to go about this type of intentional investment in the post-acute transition context. 
This body of work takes a multi-pronged approach to generating new evidence that supports meaningful use of HIE for post-acute transitions of care. Chapter 1 establishes the landscape, and is the first published analysis that uses hospital survey data to estimate the national prevalence of hospital engagement in HIE with long term and post-acute providers of care. More importantly, this analysis is also the first of its kind to identify key organizational factors associated with whether hospitals have chosen to invest in this type of HIE. Findings show that measures of a hospital's overall level of IT investment and sophistication (i.e. Meaningful Use attestation status, strength of HIE activity in other transitional care contexts) most strongly predict whether hospitals engage in HIE with post-acute providers. While this suggests a "rising tide lifts all ships" dynamic, with hospital-PAC HIE occurring perhaps more incidentally than strategically, we do find some evidence that hospitals engaged in other payment and delivery reform efforts to strengthen ties to post-acute providers are also reporting HIE activity in this context.

Any continued organizational investment in HIE infrastructure with PAC, and policymakers' strategy to facilitate these efforts, requires an evidence base for whether and how use of these systems actually improves transitional care and patient outcomes. Even more so than evaluations of HIE in other contexts (hospital-to-hospital, hospital-to-primary care), it remains an open question whether the lack of normative integration between hospitals and PAC settings such as skilled nursing facilities (SNFs) can be overcome by these system-level functional changes. But, teasing out changes in patient outcomes directly attributable to IT implementation is difficult, given a constantly shifting policy landscape and numerous other delivery system changes occurring in the same timeframe. I therefore first used a local natural experiment to identify and 
directly attribute changes in patient outcomes to IT implementation, created by the selective implementation of portal-enabled HIE between one focal hospital and chosen local SNF partners in the community. A difference in differences analysis comparing facilities that did and did not have HIE capabilities found no evidence of relative improvement in likelihood of readmission for patients discharged from the focal hospital to HIE-enabled SNFs.

This research design did not, however, allow me to delve in to whether and how the available portal functionality was actually utilized for any particular patient. Providing useful guidance to providers that seek to leverage electronic information sharing as a tool for improved continuity and coordination requires a focused analysis of how IT capabilities interact with existing complex "people processes" (i.e. roles, workflows, organizational structures and norms) that shape transitional care. Using a mixed methods approach, I thus sought to identify sociotechnical drivers and consequences of variation in use of HIE functionalities, and synthesize strategies for removing barriers to achieving optimal value. $(1,2)$

Quantitatively, we combined our patient-level hospital admission and discharge records with novel audited log file data maintained by the hospital that captures every information retrieval action taken by a SNF provider through this portal. This type of data, though not initially generated for research purposes, is starting to be used more to enable health IT workflow analysis and information seeking behavior. $(3,4)$ We analyzed this data and then conducted indepth qualitative interviews with the focal hospital and five local SNFs (three of which were the original facilities in which HIE was implemented) to validate, refine, or synthesize evidence 
contrary to insights generated by our quantitative analyses. More broadly, the purpose of the qualitative data collection was to contextualize our knowledge of how HIE was being utilized by understanding the dimensions of information discontinuity that created transitional care pressure points, and key sociotechnical facilitators and barriers to using HIE to address these challenges.

Log-file analysis reveals that portal-enabled HIE was utilized for fewer than half of all patients for whom it was available. If we only look at use within the transition window of care -48 hours before transfer and up to 72 hours after - HIE was used less than $30 \%$ of the time. The portal was less likely to be utilized for patients of greater medical complexity. This finding was somewhat counter-intuitive, as we expected sicker patients would generate more informational needs for care planning and medical decision-making. This was confirmed in SNF interviews, as nurses and administrators described using the system more often to retrieve special care instructions for medically complex patients, such as those with tracheostomies or feeding tubes, or those on ventilators. However, interviews also revealed that these patients were seen more quickly and more intensively by the on-site sub-acute physicians employed by the focal hospital. This physician presence resulted in SNF staff often bypassing the view-only portal in favor of asking physicians to retrieve needed information through their direct access in to the hospital EHR system. Thus, SNF staff may unintentionally have created a dual workflow that favors portal use for more straightforward patient cases and physician-mediated information retrieval for those who are more complex. 
The unintended consequences of these parallel processes - physician to physician handoff taking place alongside organization to organization handoff - has been under-considered. Though hospital-employed physician presence in the SNF is generally considered beneficial for care continuity, robust handoff processes directly to SNF nursing staff and management are still critical to establish and maintain a care plan, especially as it relates to the nursing, therapy and social determinant aspects of care. Value-based payment initiatives and rehospitalization penalties outlined under the Under the 2014 Protecting Access to Medicare Act, which will affect both hospitals and SNFs, are currently scheduled to go in to effect in 2019. These regulations place greater pressure on providers to think critically about how to maintain and enhance the ability of non-physician SNF providers to deliver timely and effective care with sufficient autonomy and workflow efficiency.

A second key observation from the log-file analysis was that portal use was more likely following discharge situations where hospital workflows supporting transitional care may deviate from standard practices, such as discharge from the ED or an observational bed rather than an inpatient unit. SNF respondents did not discuss this particular situation, but did confirm more broadly that HIE was used to address issues of information being missing or delayed through other standard transitional care processes (i.e. the paper discharge packet, or a nurse handoff call). Using HIE to address situations with heightened information discontinuity, however, requires a SNF environment with aligned and enabling workflows to facilitate its use on the receiving end of transitional care. For example, we find reduced likelihood of HIE use by SNFs when patients are discharged on the weekend, suggesting that use is driven by management and 
perhaps other ancillary team members that are typically only present during normal business hours. Indeed, SNF nurses explained that HIE access was restricted to those in management positions, and admissions on nights and weekends were more difficult because these individuals were not there to help with information retrieval that could facilitate intake processes. Understanding this interdependency between social and technical processes of care will be critical to guiding organizational implementation practices and use cases that meaningfully improve care delivery practices.

Finally, we used the log file data to generate insights regarding how variation in HIE usage patterns was associated with likelihood of patient readmission, our outcome indicator for the quality of transitional care. Specifically we looked at the timing of portal use (relative to the time of transfer) as well as intensity (the depth and volume of information retrieved). We found evidence in one of the three facilities that retrieving more information during the transition window of care was associated with a reduced likelihood of readmission. Only by pairing this finding with qualitative data were we able to hypothesize why this facility may have achieved benefits from HIE implementation, but not the other two facilities. We find again that who utilized the HIE system drives much of the variation in perceived utility for supporting transitional care. In the other two facilities, the portal was used by staff with minimal responsibility for transitional care, and had little communication with those who did. Only the facility that had HIE use associated with improved outcomes had workflows established for onsite nurse management staff to support patient intake processes with timely information retrieval responsive to the needs of those with direct patient care responsibilities. 
Two additional themes emerged only from the qualitative data that merit further consideration. First, SNFs perceived the primary value from HIE access to be the ability to access information in a more timely way, to be more proactive in preparing to meet patient care needs. For some facilities, this meant accessing information through the portal in advance of receiving the patient. For others, there was too much uncertainty regarding access policies and they only used the system once a patient entered the facility. To better support this particular use case, hospitals need to meet with SNFs and establish clear access guidelines that consider the nature and timing of informational needs for optimal care transitions. The second issue concerns the withholding of information from SNFs regarding social history and determinants such as nature of family support or food and housing security, as well as behavioral risk factors. Hospitals were hesitant to share this information - typically contained in nursing notes and social work documentation out of concern that it would risk ability to place a patient in post-acute care. This concern has been identified and discussed in prior research. (5-7) SNF staff felt hamstrung in their ability to effectively continue care from a nursing and social services perspective when they received a patient, and were unnecessarily delayed in their efforts to work towards a timely discharge of the patient home following SNF care. As delivery and payment reforms continue to emphasize provider risk for the total episode of care, these issues will become increasingly salient to healthcare organizations. Strategically, hospitals will need to reconsider the risks of short-term decisions about information withholding potentially leading to significant downstream cost implications. 


\section{$\underline{\text { Strength of Methodological Approach }}$}

Taken together, this combination of log file analysis and in-depth qualitative inquiry provides unprecedented insight in to how HIE is, can, and perhaps should be used to support post-acute transitions of care. This analysis distinguishes itself methodologically in its use of mixed methods. Use of mixed methods in formative and evaluative health services research is a strong and steadily growing trend (8), but mixed methods in the domain of health IT research has been undervalued (9) and relatively sparse. (10-12) Combining the complementary analyses described above helps mitigate the primary limitations of each data source. Qualitative interviews rely on self-report of respondent behavior regarding what they do with HIE, and when/how they do it. This recall and reporting is prone to both intentional and unintentional misremembering (13); audited records that capture actual behavior help validate and/or correct for inaccurate reporting of activity. On the other side, analysis of the log files provides minimal information regarding the context in which HIE is used, such as aspects of the organizational environment that might facilitate/hinder use, as well as the nature, range, and frequency of specific information needs that prompt use. It is also extremely difficult to extract some meaningful understanding of the value delivered by HIE use. Readmissions is a downstream, noisy signal of care quality. Qualitative description of how processes have changed, and/or perceived changes in patient safety and quality, are important tools with which to also understand the impact of HIE implementation. 


\section{$\underline{\text { Implications for Policymakers }}$}

Policy efforts to strengthen hospital-PAC relationships - for example, the Medicare Readmissions Reduction program as well as updates to the SNF Value-Based Prospective Payment System - are encouraging these organizations to work together in unprecedented ways. However, payment reforms that reward or penalize provider systems based on downstream outcomes sensitive to care coordination and care transitions are insufficient to drive improvement. Organizations need not only a realignment of financial incentives, but guidance on building and effectively using tools tailored to the specific information needs during post-acute transitions of care.

Findings from this work strongly suggest that, to the extent that electronic information sharing is currently occurring between hospitals and PAC providers, it is likely an extension of existing HIE functions already being used in other transitional care contexts. Integrating care processes among organizations with institutional structures, cultures, and care goals as distinct as what we see in the post-acute transition context is challenging. These changes require more customized information sharing tools to build shared understanding across settings and reshape not only the functional but the normative aspects of these transitions. As we hypothesize in the introduction, hospitals are likely to select mechanisms for information sharing that minimize the organizational burden of implementation. Use of a portal, as we explore in Chapter 3, required no changes by hospital providers to documentation or discharge practices in ways that could have made information available to the SNF more customized to their specific needs. Consequently, this IT-based solution to improve transitions had less perceived value among SNF 
providers and was not used consistently and as intended to support transitional care practices. Targeted legislation to address, and possibly provide incentives for capital investment in, PACspecific information sharing design and infrastructure could significantly help to advance this activity. This would require a push first on major EHR vendor organizations and hospital users to develop more flexible information sharing platforms and interfaces that meets provider informational needs beyond the acute care setting. In addition, recently proposed legislation that establishes financial incentives for EHR adoption among behavioral health providers - key providers who, like PAC organizations, were excluded from Meaningful Use -suggests that perhaps PAC providers also need more direct investment to get their clinical EHR capabilities to a level where interoperability with acute care providers could be possible. (15)

We also found significant evidence to support our second hypothesis regarding the difficulty of SNF providers' feeling motivated to, and finding effective strategies for, integrating HIE use in to transitional and post-acute care processes. Each organization interviewed had different conceptions of when and how information sharing platforms should be used, who within the organization should be involved in these workflows, and ultimately what the value of HIE currently is and could be in the future. Policymakers could consider seeding a relatively small amount of money to build or appoint a central organization that could support the operation of local hospital-PAC collaboratives as a setting in which providers could discuss, learn from, and reconcile these differing views. These collaboratives, already prevalent across the country, could benefit substantially from a national platform that provides tools and technical assistance for HIE-based challenges, fostering the development of shared solutions to improve the use of IT in 
addressing post-acute care transition challenges. These collaboratives also provide an avenue through which to promote and support more inclusive community-based information sharing practices (rather than selective, proprietary partnerships) to avoid creating or worsening quality and outcome disparities among providers within a local market.

Hospitals and SNFs are currently limited in their ability to improve the complex sociotechnical systems in place to support PAC transitions. For the hospital, clear roadblocks that emerged from these analyses were rooted in the lack of feedback regarding system interdependencies that extended beyond organizational walls. Hospital administrators and IT support teams, let alone individual hospital providers, had almost no understanding of what occurred on the SNF side of PAC transitions. There was little knowledge of (1) what information SNFs really needed to improve perceptions of discontinuity, (2) how available technology was actually being used by SNFs, or (3) the causal relationships between hospital documentation/discharge planning practices and perceived value of HIE among SNFs to meaningfully improve care. SNF leadership and staff also lacked the bandwidth and enabling tools to reflect organizationally on current and potential HIE use practices, and the relevant situational modifiers of that use. Continued government support of healthcare organizations becoming learning health systems (LHS) provides a promising avenue through which to help hospital and SNF providers work together to build more intentional and data-driven HIE use practices, emphasizing an integrated systems of care perspective. A robust LHS infrastructure can capture and use the massive amounts of data generated by healthcare delivery processes to generate new insights regarding how to provide healthcare that is safer, more effective, and more efficient. Though policymaker 
support for LHS models is already well underway, this research highlights the need for agencies responsible for grant-making and programmatic support of these initiatives to emphasize learning opportunities not only from clinical data warehousing (i.e. pulling and analyzing all treatment plans and outcomes for patients with a particular form of cancer), but also from use of EHR metadata. By analyzing audited HIE use log files in this research, novel knowledge emerged regarding when, for whom, and how the technology portal was utilized for patient care delivery. Organizations would benefit substantially from understanding these use patterns, and leveraging this knowledge to build better tools and workflows that encourage technology use in ways and situations that are most valuable. In the context of PAC transitions, this presents a unique opportunity to bring hospitals and SNFs together to work on coordination and integrated care practices. Policymakers are best positioned to support research regarding optimal approaches for how this data needs to be collected, aggregated, stored, and harnessed for research and practice. Further, as evidence emerges from existing LHS organizations regarding opportunities for improving IT use in context - examples of usage patterns and workflows that seem to enhance transitional care practices - policymakers may want to consider a platform for sharing and promoting these insights among other healthcare organizations.

\section{$\underline{\text { Implications from Providers }}$}

For both hospitals and PAC providers, using a sociotechnical framework to guide implementation and use of information sharing systems - that is, thinking intentionally about the integration of new technical capabilities with existing "people" processes - can help maximize the value of IT investment. This research underscores the need for providers on both sides of 
post-acute transitions to establish regular meetings - either as part of a LHS initiative or more informally - where they can discuss needs, challenges, and opportunities to improve care practices in a collaborative way. These conversations should include, at a minimum from both care settings: administrators for demonstration of leadership buy-in, clinical representation, and IT personnel to determine feasibility of proposed changes. To begin addressing the functional limitations and normative pressures impeding care integration, these local partnerships should focus on establishing guidelines in the following key domains:

\section{Informational Needs and Usability: PAC providers need a way to communicate to hospitals} the specific aspects of patient information relevant to establishing a continuing care plan in the post-acute setting, and ideas for how that information can best be conveyed. Providers should discuss strategies for enhancing the visibility and usefulness of information already contained within discharge documentation (i.e. availability of tools for filtering, highlighting, customization, etc.). These conversations should also broach expanding informational breadth either by relaxing restrictions (i.e. to social work notes) or adding new informational fields in the acute care setting that would be helpful for facilitating transitional and post-acute care.

2. Information Accessibility: Significant variability was observed across interviewed SNFs with respect to when information was or could be accessed via the portal, and who was doing most of the information retrieval. SNFs could benefit from hearing about the workflows and use cases used in other PAC settings, including strategies for integrating information retrieval across admissions and clinical patient intake units and defining management responsibilities for addressing informational needs and gaps. These meetings also provide an opportunity for input from the hospital regarding intended and appropriate information access practices. 
3. Feedback Loops: To facilitate conversations regarding ongoing improvement, all participating organizations should consider establishment of shared goals and associated relevant metrics for use of the portal or other information sharing initiatives. Articulating these goals, and implementing ways of tracking use and progress towards these established metrics, helps to develop "same team" ideology, maintain change momentum, and promote continued intentionality regarding use of available IT tools within the broader context of transitional care processes.

\section{Limitations and Opportunities for Future Work}

The strengths of these analyses are countered by critical limitations that create opportunity for further research advancements. First, the data we relied on in Chapter 1 to estimate prevalence of HIE between hospitals and PAC providers is relatively superficial. Health IT survey questions generally tend to be binary indicators of whether systems are available and/or reported to be in use; this gives no indication of the nature of or perceived value derived from use. In the context of electronic information exchange, we lack information at the national level regarding the total number and specific PAC partners with whom a hospital exchanges information as well as the types of information being exchanged. Collecting this information is critical if we are to understand and evaluate effects of HIE to support post-acute transitions of care at the national level.

Second, the small number of organizations included in our mixed methods analysis challenges generalizability. We are also unable to robustly explore variation due to factors at the dyadic 
level (i.e. percent of hospital discharges going to a particular SNF as a percent of total referrals) that affect HIE usage patterns and potentially impact on patient care. Scaling up this type of logfile analysis to the level of HIE operating at a regional level would enable more robust multilevel modeling, where we could partition and explore drivers of variation within a more nested data model (patients within organizational dyads within markets). This expansion would also potentially enable evaluation of more sophisticated forms of HIE. The portal-enabled HIE in our analysis was unidirectional (hospital to SNF) and view-only sharing, with no aspects of robust search or integration aspects of interoperability. (14) Only by assembling and comparing analyses of different types of HIE will we be able to assess the relative value of different IT capabilities and inform sound investment strategies for provider organizations as well as the policymakers trying to support these efforts.

Finally, the hypotheses generated by this mixed methods analysis create exciting opportunity to engage in embedded, interventional work that blends research and practice. The HIE use cases we've identified, and in-depth knowledge of the sociotechnical facilitators and barriers to optimal usage practices, should be of great interest to existing collaboratives of hospitals and SNFs working together to improve coordination. And, there is significant need on the evaluative side for development of alternative measures of HIE impact, as well as prospective research design that enables causal inference. Policymakers and federal agencies are increasingly focused on supporting translational research that integrates newly acquired knowledge in to everyday practice. By working with providers to inform and support their organizational redesign efforts, 
and embedding an evaluative research component, we can create novel research-practice partnerships that advance this goal.

\section{Conclusion}

Addressing information discontinuity between hospitals and skilled nursing facilities (SNFs) is essential to improving post-acute transitions of care and associated patient outcomes. Electronic health information exchange (HIE) is perceived to have great potential to facilitate information sharing, but requires a much better understanding of what motivates investment in HIE to support post-acute transitions, as well as specific challenges and opportunities in using HIE to meaningfully change transitional care processes from an integrated sociotechnical perspective. Using a mixed-methods approach, I contribute important new knowledge regarding how HIE can be implemented and used to meaningfully effect change in care delivery. I also identify critical areas for further research that can generate further insights to help stakeholders in system design (i.e. IT vendors), payment policy, and healthcare delivery systems pursue strategies that maximize the value of investment in HIE capabilities. Having integrated tools and processes that promote information continuity will be critical moving forward in determining chances for success in the numerous finance and delivery reforms aimed at improving the quality, safety, and value of post-acute patient care. 


\section{$\underline{\text { Works Cited }}$}

1. Sittig DF, Singh H. A new sociotechnical model for studying health information technology in complex adaptive healthcare systems. BMJ Quality \& Safety. 2010;19(Suppl 3):i68-i74.

2. Harrison MI, Koppel R, Bar-Lev S. Unintended consequences of information technologies in health care - an interactive sociotechnical analysis. Journal of the American medical informatics Association. 2007;14(5):542-9.

3. Hirsch AG, Jones JB, Lerch VR, Tang X, Berger A, Clark DN, et al. The electronic health record audit file: the patient is waiting. Journal of the American Medical Informatics Association. 2016;24(e1):e28-e34.

4. Hribar MR, Read-Brown S, Goldstein IH, Reznick LG, Lombardi L, Parikh M, et al. Secondary use of electronic health record data for clinical workflow analysis. Journal of the American Medical Informatics Association. 2017;25(1):40-6.

5. King BJ, Gilmore-Bykovskyi AL, Roiland RA, Polnaszek BE, Bowers BJ, Kind AJ. The consequences of poor communication during transitions from hospital to skilled nursing facility: a qualitative study. Journal of the American Geriatrics Society. 2013;61(7):1095102.

6. Clark B, Baron K, Tynan-McKiernan K, Britton M, Minges K, Chaudhry S. Perspectives of Clinicians at Skilled Nursing Facilities on 30-Day Hospital Readmissions: A Qualitative Study. Journal of hospital medicine. 2017;12(8):632-8.

7. Shah F, Burack O, Boockvar KS. Perceived barriers to communication between hospital and nursing home at time of patient transfer. Journal of the American Medical Directors Association. 2010;11(4):239-45.

8. Plano Clark VL. The adoption and practice of mixed methods: US trends in federally funded health-related research. Qualitative Inquiry. 2010;16(6):428-40.

9. Goldzweig CL, Towfigh A, Maglione M, Shekelle PG. Costs and benefits of health information technology: new trends from the literature. Health affairs. 2009;28(2):w282w93.

10. Cross DA, Cohen GR, Nong P, Day A-V, Vibbert D, Naraharisetti R, et al. Improving EHR capabilities to facilitate stage 3 meaningful use care coordination criteria. AMIA Annual Symposium Proceedings, 2015. American Medical Informatics Association: 448.

11. Ash JS, Sittig DF, Dykstra R, Campbell E, Guappone K. The unintended consequences of computerized provider order entry: findings from a mixed methods exploration. International journal of medical informatics. 2009;78:S69-S76.

12. Krist AH, Woolf SH, Bello GA, Sabo RT, Longo DR, Kashiri P, et al. Engaging primary care patients to use a patient-centered personal health record. The Annals of Family Medicine. 2014;12(5):418-26.

13. Feldman MS. Strategies for interpreting qualitative data: Sage; 1995.

14. Holmgren AJ, Patel V, Charles D, Adler-Milstein J. US hospital engagement in core domains of interoperability. Am J Manag Care. 2016;22(12):e395-402.

15. Improving Access to Behavioral Health Information Technology Act, S. 1732, 115th Cong. (2017-2018). 


\section{Appendix A: Chapter 1}

Table A.1: Comparison of Sample Characteristics, Analytic Sample $(\mathrm{N}=1,981)$ compared to 2014 AHA Annual Survey Sample who did not respond to the IT Supplement $(\mathrm{N}=2,478)$

\begin{tabular}{|llll|}
\hline Characteristic & $\begin{array}{l}\text { Non- } \\
\text { Respondents }\end{array}$ & Respondents & P-value \\
\hline All & 55.6 & 44.4 & $<0.001$ \\
\hline Hospital size & 55.6 & 44.7 & \\
\hline $100-399$ & 38.1 & 41.4 & \\
$400+$ & 6.3 & 13.9 & $<0.001$ \\
\hline Teaching status & & & \\
Major & 3.6 & 7.8 & \\
Minor & 20.0 & 25.2 & \\
Nonteaching & 76.4 & 67.0 & \\
\hline Ownership & 25.8 & 10.3 & \\
\hline For profit & 51.5 & 67.6 & \\
Not for profit & 22.7 & 22.1 & \\
Public (state only) & & & \\
\hline Location & 56.4 & 58.8 & \\
\hline Urban & 43.6 & 41.2 & \\
Rural & & & \\
\hline Region & 11.9 & 13.2 & \\
\hline Northeast & 24.3 & 36.8 & \\
Midwest & 42.2 & 34.0 & \\
South & 21.7 & 16.0 & \\
West & 29.1 & 25.4 & \\
\hline Critical-access status & & 74.6 & \\
Yes & 70.9 & & \\
No & & & \\
\hline
\end{tabular}




\section{Appendix B: Chapter 2}

Table B.1: Patient Drivers of ECL Use within the Transition Window (Bivariate Analyses)

\begin{tabular}{|c|c|c|c|c|c|}
\hline & \multicolumn{2}{|c|}{$\begin{array}{l}\text { First ECL Use- During } \\
\text { Transition-Window } \\
\text { N }=1,585\end{array}$} & \multicolumn{2}{|c|}{$\begin{array}{l}\text { First ECL Use- After } \\
\text { Transition Window } \\
\text { N=940 }\end{array}$} & $\begin{array}{c}\text { T-test } \\
\text { difference } \\
\text { in means } \\
\text { (P-value) }\end{array}$ \\
\hline \multicolumn{6}{|c|}{ Context Factors } \\
\hline Weekend discharge & \multicolumn{2}{|c|}{$8.6 \%$} & \multicolumn{2}{|c|}{$16.7 \%$} & $<0.001$ \\
\hline $\begin{array}{l}\text { Patients that are new } \\
\text { (rather than returning) } \\
\text { SNF residents }\end{array}$ & \multicolumn{2}{|c|}{$86.8 \%$} & \multicolumn{2}{|c|}{$92.8 \%$} & 0.001 \\
\hline $\begin{array}{l}\text { Patients admitted to } \\
\text { SNF following ED or } \\
\text { observational stay only }\end{array}$ & \multicolumn{2}{|c|}{$11.9 \%$} & \multicolumn{2}{|c|}{$13.3 \%$} & 0.312 \\
\hline \multicolumn{6}{|c|}{ Complexity Factors } \\
\hline Age at discharge & \multicolumn{2}{|c|}{$68.3(13.9)$} & \multicolumn{2}{|c|}{$73.7(13.9)$} & $<0.001$ \\
\hline Gender & \multicolumn{2}{|c|}{$47.7 \%$} & \multicolumn{2}{|c|}{$42.3 \%$} & 0.009 \\
\hline Non-white race & \multicolumn{2}{|c|}{$21.9 \%$} & \multicolumn{2}{|c|}{$20.1 \%$} & 0.289 \\
\hline Length of stay (days) & \multicolumn{2}{|c|}{$9.2(8.9)$} & \multicolumn{2}{|c|}{$8.0(8.0)$} & 0.001 \\
\hline $\begin{array}{l}\text { Number of conditions } \\
\text { on current problem list }\end{array}$ & \multicolumn{2}{|c|}{$19.9(9.0)$} & \multicolumn{2}{|c|}{$18.2(8.3)$} & $<0.001$ \\
\hline $\begin{array}{c}\text { Number of medication } \\
\text { classes }\end{array}$ & \multicolumn{2}{|c|}{$9.0(5.2)$} & \multicolumn{2}{|c|}{$10.0(5.1)$} & $<0.001$ \\
\hline \multirow{5}{*}{$\begin{array}{l}\text { Most Frequent Patient } \\
\text { Conditions }\end{array}$} & $\begin{array}{l}\text { ADP } \\
\text { Admit }\end{array}$ & $17.7 \%$ & $\begin{array}{l}\text { ADP } \\
\text { Admit }\end{array}$ & $19.8 \%$ & \\
\hline & $\begin{array}{c}\text { Signs/ } \\
\text { Symptoms }\end{array}$ & $16.6 \%$ & $\begin{array}{c}\text { Signs/ } \\
\text { Symptoms }\end{array}$ & $12.0 \%$ & \\
\hline & Respiratory & $8.9 \%$ & Falls & $9.9 \%$ & \\
\hline & Behavioral & $7.7 \%$ & Respiratory & $8.6 \%$ & \\
\hline & Falls & $7.0 \%$ & Behavioral & $7.6 \%$ & \\
\hline
\end{tabular}

